\title{
Paving the High-Way to Sustainable, Value Adding Open-Innovation Integrating Bigger-Data Challenges: Three Examples from Bio-Ingredients to Robust Durable Applications of Electrochemical Impacts
}

\author{
Salvadora Ortega-Requena ${ }^{1}$, Serge Rebouillat ${ }^{2}$, Fernand Pla $^{3}$ \\ ${ }^{1}$ Chemical Engineering Department, University of Murcia, Murcia, Spain \\ ${ }^{2}$ Currently with DuPont Int. Op., European Headquarter, Geneva, Switzerland \\ ${ }^{3}$ Laboratoire Réactions et Génie des Procédés, Université de Lorraine, CNRS, LRGP, Nancy, France \\ Email: sergereb@yahoo.com
}

How to cite this paper: Ortega-Requena, S., Rebouillat, S. and Pla, F. (2018) Paving the High-Way to Sustainable, Value Adding Open-Innovation Integrating Bigger-Data Challenges: Three Examples from Bio-Ingredients to Robust Durable Applications of Electrochemical Impacts. Journal of Biomaterials and Nanobiotechnology, 9 , 117-188.

https://doi.org/10.4236/jbnb.2018.92010

Received: March 12, 2018

Accepted: April 24, 2018

Published: April 27, 2018

Copyright $\odot 2018$ by authors and Scientific Research Publishing Inc. This work is licensed under the Creative Commons Attribution International License (CC BY 4.0).

http://creativecommons.org/licenses/by/4.0/

\begin{abstract}
A trilogy review, based on more than 300 references, is used to underline three challenges facing 1) the supply of sustainable, durable and protected biosourced ingredients such as lipids, 2) the accounting for valuable bio-by-products, such as whey proteins that have added-value potential removing their environmental weight and 3) the practical reliable synthetic biology and evolutionary engineering that already serve as a technology and science basis to expand from, such as for biopolymer growth. Bioresources, which are the major topic of this review, must provide answers to several major challenges related to health, food, energy or chemistry of tomorrow. They offer a wide range of ingredients which are available in trees, plants, grasses, vegetables, algae, milk, food wastes, animal manures and other organic wastes. Researches in this domain must be oriented towards a bio-sustainable-economy based on new valuations of the potential of those renewable biological resources. This will aim at the substitution of fossil raw materials with renewable raw materials to ensure the sustainability of industrial processes by providing bioproducts through innovative processes using for instance micro-organisms and enzymes (the so-called white biotechnology). The final stage objective is to manufacture high value-added products gifted with the right set of physical, chemical and biological properties leading to particularly innovative applications. In this review, three examples are considered in a green context open innovation and bigger data environment. Two of them (lipids antioxidants and milk proteins) concern food industry while the third (biomonomers and
\end{abstract}


corresponding bioplastics and derivatives) relates to biomaterials industry. Lipids play a crucial role in the food industry, but they are chemically unstable and very sensitive to atmospheric oxidation which leads to the formation of numerous by-compounds which have adverse effects on lipids quality attributes and on the nutritive value of meat. To overcome this problem, natural antioxidants, with a positive impact on the safety and acceptability of the food system, have been discovered and evaluated. In the same context, milk proteins and their derivatives are of great interest. They can be modified by enzymatic means leading to the formation of by-products that are able to increase their functionality and possible applications. They can also produce bioactive peptides, a field with almost unlimited research potential. On the other hand, biosourced chemicals and materials, mainly biomonomers and biopolymers, are already produced today. Metabolic engineering tools and strategies to engineer synthetic enzyme pathways are developed to manufacture, from renewable feedstocks, with high yields, a number of monomer building-block chemicals that can be used to produce replacements to many conventional plastic materials. Through those three examples this review aims to highlight recent and important advancements in production, modification and applications of the studied bioproducts. Bigger data analysis and artificial intelligence may help reweight practical and theoretical observations and concepts in these fields; helping to cross the boarders of expert traditional exploration fields and sometime fortresses.

\section{Keywords}

Bio, Green, Sustainability, Bigger Data, Biomimetic, Artificial Intelligence, Synthetic Biology, Lipids, Oxidation, Antioxidants, Milk, Protein, Whey, Biopolymers, Electrochemical, Conductive

\section{Introduction}

"Green and nature mimicking is done on any conceptual level. It can mean rather a straightforward copy of the solution like in the case of Velcro or, can adapt a concept such as behavioural phenomena of animals to create problem solving techniques used in computing.

Another examples are new protein engineering methods such as enzymes, bioinformatics \& high throughput screening, Deoxyribonucleic acid (DNA) sequencing/editing, cellulose depolymerization, enzymatic polymerization, etc., are part of the activities associated to this growth. This appears in Figure 1 where the lock-and-key analogy underlines specificity of enzymes.

It also appears in the $\operatorname{Kevlar}{ }^{\circledR}$, carbon and spider web inter-inspirational innovation for an improved hybrid ballistic shield [1] [2] somehow inspired by Figure 2 [1].

As discussed during the $3^{\text {rd }}$ International Conference on Bioinspired and Biobased Chemistry \& Materials (October 16-19, 2016, Nice, France), nature 'brand' 


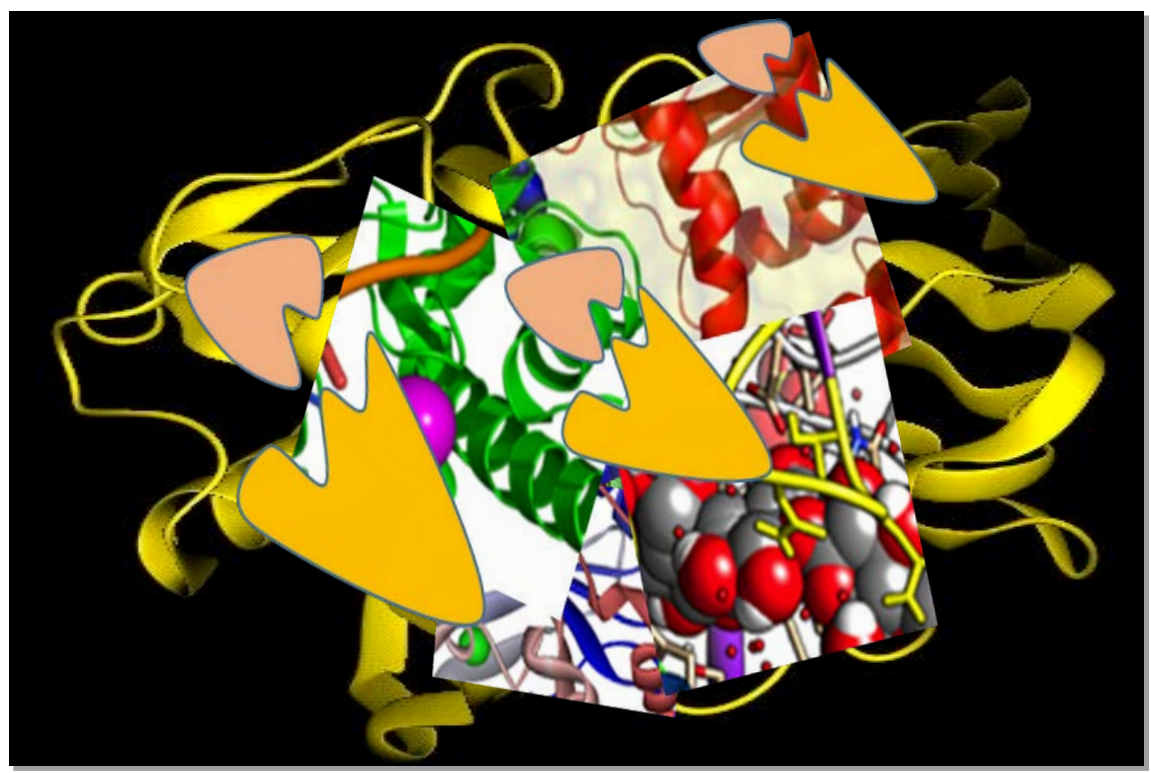

Figure 1. The lock-and-key analogy underlines specificity of enzymes and cocktail engineering thereof.



Figure 2. Inter-inspirational innovation for hybrid conceptualization and ideation budding [1].

comes with firm promise of solutions that resisted the durability test, have optimal energy consumption and can be simple to implement (provided we sufficiently understand them). It would be unwise to assume though that we can find all the best solutions in Earth environment, nevertheless, it's a pool of innovative ideas that one cannot neglect, and actually research results present in this very 
conference are a proof of that."

This introduction excerpt of the talk given by M. Lapray and S. Rebouillat [3] at the $3^{\text {rd }}$ International Conference on Bioinspired and Biobased Chemistry \& Materials sets the scene for this review, further outlining "A Science \& Business Equation for "Bio-Inspired" Innovation". Which equation comes as a continuous behind the scenes structuring column in the series of review by Rebouillat et al. [4]-[8].

The closing remarks, provided next, made by M. Lapray and S. Rebouillat [3] at the NICE $3^{\text {rd }}$ International Conference on Bioinspired and Biobased Chemistry \& Materials, cited above, provide further lighting on the multifaceted dimension of modern innovation. The latter is inseparable of the Bigger Data challenge and necessity for research work such as this proposed scope and size review which has to integrate large amount of patent and non-patent literature to truly represents the science and technology extents.

"At a glance, this concluding slide, Figure 3, provides the number of current innovation styles, from open to close, disruptive, collaboratory ${ }^{\oplus}$, from reverse to inclusive, nested and frugal. Those terminologies are more or less self-explanatory and further enlightenment can be found e.g. in Lapray et al. [7] [8] in a review on the matter, covering some of them.

On the same figure, the 'Not Invented Here', NIH, is illustrated; to that effect it is worth mentioning that the Bigger Data approach tends to naturally challenge that old NIH orthodoxy still largely encountered in large organizations. The creative reverse cycling shower picture tends to illustrate how essential the last mile and the reachability of the target in a creative fashion are. Frugal concepts unable adaptation and use of local means allowing the 'same' performance than so called top of the line, rocket science or trendy, offerings. Biosourcing has a role to play with regard to that frugal orientation, definitely happening in line with inclusive approaches. The last picture of this slide, Figure 3 attracts the attention to the need for innovation to be inherently and as an oxymoron 'Competitively Unpredictable'. Let's leave room to the reader for his/her own interpretation. Some famous products such as breathable selective membranes constitute examples especially in the way they became commercial. Additionally, biomimicry brain storming [5] [6] often reveals paradoxes such as those illustrated on that drawing of Figure 3."

Indeed, reviews are "immensely" stimulating in terms of innovation, although they tend to miss the adjacent technology analysis that innovation most often derives from. One objective of the current review is to promote innovation from a public literature analysis and to propose some interpretations with an educational illustrative mindset.

Before getting on with this review, and, keeping in mind that this review has also innovation incentivizing and educational purposes, we want to illustrate using bigger data analysis whether the well-known interdisciplinary bridging resistance or risk adversity is a myth or a reality? 


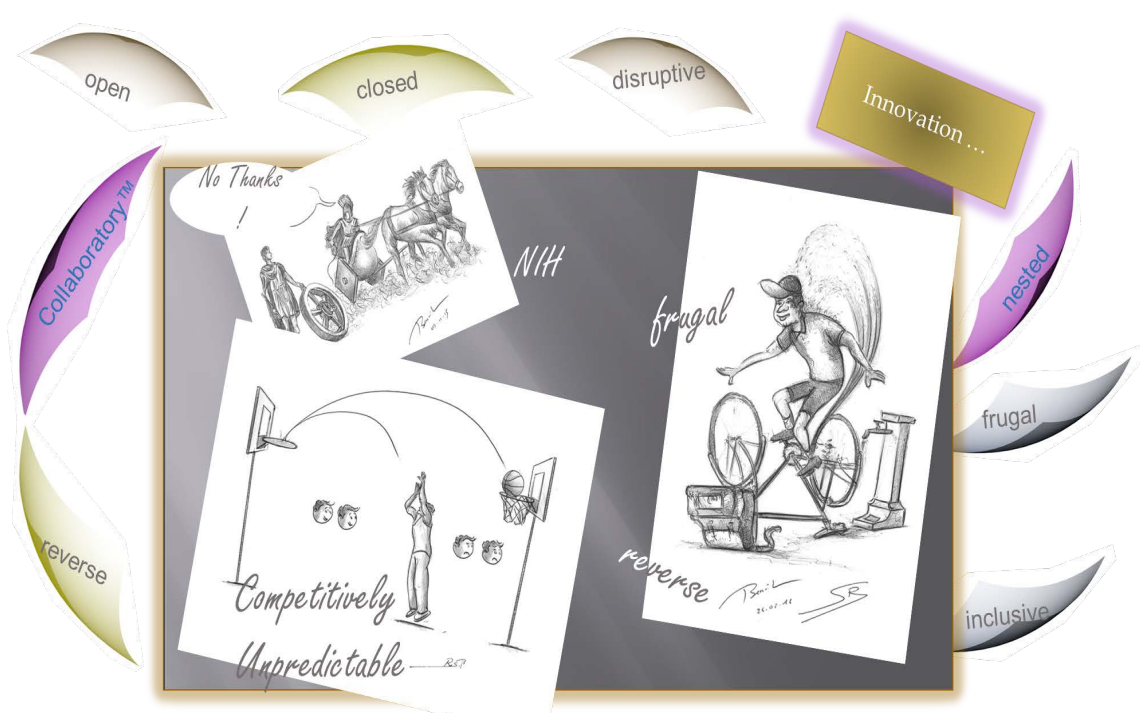

Figure 3. Innovation Styles within Current Business Challenges [184]. Being Competitively Innovatively Unpredictable; Surmounting the Cultural Not Invented Here (NIH); Providing Simpler, Leaner, Faster, Safer Solutions; Including the Last Mile Challenge \& Local Frugal Sustainability.

Then let's try to depict a much larger picture of that precise aspect, from a BIGGER DATA standpoint...

Representations of liaisons between the most appearing keywords/concepts (nodes) in, for example, selected patent sections, can help understand the existing technology relationships; between various protein sources for example.

Figure 4, [9] provides, for educational value, an example of a representation based on 20,000 relevant patents and associated pertinent scientific papers, non-patent literature. On that representation a tetrahedral figure, delineated with the coarser and broader lines and bigger nodes, representing the largest numbers of connections, appears between the three selected sources of protein, i.e. milk, whey and vegetable, and food ingredients.

This tends to reflect that the paradigm or orthodoxy that assumes a lack of relationship in practice between food and vegetable proteins would not be supported by technology and scientific similarity/concordance/co-occurrence analysis.

Figure 4 below does not require more explanations on that matter and proves that the lack of bridging between the various protein domains is not confirmed from that analysis angle. This review can help alleviate the orthodoxy and promote technology disruptive innovation.

This type of analysis is the basis for Artificial Intelligence, also referred to as Augmented Intelligence, preliminaries derived from the potential provided by large number of diverse ontologies/data and multidisciplinary co-semantic Combinatorial-Associative-Intersecting analysis and media mixing-hybridization to derive multimedia based revolutionary concept rather than evolutionary human ideation [7]. In the context of Bigger Data the consensus among all professionals 


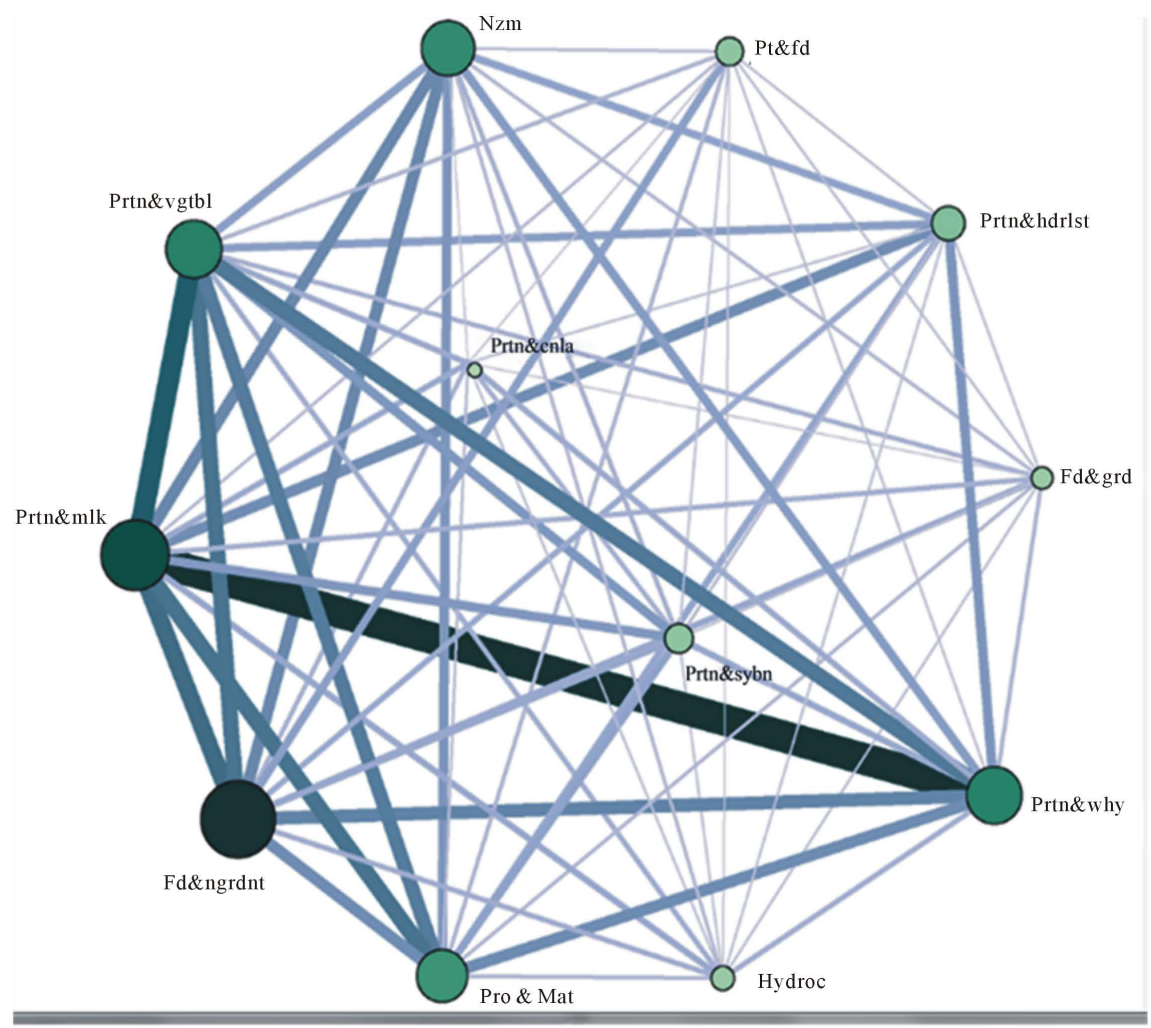

Figure 4. The protein (Prtn) neural network (co-occurrence chart) based on 20000 patents and NPL of the selected field. (Prtn\&x), ( $x=$ mlk, why, vgtbl respectively milk, whey, vegetable), (food ingredients $=$ Fd\&ngrdnt) [9].

is that it can help identify emerging trends, improve business decision making and develop new revenue-making strategies.

The great biodiversity of nature (i.e., plants, animals, insects, enzymes, microbes etc.) coupled with the enormous advances developed in the biotechnological processes, makes it today possible to manufacture high value-added sustainable products endowed with physical, chemical and biological properties leading to particularly innovative applications.

The products presented in this review are oriented towards two major industries i.e., food and bioplastic materials industries. Three examples will illustrate recent strategies used for developing in those domains innovative bioproducts. Each of those examples will be considered in a green context open innovation. Two of them (lipids antioxidants and milk proteins) will concern food industry while the third (biomonomers and corresponding bioplastics and derivatives) relates to biomaterials industry.

- Lipids play a crucial role in the food industry, but they are chemically unstable and very sensitive to atmospheric oxidation. Lipid oxidation leads to the formation of numerous other compounds which have adverse effects on the quality attributes (such as color, texture, odor, flavor etc.) and on the nutritive value of meat. To successfully prevent lipid oxidation, several synthetic antioxidants have been used, but consumers are concerned about the health 
risk potential related to consumption of some of those compounds. Therefore, in recent years there has been a growing interest in developing novel antioxidants from natural sources. Nowadays, many natural antioxidants, with a positive impact on the safety and acceptability of the food system, have been discovered and will be evaluated in this review.

- Growing concerns for health and environment characterize today's society, which increases the acceptability of food ingredients manufactured from milk, recognized by the consumer as "natural". This can be one of the reasons why dairy ingredients are becoming more and more important in food product innovation.

In this context, Milk proteins and their derivatives are of great interest. They can be modified by enzymatic means leading to the formation of by-products that are able to enhance their functionality and possible applications. They can also produce bioactive peptides, a field with rather unlimited research potential.

- Biosourced chemicals and materials, mainly biomonomers and biopolymers, are produced today to reduce the fossil resources depletion and dependency in the domain of plastics. In this context, metabolic engineering tools and strategies to engineer synthetic enzyme pathways are developed to manufacture, from renewable feedstocks, a number of monomer building-block chemicals that can be used to produce replacements to many conventional plastic materials. This review aims to highlight several recent and important advancements in the microbial production of these biomonomers and corresponding biomaterials.

Finally, the common ontology node of the bigger data analysis is related to common applications of the three domains here explored, which is central to electrochemical applications and technological consequences.

A few examples:

- The use of mineral oils in transformers in now being superseded by the advent and progressive adoption of lipids and more precisely vegetable oil. Both options are the centre of electrochemical events during normal operation, overload, arcing and corona occurrence. This not only impends the harmless operation of the transformers but also can provoke grave accidents. Therefore, oxidation control and stability is one of the key features for transformer fluids. Electrochemical phenomena are not only to be mastered and comprehended in these applications but remedies via antioxidants preservations and tracing are to be in place effectively; adding to the challenge the very low amount of those, which are being used. It is now demonstrated that the electrochemical methods can be applied to the determination of the content of butylhydroxytoluene, for instance, as antioxidant in transformer oils. The adoption in this area of lipids and triglycerides as biosourced sustainable and green replacement fluids implies the need for oxidation control via electrochemically predictive tools. The electrochemical supervision of the 
device operation is now foreseen as a smart and connected continuous operations to make new grid even more suited to new energy demands and locations.

- Protein electrochemistry is an important application in medicine. Protein electrochemistry already scientifically proven and has solid theoretical basis; its advanced applications in medicine where proteins serve as the furthermost valued biomarker, is still under tremendous attention. The identification of new source of protein from disregarded biosources can be an exceptionally innovative approach to reinforce the traceability and specificity of these markers. The electrochemical dimension for the analysis of possible denaturation and combination, measurement and control of enzyme activity, are part of the major focus of protein science and medical applications.

- Synthesis and electrochemical applications of the composites involving conducting polymers need no further pertinence justification in a review including biopolymers, given their paramount importance in the energy fields for example. Conducting polymers have been extensively applied for the manufacturing of various electrochemical components such as sensors, actuators, solar panels, etc. To extend the purposes or improving the performances of these devices, conductive polymers often have to be combined with other functional constituents to form composites, which are as well the very subject of interest in many advanced techniques such as aeronautical and aerospatial, osmosis energy electro-conversion, desalination applications... also associated with a connected-smart dimension vs the continuous performance monitoring of those materials.

\section{Lipid Oxidation and Antioxidants}

Consumer trend towards more healthy and natural foods brings out one of the biggest challenges for the food industry: the necessity of reducing the amount of additives. This control in the use of additives is especially important when it comes to synthetic substances. In this sense, among the natural ressources, lipids are substances of biological origin that are soluble in nonpolar solvents [10] and possess important biological functions including storing energy, signalling, and acting as structural components of cell membranes [11] [12]. They have applications in the cosmetic and food industries as well as in nanotechnol$o g y$ [13]. They originate entirely or in part from two distinct types of biochemical subunits or "building-blocks": ketoacyl and isoprene groups [11] and comprise a group of naturally occurring molecules that are divided into the eight following categories [11]:

- fatty acids (carboxylic acids with a long aliphatic chain, which is either saturated or unsaturated),

- glycerolipids, composed of mono-, di-, and tri-substituted glycerols, the best-known being the fatty acid triesters of glycerol, called triglycerides,

- sphingolipids, (lipids with a backbone of sphingoid bases and a set of ali- 
phatic amino alcohols that includes sphingosine),

- saccharolipids, (compounds in which fatty acids are linked directly to a sugar backbone),

- polyketides (complex organic compounds derived from condensation of ketoacyl subunits that are often highly active biologically),

- sterol lipids, such as cholesterol and its derivatives,

- prenol lipids, synthesized from the 5-carbon precursors isopentenyl diphosphate and dimethylallyl diphosphate that are produced mainly via the mevalonic acid (MVA) pathway,

- phospholipids (PLs) and derivatives such as glycerophospholipids, that are natural surfactants, which are the basic lipid components of plasmatic cell membranes and membranes of subcellular organelles of animals, plants, and microorganisms [13]. The structure of the phospholipid molecule generally consists of two hydrophobic fatty acid "tails" and a hydrophilic "head" consisting of a phosphate group. The two components are joined together by a glycerol molecule. The phosphate groups can be modified with simple organic molecules such as choline. Phosphatidylcholines (1,2-diacyl-sn-glycero-3-phosphocholines or lecithins) are the most widely used. Unsaturated fatty acid residues of PLs are readily oxidized with atmospheric oxygen as well as nonpolar unsaturated lipids. The primary products of PLs oxidation are mainly isomeric hydroperoxides. The oxidability of PLs in aqueous dispersions is lower than that in organic solvents by an order of magnitude. It is assumed that the micro-heterogeneity of PLs solutions and the dispersity of colloidal solutions do not influence the oxidability of unsaturated lipids in both aqueous and organic media.

Lipids significantly enhance the organoleptic perception of foods, including attributes of texture, structure, mouth feel, flavor and color. However, they are also one of the most chemically unstable food components. It is noteworthy that the biggest problem in the food industry is food spoilage, with lipid peroxidation and microbial growth as the main causes.

\subsection{Lipids Peroxidation Process}

Considerable attention has been given to the evaluation and assessment of oxidative and flavor deterioration of lipids, but not enough effort has been made to look into the basic sources of offensive odors and flavors in oxidized fat. This section will summarize mechanistic concepts of peroxidation with the belief that more knowledge in these areas would lead to more useful methods of controlling lipid deterioriation. For instance, soybean oil, which provides now the most important world source of vegetable food fat, develops a very complex type of lipid deterioration known incorrectly as "flavor reversion".

Currently, lipid peroxidation is considered as a molecular mechanism involved in the oxidative damage to cell structures and in the toxicity process that lead to cell death. It occurs in both plants and animals and consists mainly in 
the oxidative deterioration of lipids containing carbon-carbon double bonds, e.g., fatty acids and cholesterol.

The main types of lipids peroxidation are:

- Photooxidation with singlet oxygen using sensitizers such as chlorphyl, porphyrins, myoglobin, riboflavin, bilirubin, rose bengal, methylene blue ...

- Enzymatic oxidation using particularly Cyclooxygenase and lipoxygenase that catalyse reactions between oxygen and polyunsaturated fatty acids

\section{- Autooxidation.}

Lipid peroxidation is a free radical chain reaction that can be described in terms of initiation, propagation, and termination processes. It is initiated by hydrogen abstraction or by addition of an oxygen radical, resulting in the oxidative damage of polyunsaturated fatty acids (PUFA).

Since PUFA are more sensitive than saturated ones, it is obvious that the activated methylene $(\mathrm{RH})$ bridge represents a critical target site. This initiation is usually performed by a radical of sufficient reactivity:

$$
\mathrm{R}_{1} \mathrm{H}+\mathrm{R} \rightarrow \cdot \mathrm{R}_{1}+\mathrm{RH}
$$

Molecular oxygen rapidly adds to the carbon-centred radical (R) formed in this process, yielding the lipid peroxyl radical (ROO):

$$
\cdot \mathrm{R}+\mathrm{O}_{2} \rightarrow \mathrm{ROO} \cdot
$$

The formation of peroxyl radicals leads to the production of organic hydroperoxides, which, in turn, can abstract hydrogen from another PUFA, analogous to reaction (1):

$$
\mathrm{R}_{1} \mathrm{H}+\mathrm{ROO} \rightarrow \cdot \mathrm{R}_{1}+\mathrm{ROOH}
$$

This reaction is termed propagation, implying that one initiating hit results in the conversion of numerous PUFA to lipid hydroperoxides. In the sequence of their appearance, alkyl, peroxyl, and alkoxyl radicals are generated in the free radical chain reaction.

The alkyl radical is stabilized by rearrangement into a conjugated diene that is a relatively stable product. Lipid hydroperoxide $(\mathrm{ROOH})$ is the first stable product of the lipid peroxidation reaction.

Under conditions where lipid peroxidation is continuously initiated, radical annihilation or termination occurs with the destroying of two radicals at once:

$$
\mathrm{ROO}+\mathrm{ROO} \rightarrow \mathrm{ROH}+\mathrm{RO}+\mathrm{O}_{2}
$$

Other termination reactions can also occur:

$$
\begin{gathered}
\mathrm{R}+\mathrm{R} \rightarrow \mathrm{R}-\mathrm{R} \\
\mathrm{R}+\mathrm{ROO} \rightarrow \mathrm{ROOR}
\end{gathered}
$$

This chain reaction results in a complex mixture of substances of low and high molecular weight and diverse nature and composition (including alcohols, ketones, alkanes, aldehydes and ethers) that confer bad smell and taste to lipids, influencing also the appearance and the quality of food [14] developing rancidity in raw or fatty tissues, producing warmed-over flavor in cooked meats and oxi- 
dized flavors in oils with loss of functional properties and nutritional values. It can also result in the accumulation of toxic compounds and coloured products [15] [16].

Many of those toxic compounds (e.g. epoxides and hydrogen peroxide by-products) are potential carcinogens while hydroperoxides are known to damage DNA. Moreover, as a consequence, the oxidized foods can cause oxidative stress in biological systems and cause diseases.

The spectrum of reactive oxygen species (ROS), reactive nitrogen species (RNS) and free radicals that are considered responsible for biological oxygen toxicity, include the intermediates of the partial reduction of oxygen, superoxide radicals, hydrogen peroxide and other reactive species such as hydroxyl radical, peroxyl radical, nitric oxide, peroxinitrite, singlet oxygen, iron-oxygen complexes (ferryl and perferryl radicals), thiyl radicals (RS). They comprise also reactive metabolites or intermediates (drugs, toxins, pollutants, cigarette smokes, etc.).

ROS primary source is human body during energy production (generation from single electrons escaping the electron transport chain in mitochondria). They also can be formed by environmental contaminants, ionizing and ultraviolet radiation, diet (fatty and processed foods) etc.

The damages inflicted by ROS concern particularly membranes, proteins and DNA.

The main observed membrane damages are a decreased activity of membrane-bound enzyme (e.g. sodium/potassium pumps), altered activities of membrane receptors and electrolytes transport (especially to sodium and calcium ions). Increased intracellular sodium ions cause water to follow them causing cellular swelling and increased calcium ions damages mitochondria and causes "cellular hardening", seen in arterial plaques.

Protein damage occurs if radicals accumulate (not likely in normal cells), or if the damage is focused on a particular site of the protein, such as if a protein binds a transition metal ion.

It is known, however, that the reaction of radicals with proteins and peptides in the presence of oxygen gives rise to alterations in both the backbone and of the amino acid side chains. These oxidative changes include cleavage of peptide bonds, modification of amino acid side chains and formation of covalent intermolecular cross-linked protein derivatives. Some of the most general amino acid modifications are the formation of protein carbonyl groups and protein hydroperoxides, while cross-linking has mostly been described as formation of disulfide and dityrosine through the loss of cysteine and tyrosine residues.

The consequences of protein oxidation in muscle food have often been associated with changes in solubility and protein functionality such as gelation and emulsifying properties, or water-holding capacity.

Furthermore, oxidative modifications of proteins can lead to loss of essential amino acids and decreased digestibility affecting ultimately the nutritional quality of muscle foods, their water-holding capacity and tenderness.

DNA damage: oxidising radicals readily attack DNA if they are formed in its 
vicinity as seen in radiation. For damage to occur it must either be site specific (leading to strand breaks) or it must elude the repair systems before replication occurs leading to mutation.

The main factors affecting the development of lipid oxidation in foods are: the fatty acids composition, the oxygen free radicals, the prooxidants (nature and concentration), the antioxidants and additives (nature and concentration), the processing conditions of meat (e.g., irradiation, cooking, grinding, cutting, mixing, restructuring, and packaging) and their storage time and conditions. Peroxidation can also be catalyzed by transition metals such as $\mathrm{Fe}, \mathrm{Cu}, \mathrm{Mg}$, $\mathrm{Ni}$, etc.

\section{Lipid peroxidation and aging}

Consistent evidence supports the hypothesis that a progressive accumulation of oxidative damage to important cellular molecules is a fundamental mechanism involved in most senescence-associated alterations. Moreover, oxidative damage occurs when free radicals produced within an organism are not completely destroyed by the appropriate endogenous defense systems [17].

Because lipids are a major component of living organisms and probably the first easy target of free radicals once they are produced, lipid peroxidation might play a major role in initiating and/or mediating some aspects of the aging process, especially since it has been widely demonstrated 1) that there is an age-associated increase in the steady-state concentrations of lipid peroxidation products 2) and that oxidation of biomolecules has also been related to susceptibility to diseases, such as cancer and heart disease, as well as associated with the process of aging [18] [19] [20].

This increase in lipid peroxidation products was directly correlated with age, and was associated with decreases in vitamins $\mathrm{E}$ and $\mathrm{C}$.

However, establishing the involvement of this phenomenon in the pathogenesis of the aging process has not been an easy task and it is clear that the recent development of more reliable techniques to measure lipid peroxidation, together with more well-defined animal models of aging, should be of great help in future studies in this field.

\subsection{Antioxidants-Inhibitors of Lipids Peroxidation}

Addition of exogenous antioxidants is still a foremost tool to avoid lipid peroxidation. Antioxidants can delay or slow the rate of peroxidation of lipids. Indeed, they are able 1) to prevent the transfer of electrons from $\mathrm{O}_{2}$ to organic molecules, 2) to stabilize free radicals and 3) to terminate free radical reactions.

Moreover, the activity of antioxidants depends on complex factors including the nature of the antioxidants, the conditions of oxidation, the properties of substrate being oxidized and the stage of oxidation.

The capacity of antioxidant is at least two folds:

- the antioxidant potential, determined by its composition and properties of constituents, 
- its biological effects depending on its bioavailability which is of a medical and biological nature.

However, as previously mentioned, a deep knowledge of oxidation mechanisms and additional influential factors might help in developing newer, more natural and more effective antioxidant technologies.

There are two major types of antioxidants:

- chain-breaking antioxidants $(\mathrm{AH})$ which, at low concentration, can inhibit or retard peroxidation by interfering with either chain propagation or initiation:

$$
\begin{aligned}
& \begin{array}{l}
\mathrm{ROO}+\mathrm{AH} \rightarrow \mathrm{ROOH}+\mathrm{A} . \\
\mathrm{A}+\mathrm{ROO} \rightarrow \\
\mathrm{A}+\mathrm{A} \rightarrow \text { nonradical products }
\end{array}
\end{aligned}
$$

Those antioxidants include phenol and aromatic amino compounds hindered with bulky alkyl substituents. They are designed to form either A. radicals or loose molecular complexes that are too unreactive to propagate the chain:

$$
\begin{gathered}
\text { ROO }+ \text { AH } \rightarrow[\text { AH-ROO }] \\
{[\text { AH-ROO. }]+\text { ROO } \cdot \rightarrow \text { nonradical products }}
\end{gathered}
$$

They generally lose their efficiency at elevated temperatures because of homolytic decomposition of hydroperoxides formed by reaction (7) and because of a reaction of the antioxidants with oxygen:

$$
\mathrm{AH}+\mathrm{O}_{2} \rightarrow \text { free radicals }
$$

- preventive antioxidants (Figure 5) which overcome these disadvantages by acting to reduce the rate of chain initiation. The most important initiation suppressors are metal inactivators that can bind catalysts, such as metal ions to prevent initiating radical generation. Metal inactivators used for stabilizing edible fat and lipid-containing foods include ascorbic acid, erythorbic acid and citric acid.

Other preventive antioxidants are the peroxide destroyers, which react with hydroperoxides to give stable products by nonradical processes. These inhibitors include sulfur compounds, phosphites and phosphines, which reduce hydroperoxides into the more stable alcohols. Whether these compounds can be used in foods has not been established. One more type of preventive antioxidant includes ultraviolet light deactivators that absorb irradiation without formation of radicals. Examples are pigments like carbon black, phenyl salicylate, and a-hydroxy-benzophenone.

Although many chain-breaking and preventive antioxidants, peroxide destroyers, and UV deactivators are used effectively in rubber and petroleum products, they cannot be added to foods because of established or potential health hazards. One approach to reduce this hazard is to use polymeric antioxidants that are claimed to be unabsorbed in test animals. 
<smiles>O=C1O[C@H]([C@@H](O)CO)C(O)=C1O</smiles>

Ascorbic acid<smiles>O=C1O[C@H]([C@@H](O)CO)C(O)=C1O</smiles>

Erythorbic acid<smiles>O=C(O)CC(O)(CC(=O)O)C(=O)O</smiles>

Citric acid<smiles>CCCCCCCCCCCCCCCC(=O)OC[C@H](O)[C@H]1OC(=O)C(O)=C1O</smiles><smiles>O=C(O)CN(CCN(CC(=O)O)CC(=O)O)CC(=O)O</smiles><smiles>[Y]OS(=O)(=O)[O-]</smiles>

Dipotassium disulfite

Ethylenediaminetetraacetic acid<smiles>O=C(Oc1ccccc1)c1ccccc1O</smiles>

Phenyl salicylate<smiles>O=C(c1ccccc1)c1ccccc1O</smiles>

$\alpha$-hydroxy-benzophenone

Figure 5. Chemical structures of common preventive antioxidants.

When multiphase situations are involved, it has been reported that the physical properties of the oil-water interface have a critical effect on oxidative stability of lipids [21] [22] [23] [24] [25]. Physical properties of lipid systems are determined by compositional aspects, numerous compounds, amphiphilic substances and emulsifiers, likely to play an essential role on oxidation. One of the main objective of this section is to show the relationship between amphiphilic compounds and activity of antioxidants. Beyond this study, a "deep dive" and more fundamental understanding of this relation would help to reach an optimal, more ideal, oxidative protection. In addition, multifunctional antioxidants and natural antioxidants extracted from plants (with additional health benefits and environmental benefits when extracted from waste products) also deserve special consideration.

\subsection{Classification of Antioxidants}

Depending on their mechanism of action, their nature, their biological activity and the number of phenolic groups antioxidants can be classified as following:

\section{- Depending on their mechanism of action:}


- Antioxidants inhibiting lipid oxidation by trapping lipid peroxide radicals (aromatic compounds with weak $\mathrm{O}-\mathrm{H}, \mathrm{N}-\mathrm{H}$ bonds (phenols, amines, aminophenols, diamines etc.).

- Antioxidants inhibiting the oxidation process by trapping alkyl radicals (quinones, methylene quinones, which are effective in low oxygen concentration).

- Hydroperoxide decomposers that react with hydroperoxides without formation of free radicals.

- Metal chelators with which oxidation process can be inhibited by addition of compounds forming complexes with metal ions and thus making them inactive towards hydroperoxides. Citric acid (and its lipophilic, monoglyceride ester), phosphoric acid (and its polyphosphate derivatives), and ethylenediaminetetraacetic acid (EDTA) are common chelators.

- Antioxidants with multistage action which are systems containing alcohols and amines and which can be regenerated during the oxidation process.

- Multifunctional antioxidants promoting and intensifying interactions between antioxidants i.e. inhibitor molecules with two or more functional groups, each of them being able to react in different reactions; 1-ascorbic acid is a "perfect" example. Several reactions related to antioxidant mechanisms of l-ascorbic acid have been identified. Those are quenching of singlet oxygen, reductions of free radicals and primary antioxidant radicals by hydrogen atom donation, and removal of molecular oxygen in the presence of metal ions [26]. Conversely, l-ascorbic acid can act as a prooxidant by reducing transition metals [27]. Propyl gallate and proanthocyanidins are other examples of multifunctional antioxidants, they are free-radical scavengers and chelator agents [28]. Tocopherols can also exhibit prooxidation behavior. Their antioxidant activity increases with concentration up to certain levels at which an inversion of activity may take place [29]. Optimal concentrations of different tocopherols to prevent soybean oil oxidation have been estimated. Those are around $100 \mathrm{ppm}$ for $\alpha$-tocopherol and $300 \mathrm{ppm}$ for $\gamma$-tocopherol. $\delta$-Tocopherol did not show prooxidant behavior in the range of studied concentrations [30]. Ascorbyl palmitate also showed prooxidant effects at high concentrations (>300 ppm) [31].

\section{- Depending on their nature:}

- Natural antioxidants, usually with low toxicity, and a wide spectrum of biological and antioxidant activities e.g. Nutrients (vitamin $E$, vitamin $C$, beta-carotene), phytochemicals (antioxidants from plants).

- Synthetic antioxidants, with a high antioxidant activity. However, antioxidants for application in foods and additives or supplements must pass additional criteria (no toxicity, no allergenicity, safety, healthy, low cost, etc.)

- Depending of their biological activity.

- Bio-antioxidants i.e. compounds with both active biological matters and antioxidant activities. The most important known bio-antioxidants are flavo- 
noids and phenolic acids mainly from particular medicinal plants species such as Mellilotus officinalis (Fabaceae), Equisetum maximum (Equisetaceae) [32] or Rumex hastatus roots [33] Antioxidants without a useful biological activity - some, even being natural antioxidants, can show a toxic activity and for that reason they must be tested.

- Depending on the number of phenolic groups: (Figure 6 and Figure 7)

- Monophenols: 2-and 3-ter-butyl-4-hydroxyanisole (BHA), 2,6-di-terbutyl4-methylphenol (BHT), p-coumaric acid, ferulic acid, sinapic acid, tocopherols, etc.

- Biphenols caffeic acid, hydroquinone, tert-butylhydroquinone (TBHQ), etc.

- Polyphenols: Propyl gallate (PG), Catechin, flavonoids such as quercetin, luteolin, kaempferol, rutin, etc.

Furthermore, different interactions with a combination of antioxidants can happen. These interactions can promote antagonism, additive or multiplying synergism. The type of interaction might depend on diverse factors such as composition and weight ratio of antioxidants, or media $\mathrm{pH}$ and solvents [34] [35].<smiles>COc1ccc(O)cc1C(C)(C)C[14CH3]</smiles>

2-and 3-ter-butyl-4-hydroxyani (BHA)<smiles>COc1cc(/C=C/C(=O)O)cc(OC)c1O</smiles>

Ferulic acid<smiles>Cc1cc(C(C)(C)C)c(O)c(C(C)(C)C)c1</smiles>

(BHT)<smiles>O=C(O)/C=C/c1ccc(O)cc1</smiles>

P-coumaric acid<smiles>[R]c1c([R])c2c(c([R])c1O)CC[C@@](C)(CCC[C@H](C)CCC[C@H](C)CCCC(C)C)O2</smiles>

Tocopherols

( $\alpha$ tocopherol: 5,7,8-trimethyl $\beta$ tocopherol: 5,8-dimethyl $; \gamma$ tocopherol:7,8dimethyl; $\delta$ tocopherol: 8-methyl) ; With: $\mathrm{R}=\mathrm{ME}$ or $\mathrm{H}$<smiles>O=C(O)/C=C/c1ccc(O)c(O)c1</smiles>

Caffeic acid

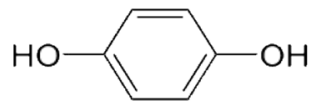

Hydroquinone<smiles>CC(C)(C)c1cc(O)ccc1O</smiles>

Ter-butylhydroquinone (TBHQ)

Figure 6. Chemical structure of some monophenolic and biphenolic antioxidants. 
<smiles>CCCOC(=O)c1cc(O)c(O)c(O)c1</smiles>

Propyl gallate $(\mathrm{PG}) \quad$ Catechin $\quad$ 付ercitine<smiles>O=c1cc(-c2ccc(O)c(O)c2)oc2cc(O)cc(O)c12</smiles><smiles>O=c1c(O)c(-c2ccc(O)cc2)oc2cc(O)cc(O)c12</smiles>

Luteolin

Kaempferol

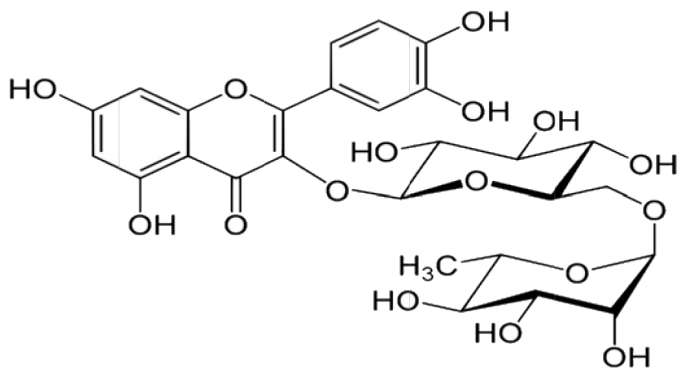

Rutin

Figure 7. Chemical structure of some polyphenolic antioxidants.

Synergism, (when a combination of different antioxidants can be more effective in retarding lipid oxidation than the sum of their individual activities), is the most widely studied interaction. The synergic effect is very common between antioxidants with chelating properties and phenolic antioxidants. When the chelator is citric or other acids, this synergism is referred as acid synergism [36]. Metal chelators are also proposed to improve the antioxidant activity of 1-ascorbic acid by decreasing its prooxidant character [27].

Ascorbic acid and its oil-soluble derivative ascorbyl palmitate, as well as lecithin, can act as antioxidant synergists to tocopherols [29] [37]. A combination of lecithin, ascorbyl palmitate and tocopherols also showed higher antioxidant activity compared to using them separately in structured lipids of caprylic acid and soybean oil [38]. The same results were obtained using them in fish oils [39]. The synergist action of lecithin and ascorbic acid on the antioxidant effectiveness of $\alpha$-tocopherol was also proven. A combination of $0.01 \%$ tocopherol $+0.5 \%$ lecithin $+0.05 \%$ ascorbic acid showed the highest effectiveness in sardine lipids [40]. The antioxidative efficacy of EDTA in fish oil enriched salad dressing increased by the addition of $\gamma$-tocopherol and ascorbyl palmitate [31].

One great advantage of synergist interactions is the possibility of using natural antioxidants to increase the activity of synthetic antioxidants, and diminish 
the amount required for total oxidation protection. Rosemary extract have been reported to increase the antioxidant capacity of a combination of BHT and BHA [41]. Nevertheless, to make the most of antioxidant interactions, a deeper, more fundamental understanding of their mechanisms is required, which need further adaptation to complex situations.

Several theories support synergistic interactions due to chemical reactions of antioxidants via free radical transference. For example, regeneration reactions of oxidized $\alpha$-tocopherol by ascorbic acid, flavonoids, carotenoids, phospholipids, amino acids, and peptides have been reported [42].

However, some inaccuracies of the pure chemical model suggested that physical interferences and microenvironment of the site of oxidation might be important to explain antioxidant interactions [42] [43].

For instance, synergistic effects of phospholipids with antioxidants have been explained by an increase of the availability of antioxidants in the aqueous microenvironment. The polar heads of the antioxidant are located at the water-oil interface and radical-scavenging activity is increased [28] [44] [45]. This would be comparable to the interaction of emulsifiers and antioxidants. Even though many studies have been carried out, the antioxidant-interaction mechanisms seem to be only partially understood.

\subsection{Antioxidant Action in Multiphase Systems}

Mechanisms and efficiency of antioxidants in emulsions and bulk oils have been extensively studied. It is considered that lipid peroxidation is an interfacial phenomenon taking place at the interface. In general, the oxidation rate is faster in emulsions than in bulk oils. This fact can be attributable to the large interfacial area in emulsions compared to the relatively small interface in bulk oils [46]. Hydrophobicity plays an important role in antioxidant properties, but its complex influence is still not completely understood. Traditionally, the most widely accepted theory has been the polar paradox. According to this theory, polar antioxidants are more active in non-polar media, like bulk oils. On the other hand, non-polar antioxidants are more active in polar media, such as oil-in-water emulsions. This apparent paradoxical effect is speculated to be a result of the antioxidant partitioning into the different phases [23]. Carnosol, carnosic acid and two rosemary extracts, were tested in bulk oils and in oil-in-water emulsions. The rosemary extracts and the compounds effectively inhibited oxidation in corn oil, soya bean oil, peanut oil and fish oil systems by being oriented in the air-oil interface, where oxidation was suggested to take place. However, they were not so effective in oil-in-water emulsions, which was explained by their partitioning into the water phase [47]. Antioxidants such as propyl gallate and trolox were also reported as ineffective in preventing oxidation in oil-in-water emulsions, because of the accumulation of these substances in the water phase [46]. On the other hand, lipophilic antioxidants such as tocopherols and ascorbic palmitate are more active in polar systems like oil-in-water emul- 
sions, because the non-polar lipid soluble antioxidants will be located in the oil phase where oxidation propagates. Since its proposal, numerous studies can be found to prove the polar paradox. However, those investigations have been considered as inappropriate to confirm a general trend based exclusively on antioxidant polarity [48]. The corresponding arguments were founded on the fact that some studies were mainly based on the comparison of only two analog antioxidants. Other studies compared antioxidants differing not solely in their polarity. Laguerre et al. developed a new antioxidant model to evaluate that influence. They named it "phenolipids" corresponding to a phenolic compound conjugated to a lipid moiety [49].

Another argument against polar paradox is that bulk oils are now described not as a continuous phase of triacylglycerols, but as a multiphase containing triacylglycerols as well as others minor components such as free fatty acids, monoand diacylglycerols, phospholipids, sterols, trace metals and water. These amphiphilic components would likely associate in colloidal structures, generally reverse micelles and lamellar structure [28], what leads to consider bulk oils as water-in-oil emulsions, so the interface is a likely site of oxidation reactions. Some unexpected findings and new evidences showed that the polar paradox may fail in predicting antioxidant effectiveness in bulk oil and therefore constitute good bais for new theories. To date, no rule has been found to accurately predict the ability of antioxidants to prevent lipid oxidation in these rather complex systems [48].

Both in oil-in-water and in water-in-oil emulsions, the lipid and the aqueous phases are separated by an interface containing amphiphilic compounds. Phenolic antioxidants, as amphiphilic compounds, would collocate in this interface and usually are more effective in oil-in-water emulsions. Several studies reported that their antioxidant potential depends on both amphiphilicity and chain length [50] [51] [52]. A non-linear (or cut-off) influence of the chain length of antioxidants on their capacity has been observed. That is to say, the antioxidant capacity suddenly collapses when a critical chain length is reached (Figure 8). This non-linear phenomenon has been explained by three mechanisms: the "reduce mobility" of long chain antioxidants, the "internalization" into the emulsion droplet core and the "self-aggregation" to form micelles in the aqueous phase [48] [52].

Oxidation is affected by many other factors such as thickness and charge of the interface [53] [54] [55] as well as metal binding capacity of amphiphilic compounds and mass transfer phenomena [46]. Similarly, these factors impact on antioxidant action in multiphase systems so much that the effect of one particular antioxidant can be very different depending on the food system increasing the complexity of lipid-oxidation control.

Effects of emulsifiers/surface-active compounds on antioxidant activity

Emulsifiers are surface-active molecules that prevent the aggregation of droplets in an emulsion forming a protective membrane. Food emulsifiers are 


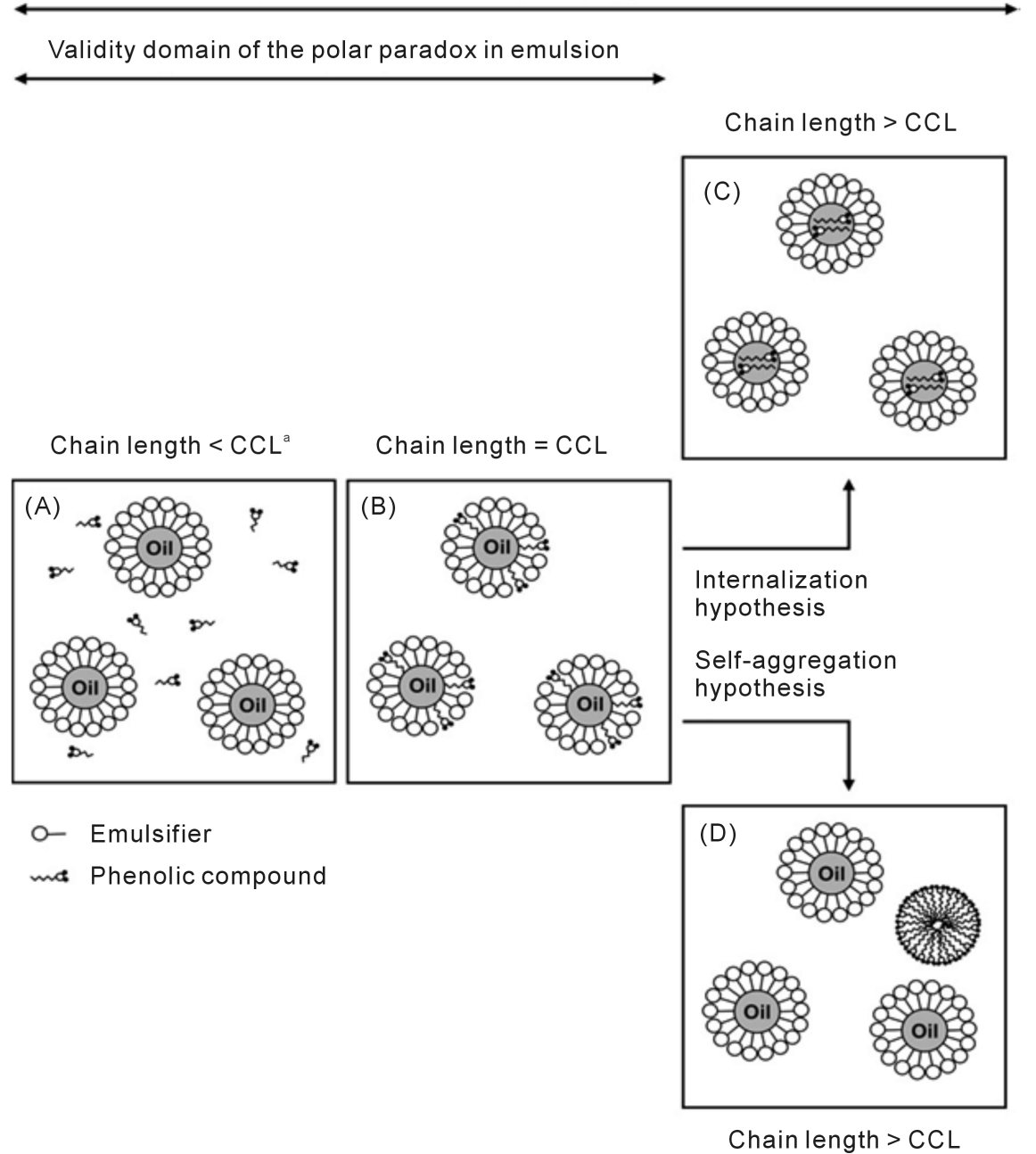

Figure 8. Scheme of the distribution of phenolic antioxidants in oil-in-water emulsions when their chain length is lower than CCL: (A), equal to CCL: (B), and higher than CCL (C): "internalization" into the emulsion droplet core and (D): "self-aggregation" to form micelles in the aqueous phase. (CCL: Critical Chain Length) [48] [52].

amphiphilic molecules, and the most common ones are small-molecule lipid-based emulsifiers, phospholipids, proteins and polysaccharides.

The potential of antioxidants to inhibit lipid peroxidation in emulsions depends on the emulsion composition, where the emulsifier plays an important role. Particularly, the emulsifier type, emulsifier concentration and $\mathrm{pH}$ have been proposed as the main influences on the antioxidant activity, suggesting that interactions between emulsifiers and antioxidants may be important [46]. An increase in emulsifier concentration will significantly affects antioxidant partitioning and might disguise the cut-off effect [48] leading to an unnecessary surplus of antioxidant. The surface charge of emulsion droplets is especially important for lipid oxidation catalyzed by trace metal ions, in that event, positively charged emulsifiers may reduce oxidation by repelling metal prooxidants [56]. Furthermore, the use of these antioxidants at high concentrations have been re- 
ported to increase oxidative stability by forming a thick and positively charged emulsion interface that protects the oil droplets from prooxidants [55] [57]. Regarding the influence of the $\mathrm{pH}$, lower values of $\mathrm{pH}$ generally increase metal solubility, boosting oxidation. Moreover, when using proteins as emulsifiers, the optimum $\mathrm{pH}$ will be determined according to the isoelectric point ( $\mathrm{pI}$ ) value of the protein (i.e. the $\mathrm{pH}$ value at which the protein carries no net electrical charge in the statistical mean).

Synergistic effects of some compounds might be explained by their co-surfactant properties, for instance citric acid and amino acids [43]. Phospholipids also exert synergism on antioxidants by an increase of the availability of antioxidants in the aqueous microenvironment thanks to the emulsifying properties of phospholipids.

In practice, food emulsions contain not only oil, water, and emulsifier. Their complexity is increased by the presence of many other ingredients which can have a marked influence on their physicochemical properties. The aqueous phase would include water-soluble compounds (e.g., sugars, salts, acids, bases, surfactants, proteins, and polysaccharides). The oil phase would incorporate lipid-soluble components (e.g., triacylglycerols, diacylglycerols, monoacylglycerols, fatty acids, vitamins, and cholesterol) [58]. Some of those ingredients could be distributed between different phases according to their partition coefficients. Physicochemical properties of emulsions are also affected by variations in their temperature or the action of various mechanical forces produced during their processing, storage, transport, and handling. This complexity of food emulsions makes the study of lipid peroxidation and antioxidant action even more complex. Although considerable progresses have been made, further efforts should be made in understanding the major factors that determine their oxidation stability. Bigger data analysis and artificial intelligence may help reweight practical and theoretical observations and concepts; while crossing the boarders of expert traditional exploration fields and sometime fortresses.

\subsection{Natural Antioxidants and Their Particular Benefits}

Besides the intrinsic advantages of being natural substances, natural antioxidants have multiple properties that make them good candidate to be used in the development of new food additives to retard oxidative degradation of foods while providing health benefits as well. Additionally, many of these compounds have other unique functions as food additives. For instance, acid antioxidants such as citric acid, malic acid, and tartaric acid are used as food acidulants; and phosphates function as buffers, emulsifiers or water binders. However, natural substances also have some downsides such as price, undesired flavors, possibly variable supply and price variability... Phenolic compounds are the ones attracting more attention because of their highly antioxidant potential, especially tocopherols, flavonoids, and phenolic acids [59]. Rosemary and green tea are two of the most common sources of plant-derived antioxidants. The substances of interest 
are carnosol and carnosic acid from rosemary and catechins from green tea.

Natural antioxidants from plants have been studied as anticarcinogenic agents and as inhibitors of biologically harmful oxidation reactions in the body, still those studies are carried out in-vitro or with animals. Tea and tea polyphenols demonstrated inhibitory action against cancer formation in different animals [60]. Green tea polyphenols reduced both cigarette smoke- and $\mathrm{H}_{2} \mathrm{O}_{2}$-induced DNA breakage as well as inhibiting lipid oxidation in cultured human lung cells [61]. (+)-Catechin (present in tea and other plants) prevents free radical-mediated damage in biological systems as oxidation in human blood [62]. Black tea, green tea, decaffeinated black tea, and decaffeinated green tea proved to have inhibitory effects on induced skin carcinogenesis in mice [63].

Sustainability is another driving force towards the use of natural antioxidants. This is supported by the use of plants as sources of antioxidants, as well as by the possibility of extracting active compounds from organic waste or co-products from other processes. Some examples of a long and growing list of antioxidants obtained from by-product valorisation are: carob seed peels [64], banana peels [65] [66], grape seeds [16] [67] [68] [69] [70] [71] etc.

By-product valorisation of dairy industry also represents a rich source of substances with antioxidant properties, among others [72].

\section{Lipid peroxidation and human pathologies}

It is expected that supplementation with adequate antioxidants will keep sensitive cells and organs in healthy conditions and increase lifespan [73]. The organism must confront and control the balance of both pro-oxidants and antioxidants continuously. The balance between these is tightly regulated and extremely important for maintaining vital cellular and biochemical functions. This balance often referred to as the redox potential, is specific for each organelle and biological site, and any interference of the balance in any direction might be deleterious for the cell and organism. Changing the balance towards an increase in the pro-oxidant over the capacity of the antioxidant is defined as oxidative stress and might lead to oxidative damage. Changing the balance towards an increase in the reducing power, or the antioxidant, might also cause damage and can be defined as reductive stress.

Oxidative stress and damage have been implicated in numerous disease processes, including inflammation, degenerative diseases, and tumor formation and involved in physiological phenomena, such as aging and embryonic development. The dual nature of these species with their beneficial and deleterious characteristics implies the complexities of their effects at a biological site [74].

\subsection{Further Technologies to Avoid Lipid Oxidation: Antioxidant Enzymes}

Antioxidant enzymes are the main line of defence against free radicals in animal and plant cells. Indeed, antioxidant enzymes eliminate species involved in the formation of free radicals so they can be classified as preventative antioxidants. 
Some of these enzymes are superoxide dismutase, catalase and glutathione peroxidases [75].

Superoxide dismutase can be both a secondary and a primary antioxidant, depending on the action of superoxide in the free radical chain reaction. Superoxide dismutases (SOD, EC 1.15.1.1) catalyzes the dismutation of superoxide anions to dioxygen and hydrogen peroxide.

Catalase (EC1.11.1.6) converts hydrogen peroxide to water and molecular oxygen.

Glutathione peroxidase (EC1.11.1.19) catalyzes the conversion of hydrogen peroxide or organic peroxide to water or alcohol acts while simultaneously oxidizes tripeptide glutathione.

\subsection{Concluding Comments}

Preventing lipid peroxidation can be a daunting task as it depends on many factors and many considerations need to be taken into account. Although many studies and progresses have been done trying to explain and conceptualize and theorize lipid oxidation and antioxidant influence, a better understanding of a number of interactions is clearly warranted. Interactions between emulsifiers and antioxidants have an important influence on lipid-oxidation control, as well as hydrophobicity/amphiphilicity of antioxidants. A precise control of the localization of reactants inside the food matrix is essential to limit oxidation with a minimum amount of antioxidants. In addition, diminishing the amount of additives could be reached by the use of antioxidants with emulsifying properties, or vice versa (emulsifying antioxidants vs antioxidant emulsifiers). A thorough investigation of the relationship between chain length, emulsifying properties and antioxidant capacity would open a window of opportunities for the design and fine-tuning of antioxidants. Another array of possibilities can be found in natural substances, which might be considered as one of the most competitive and appealing alternatives to synthetic antioxidants. These natural antioxidants also have health-related effects, therefore further studies should be carried out regarding the required amounts to prevent lipid oxidation in foods and the amounts having health influences reliably.

On the other hand, [76] despite the many catalytic metal complexes and photosensitizers found in plants and animals, nature has provided them with effective inhibitors, quenchers of singlet oxygen, and reducing enzymes for effective protection against hazards and toxicity from lipid hydroperoxidation. For example, plant leaves are loaded with linolenic acid, [77] [78] and yet plants have a mechanism for protection against oxidation. Research on natural antioxidants and singlet oxygen quenchers may unravel the mechanism plants enjoy for protection against linolenate oxidation. Processing of vegetable oils may upset the natural balance between photosensitizers and quenchers, resulting in decreased stability. Future research should address the problem of how processing can be changed to improve this balance in favor of quenchers. 


\section{Milk Proteins and Their Derivatives}

\subsection{Overall Composition of Milk}

Milk is a major source of dietary energy, proteins (mainly caseins and whey proteins), fat (mainly acylglycerols and phospholipids) and carbohydrates (where lactose is the main component) [72] [79].

Lactose is involved in the intestinal absorption of calcium, magnesium and phosphorus, and the utilization of vitamin D. Water is the main component in all milks, ranging from an average of 68 percent in reindeer milk to 91 percent in donkey milk.

Among the numerous nutritional benefits of milk, milk proteins have gathered enormous attention for being a "complete" protein as they provide all nine essential amino acids (leucine, isoleucine, valine, phenylalanine, tryptophan, histidine, threonine, methionine, lysine) required by humans [80]. Those proteins are categorised into major proteins that include casein and whey fractions [81] and minor proteins that include lactoferrin, lactoperoxidases, lipases, lactase [82] [83] and miscellaneous proteins (cytokines, immunoglobulins, etc.) [84]. Milk contains also small amounts of minerals (e.g., calcium, iron, magnesium, phosphorus, potassium, sodium, zinc, copper selenium and manganese) and vitamins (retinol, carotene, vitamins A, E, B2, B12, C, D...) [79] [85].

However, when different geographic regions are considered, the contribution of milk to the various nutritional components varies considerably: milk provides only 3 percent of dietary energy supply in Asia and Africa compared with 8-9 percent in Europe and Oceania; 6 - 7 percent of dietary protein supply in Asia and Africa compared with 19 percent in Europe; and 6 - 8 percent of dietary fat supply in Asia and Africa, compared with $11-14$ percent in Europe, Oceania and Americas [79].

This unique composition of nutritional components makes it usable not only to be consumed directly as a beverage or transformed into a range of traditional dairy foods, but also to obtain ingredients or raw materials for different food and non-food applications.

Factors such as the type of protein, the proportion of protein, fat, and carbohydrates, the levels of various vitamins and minerals, and the size of the butterfat globules, and the strength of the curd are among those that may vary.

The proximate compositions of cow, buffalo, goat and sheep milks are given in Table 1. Values for human milk have been included in this table for comparison [79].

This clearly demonstrates that milk is a complex food containing numerous nutrients. Most of the constituents in milk do not work in isolation, but rather interact with other constituents. Often, they are involved in more than one biological process, sometimes with conflicting health effects, depending on the specific process.

\subsection{Factors Affecting Milk Composition}

The overall composition of milk depends [81] [86]-[92] on a range of: 
Table 1. Average composition of milk of human, cow, buffalo, goat and sheep, per $100 \mathrm{~g}$ of milk [79].

\begin{tabular}{cccccc}
\hline Proximates & Human & Cow & Buffalo & Goat & Sheep \\
\hline Energy (kJ) & 291 & 262 & 412 & 270 & 420 \\
Energy (kcal) & 70 & 62 & 99 & 66 & 100 \\
Water (g) & 87.5 & 87.8 & 83.2 & 87.7 & 82.1 \\
Total protein (g) & 1.0 & 3.3 & 4.0 & 3.4 & 5.6 \\
Total fat (g) & 4.4 & 3.3 & 7.5 & 3.9 & 6.4 \\
Lactose (g) & 6.9 & 4.7 & 4.4 & 4.4 & 5.1 \\
Ash (g) & 0.2 & 0.7 & 0.8 & 0.8 & 0.9 \\
\hline
\end{tabular}

- non-nutritional factors. genetics (breeding), physiological state (age and stage of lactation), environment (food and climate) and mastisis,

o Breeding is of considerable importance, since fat and protein levels in the milk are heritable characteristics. Gains in milk composition made from breeding are permanent and accumulate from year to year. Benefits of sire and cow selection, and of mating decisions made to-day, will continue to be realized in all future descendants of the herd. In this respect, selection is a very productive means of improving milk composition. The use of breeding to improve milk composition must be better understood, since selection to improve one production trait may lead to a decline in another. Selection based on milk yield will result in an increase in milk, fat and protein yields, but will reduce fat and protein percentages.

o Although fat and protein contents decrease with increasing age, these changes are small. Since the age structure of a herd is not readily changed, the age composition of the herd is unlikely to contribute significantly to herd variation in milk composition.

o The composition of milk varies also with the stage of lactation. Cows that calve in good condition produce milk with a high fat and protein content during early lactation. The percentages of both fat and protein decline during the first six to eight weeks of lactation, then progressively rise after the cow becomes pregnant to reach their highest levels in late lactation.

o Environmental factors that affect feed intake can be associated with pronounced variations in milk yield and composition. Temperatures consistently above $30^{\circ} \mathrm{C}$ will reduce milk yield as well as the percentage of milk protein, because of a reduction in energy intake.

o Clinical and subclinical mastitis decrease milk yield and so reduce fat and protein yields.

- Nutritional factors: mainly the level of feeding, diet quality, concentrates (cereal grains, lupins...), fibres and other feeding supplements.

When milk is used in the production of traditional dairy products, such as yoghurt, cheese or kefir, huge amounts of by-products and wastes, especially 
whey, are generated. Whey is an important disposal problem in the dairy industry, but at the same time it is still rich in nutrients. Therefore, from the green point of view, it can be valorised and transformed from waste to a source of valuable ingredients.

Among those components, proteins are probably the most interesting in terms of innovation. In this sense, this review will try to highlight the potential of value-added products resulting from proteins to be used not only as food ingredients or nutritional products, but also in the non-food area.

\subsection{Production of Milk Proteins}

Milk is used as a starting material for the manufacture of many dairy products. However, the functionality of the various components in milk (e.g. whey protein, casein and fat) could be utilized more effectively if they were available as separate components. Therefore, the fractionation of milk is of great interest, not only for improvement of product quality and the obtention of other ingredients with diverse functional and nutritional characteristics, but also for economic reasons.

Each of these components differs in size, structure and physical properties. The proteins in milk consist of a group of proteins called caseins and another group called whey proteins. Of the approximately 3.6 percent protein in milk, roughly 80 percent is casein and 20 percent is whey protein. Caseins and whey proteins have very different structures and physical properties.

Processing techniques have been developed to modify the composition of milk according to the unique characteristics of its components. These processes have given the dairy industry the ability to make a wide variety of dairy ingredients manufactured from milk. Some of these processes involve the use of filtration methods that can separate milk according to the molar mass of its components [93].

Different processing techniques, usually involving the use of filtration methods based on molar mass are applied to produce value-added dairy products for traditional and also innovative applications.

\section{Membrane Processes}

Membrane separation technology is used in milk and whey processing to separate milk and concentrate whey proteins after cheese making and fractionate the whey proteins into specific components. Membrane technology is being utilized both in traditional dairy processing and for new and innovative applications, enabling the production of value-added dairy products. Some of the common membrane separation technologies used in the dairy and food industry are reverse osmosis, nanofiltration, ultrafiltration and microfiltration (Figure 9).

Ultrafiltration and microfiltration technologies are the primary membrane separation technologies used by the dairy industry. Ultrafiltration (UF) was initially used in the dairy industry to pre-concentrate milk before cheese making. It has also been successfully used to recover proteins from whey and concentrate 


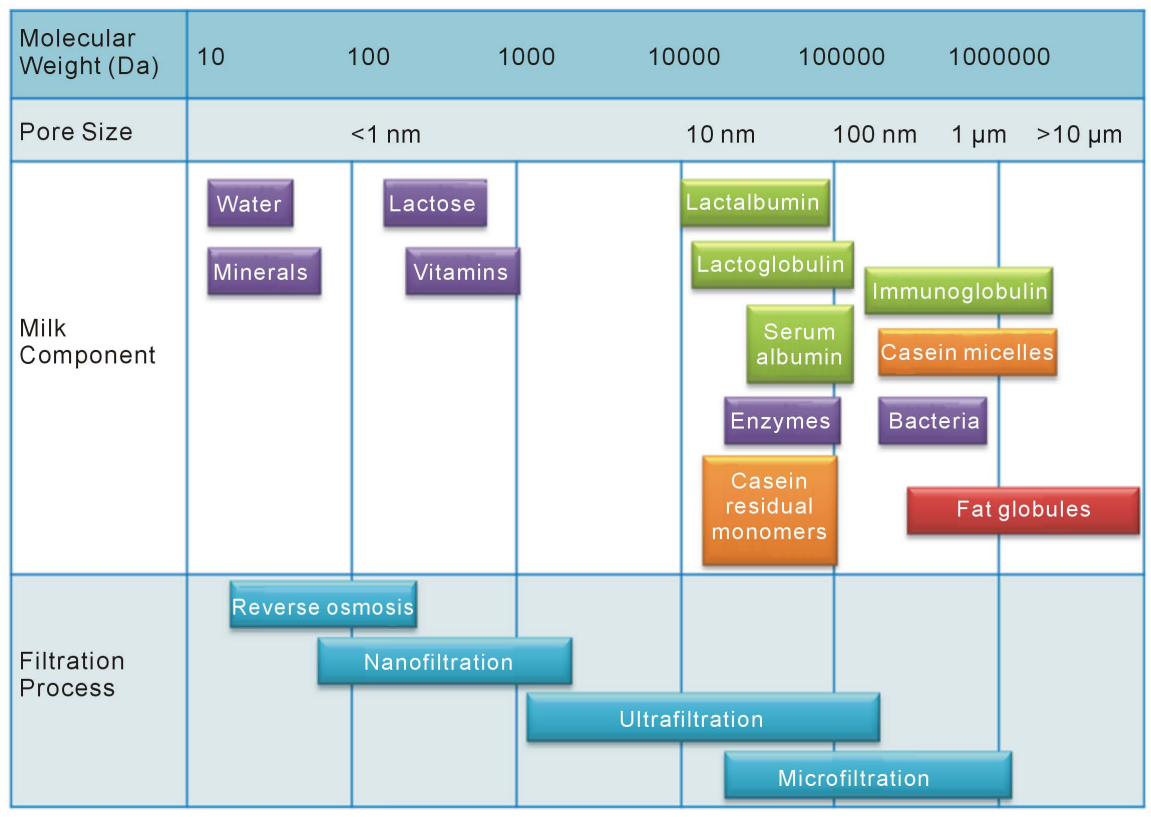

Figure 9. Relative milk component sizes in comparison with membrane pore size ranges [107].

milk proteins from smaller compounds such as lactose, vitamins and minerals. Microfiltration traditionally has been used in the dairy industry for bacteria removal, defatting of whey and micellar casein enrichment for cheese making [94]. A more recent application of microfiltration is the fractionation of caseins and whey proteins from milk [95] [96] [97].

Caseins are larger in molar mass than the majority of whey proteins and thus can be separated through the use of microfiltration.

A wide variety of microfiltration-membrane materials, geometric designs, system configurations and operating approaches are available. Two major types of membranes exist: polymeric and ceramic. Their differences reside in cost, membrane life, flux, efficiency, purity of the fractions, cleaning and energy consumption [98].

Fouling is considered the limiting factor in milk filtration, which has led to the development of different strategies to minimize this problem, e.g., uniform trans-membrane pressure (UTP), back-pulsing, air slugs, rotating or vibrating modules and ion-exchange membranes [94] [99]. Solutions based on the porosity gradient of the membrane support (Membralox GP', Pall Corporation) or a variable thickness active membrane layer (Isoflux', Tami Industries), have also been developed [93] [100].

One of the indicators of the great potential of the fractionation of milk is the number of patents that have been published over the last decade regarding the purification and concentration of its different ingredients. Some examples are: protein fractionation of skim milk by means of microfiltration [101], purification of $\beta$-casein using cross-flow polymeric microfiltration membranes [102], fractionation of $\alpha_{s}$-casein, $\kappa$-casein and $\beta$-casein [103], concentration of milk 
proteins using negatively-charged ultrafiltration membranes [104] and supercritical carbon dioxide to effectively fractionate whey proteins ( $\alpha$-lactalbumin and $\beta$-lactoglobulin), as well as to isolate casein glycomacropeptide (an amino acid fragment of $\kappa$-casein) [105] [106].

Milk proteins can be obtained directly from skim milk or from wastes and by-products of cheese making. Figure 10 summarizes the main steps to obtain milk protein products through different routes. Direct ultrafiltration of skim milk produces milk protein concentrate (MPC) that contains whey proteins and caseins in the same ratio as milk, while ultrafiltration of cheese whey produces whey protein concentrate (WPC) [93]. With a combination of micro- and ultrafiltration, separated fractions of micellar casein and whey protein concentrates are obtained. This is also possible with the coagulation of casein.

It is estimated that more than $90 \%$ of whey protein concentrates originates from separating the coagulum from milk, cream, or skim milk in cheese making. Less than $10 \%$ is obtained from casein production, from the curd formation by direct acidification of milk [108] [109].

Depending on their source, WPC have different flavor and appearance, WPC from the production of cheese is more colored than the one obtained from milk. A solution of milk-derived WPC has a clear appearance, while using cheese-derived WPC is very milky and cloudy. This is due to the higher fat content of the second. The presence of glycolmacropeptide only in cheese-derived WPC is another difference.

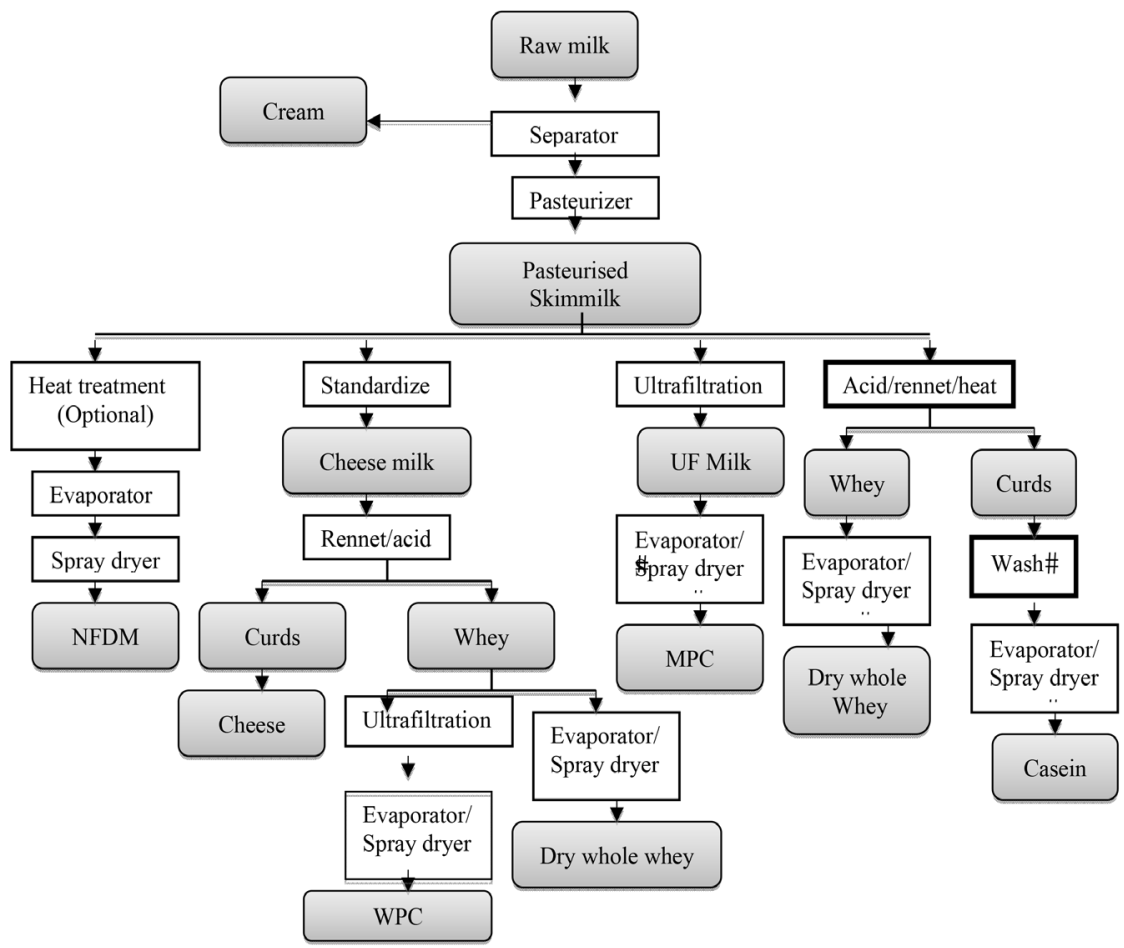

Figure 10. Different processes for manufacturing milk protein products [107] (1) NFDM: Non-Fat Dry Milk. 


\subsection{Properties and Applications of Milk Proteins}

Milk proteins are nitrogen-containing substances that are formed by amino acids. They serve as the major structural component of muscle and other tissues in the body. In addition, they are used to produce hormones, enzymes and hemoglobin. They can also be used as energy; however, they are not the primary choice as an energy source. For milk proteins to be used by the body they need to be metabolized into their simplest form, amino acids.

Dairy proteins are isolated from skim milk using membrane filtration that allows obtaining milk protein concentrates (MPCs) with concentrations ranging from $40 \%$ to $80 \%$. Those milk fractions are rich in bound calcium and contain both whey protein and casein.

The excellent surface-active and colloid-stabilizing characteristics of milk proteins make them highly valued food ingredients, both in soluble and dispersed form [110].

Some of their main functional characteristics are: solubility, water binding, gelling, foaming, emulsification and heat stability.

Their hydrophilic and hydrophobic polar nature makes them desirable emulsifiers, and able to improve texture and increase shelf-life in diverse products such as breads, meats and frozen desserts. MPCs are currently used as ingredients for manufacturing cheese and yogurt, ice cream, dietetic formulations, cereal and energy bars, infant formulas, desserts, baked goods, toppings, low-fat spreads, sports beverages/foods and geriatric nutritional products.

Not only milk proteins, but proteins in general are important ingredients in the food industry and the demand for protein-enriched food formulations is increasingly growing. Proteins provide amino acids that are required for growth, functioning and cellular maintenance of the human body. However, their composition may be so unique that their influence on physiological function in the human body could be quite different. The quality of a protein is vital when considering the nutritional benefits that it can provide. Determining the quality of a protein is determined by assessing its essential amino acid composition, digestibility and bioavailability of amino acids (FAO/WHO, 1990) [111]. There are several measurement scales and techniques that are used to evaluate the quality of protein. These techniques have been identified as protein efficiency ratio, biological value, net protein utilization, and protein digestibility corrected amino acid score.

- The protein efficiency ratio (PER) determines the effectiveness of a protein through the measurement of animal growth. This technique requires feeding rats a test protein and then measuring the weight gain in grams per gram of protein consumed.

- The Biological value $(B V)$ measures protein quality by calculating the nitrogen used for tissue formation divided by the nitrogen absorbed from food. This product is multiplied by 100 and expressed as a percentage of nitrogen utilized. The biological value provides a measurement of how efficient the 
body utilizes protein consumed in the diet. There are, however, some inherent problems with this rating system. The biological value does not take into consideration several key factors that influence the digestion of protein and interaction with other foods before absorption. The biological value also measures a protein's maximal potential quality and not its estimate at requirement levels.

- Net protein utilization is similar to the biological value except that it involves a direct measure of retention of absorbed nitrogen. Net protein utilization and biological value both measure the same parameter of nitrogen retention, however, the difference lies in that the biological value is calculated from nitrogen absorbed whereas net protein utilization is from nitrogen ingested.

Protein digestibility corrected amino acid score (PDCAAS) allows comparing the quality of various proteins. It is known as and based on the amino acid requirements of humans. According to this method, "an ideal protein that meets all the essential amino acid requirements of human body will have a value of 1.0". Table 2 summarizes the quality of proteins from different sources.

Milk proteins provide high levels of the essential and branched amino acids. They also possess many beneficial bioactivity properties and are a rich source of minerals and vitamins [114]. Another advantage of milk proteins is that they are suitable to people that are allergic to soy products and to those that reject GMO products. From the opposite position, they are inapt to people allergic or intolerant to milk products or vegans.

\subsection{Categories of Milk Proteins: Structure and Applications}

The proteins in milk are categorised into major proteins that include casein and whey fractions [81] and minor proteins that include lactoferrin, lactoperoxidases, lipases, lactase [82] [83] and miscellaneous proteins (cytokines, immunoglobulins, etc.) [84].

\subsubsection{Caseins}

Casein coagulates in the presence of rennet/acid to form the cheese curd. Coagulated casein forms a three-dimensional lattice or backbone structure,

Table 2. Comparison of the quality of proteins from different origins [112] [113].

\begin{tabular}{ccccc}
\hline Protein type & PER & BV & Net Protein Utilization & PDCAAS \\
\hline Whey protein & 3.2 & 104 & 92 & 1.00 \\
Casein & 2.5 & 77 & 76 & 1.00 \\
Milk & 2.5 & 91 & 82 & 1.00 \\
Soy protein & 2.2 & 74 & 61 & 1.00 \\
Wheat gluten & 0.8 & 64 & 67 & 0.25 \\
Beef & 2.9 & 80 & 73 & 0.92 \\
Egg & 3.9 & 100 & 94 & 1.00 \\
\hline
\end{tabular}


which then entraps fat, water, minerals and starter cultures and results in cheese curd formation. As the casein coagulates, whey begins to separate from the curd. The amount of casein at the beginning of the cheesemaking process is the single biggest factor affecting cheese yield.

\section{Structure}

The casein family consists of several types of caseins, each having its own amino acid composition, genetic variations, and functional properties. They form complexes called micelles that are dispersed in the water phase of milk. Those micelles consist [115] of subunits of the different caseins $\left(\alpha_{\mathrm{s} 1}, \alpha_{\mathrm{s} 2}, \beta\right.$ and $\left.\gamma\right)$ held together by calcium phosphate bridges and hydrophobic interactions between proteins on the inside, surrounded by a layer of $\kappa$-casein which helps to stabilize the micelle in solution. There are two main types of submicelles; one consisting of $\alpha_{s}$ - and $\beta$-caseins, that constitutes the hydrophobic center of the submicelle, and another type consisting of $\alpha_{\mathrm{s}}$ - and $\kappa$-caseins, which is distributed outside of the micelle with the hydrophilic part (the sugar residues of $\kappa$-caseins) forming an outer "hairy layer" [115].

Casein micelles are spherical and are 0.04 to $0.3 \mu \mathrm{m}$ in diameter, much smaller than fat globules which are approximately $1 \mu \mathrm{m}$ in homogenized milk. The casein micelles are porous structures that allow the water phase to move freely in and out of the micelle. Casein micelles are stable and "active" structures that do not settle out of solution. They can be heated to boiling or cooled, and they can be dried and reconstituted without, to a certain extend, adverse effects. $ß$-casein, along with some calcium phosphate, will migrate in and out of the micelle with changes in temperature, but this does not affect the nutritional properties of the protein and minerals.

The caseins have a relatively random, open structure due to the amino acid composition (high proline content).

\section{Main applications}

The high phosphate content of the casein family allows it to associate with calcium and form calcium phosphate salts. The abundance of phosphate allows milk to contain much more calcium than would be possible if all the calcium were dissolved in solution, thus casein proteins provide a good source of calcium for milk consumers.

In cheese manufacture, the $\kappa$-casein is cleaved within some of the amino acids, and this results in a protein fragment that does not contain the amino acid phenylalanine. This fragment is called milk glycomacropeptide and is a unique source of protein for people with phenylketonuria.

The most important applications of caseins in processed foods are cheese analogues, synthetic whipping creams, cream liqueurs, fabricated meats, some cereal products, various dietetic foods and as an emulsifier in coffee whiteners [81].

The amphipathic (with both hydrophilic amino acids and lipophilic amino acids) structure and the lack of stable secondary and tertiary structures of caseins contribute to their high surface activity, which gives them good foaming and 
emulsifying properties. Casein functional properties are significantly affected by changes in $\mathrm{pH}$, method of preparation, ionic strength and nature of the salt ion [116].

Regarding the isolate proteins from casein, $\beta$-casein has very high surface activity and may find applications as a high-quality emulsifier or foaming agent. The consolidation of milk with $\beta$-casein improves its cheese making properties. This protein is also an attractive ingredient for the manufacture of bovine milk-based infant formula that more closely mimic human breast milk, which has a higher ratio of $\beta$-casein. $\kappa$-Casein might be a useful additive for certain milk products [81]. Nevertheless, the casein proteins find their major application in the production of biologically active peptides.

\subsubsection{Whey Proteins}

Whey is a general term that typically denotes the translucent liquid part of milk that remains following the process (coagulation and curd removal) of cheese manufacturing. From this liquid, whey proteins are separated and purified using various techniques yielding different concentrations of whey proteins.

All of the constituents of whey proteins (singlaror plural $>$ to be checked) provide high levels of the essential and branched chain amino acids. The bioactivities of these proteins possess many beneficial properties as well. Additionally, whey is also rich in vitamins and minerals.

There are three main forms of whey proteins that result from various processing techniques used to separate whey protein named: whey powder, whey concentrate, and whey isolate. Table 3 provides the composition of whey proteins.

Whey is a complete protein composition whose biologically active components provide additional benefits to various enhance human function and biobalance.

\section{Structure}

The whey protein fraction consists of approximately 50\% $\beta$-lactoglobulin, 20\% $\alpha$-lactalbumin, serum albumin, immunoglobulins, lactoferrin, transferrin, and the proteose-peptone fraction. Regarding their structure, whey proteins are compact globular proteins whose intramolecular folded structure is the result of disulfide bonds between cysteine residues, which encloses the hydrophobic residues into the molecule. For that reason, whey proteins do not interact with other proteins.

Table 3. Composition (\%) of whey protein forms [117].

\begin{tabular}{cccc}
\hline Component & $\begin{array}{c}\text { Whey } \\
\text { Powder }\end{array}$ & $\begin{array}{c}\text { Whey } \\
\text { Concentrate }\end{array}$ & $\begin{array}{c}\text { Whey } \\
\text { Isolate }\end{array}$ \\
\hline Protein & $11-14.5$ & $25-89$ & $>90$ \\
Lactose & $63-75$ & $10-55$ & 0.5 \\
Milk Fat & $1-1.5$ & $2-10$ & 0.5 \\
\hline
\end{tabular}


These proteins exist as individual units dissolved in the water phase of milk and stay in solution (unless denatured) over a wide range of $\mathrm{pH}$. They can be denatured by heat, what produces breaking and randomization of the stabilizing disulfide bonds, and exhibit heat-induced gelation [118].

\section{Main applications}

The primary food application of whey proteins is as emulsifiers. Some influential factors are: the processing conditions, the method of isolation, environmental conditions (e.g., $\mathrm{pH}$, temperature, ionic strength, etc.), and interaction with other food components.

Furthermore, its ability to form gels capable of holding water, lipids, and other components while providing textural properties makes them rather ideal in processed meat, dairy and bakery products. Regarding its foaming properties, these mainly depend on the degree of the protein denaturation [118].

Whey protein based products are mainly produced in food, cosmetic and pharmaceutical sectors.

\subsection{Milk Protein Modifications and Functionalities}

Enzymatic tailoring of milk proteins can be made by hydrolysis or cross-linking; this improves their functionality and stability.

\subsubsection{Hydrolysis}

Hydrolysis of milk proteins generates smaller peptide sequences from their parent protein that can be biologically active when released.

Milk proteins hydrolysis happens naturally in the gastrointestinal tract and can be simulated in the laboratory or on an industrial scale. During the normal transit through the gastrointestinal tract, milk proteins are exposed to proteinases such as pepsin, trypsin and chymotrypsin which break them down into smaller peptides. These peptides are further digested by brush border peptidases present at the surface of intestinal epithelial cells where they produce amino acids.

In laboratory or at an industrial scale, milk hydrolysates are released either by treatment of milk proteins with food grade enzymes or through fermentation with bacteria. The shorter peptide sequences often possess bioactive properties beyond their nutritional contribution along with eradicating any protein-specific allergenicity [119] [120]. Processing and enriching for food grade bioactive peptides is a goal for the specialized food industry.

Enzymatic hydrolysis of milk proteins modifies the surface hydrophobicity, the emulsifying and foaming properties, and solubility [121]. It has also influence on the digestibility and allergenicity. The enzymatic hydrolysis of milk proteins enables tailoring their functional properties to meet individual requirements of food formulations. Partial hydrolysis of proteins may improve their functionality, and excessive hydrolysis could negatively affect it. It has been reported that higher hydrolysis degrees produce bitterness [102] and can result in adverse effects on the emulsifying functionality [122]. Controlled hydrolysis 
may enhance some functional properties and simultaneously be detrimental to others [123]. For all those reasons, the control of the hydrolysis degree is crucial. To achieve that, the selection of the right proteolytic enzyme (such as pepsin, trypsin, neutrase, chymotrypsin, and plasmin), time, environmental conditions and extent of hydrolysis is crucial. Caseins, since their flexible random structures, are more susceptible to hydrolysis compared to the whey proteins, with compact globular structure [121].

The enzymatic hydrolysis process is conducted under mild conditions ( $\mathrm{pH} 6$ 8 , temperature $40^{\circ} \mathrm{C}-60^{\circ} \mathrm{C}$ ) to minimise side reactions and to retain an amino acid composition close to the starting material [124]. Enzymatic hydrolysis improves the solubility and heat stability of peptides, which is of benefit to the food industry. The food grade enzymes generally used to hydrolyse milk proteins into hydrolysates include pepsin, trypsin and chymotrypsin [125] [126].

In addition, food grade proteolytic enzymes, derived from microorganisms, can also be used to generate hydrolysates [127]. Proteolytic enzymes are of two types, depending upon their hydrolysing mechanism: endopeptidases which hydrolyse peptide bonds within protein molecules and exoproteases which hydrolyse $\mathrm{N}$ or $\mathrm{C}$ terminal peptide bonds.

Some studies carried out to elucidate interactions between native proteins and their hydrolysates clearly demonstrated that a deeper understanding of the structure-function relationship of hydrolysates behavior both in model and real food systems is essential to increase the use of enzymes in enhancing the functionality of food proteins [123].

Moreover, in the post enzymatic hydrolysis, the hydrolysates usually need an additional treatment. The most common procedures include ultrafiltration, heat treatment and/or activated carbon treatment to control molecular size and elimination of bitterness in the hydrolysates [124].

\section{Hydrolysis by microbial fermentation}

Fermentation of milk proteins with proteolytic starter culture is another method of bulk production of hydrolysates. Safety measures should be considered with regard to toxicity and pathogenicity associated with the microorganisms used for fermentation. Bacterial cultures of Lactobacilli spp., Lactococci spp. and Streptococci spp. are commonly used to generate hydrolysates from milk [128]. The proteolytic system of lactic acid bacteria (LAB) contains cell envelope-associated proteinases, endopeptidases, aminopeptidases, tripeptidases and dipeptidases for the production of hydrolysates [129].

$\mathrm{LAB}$ requires free amino acids and peptides for their growth, which they obtain from milk proteins by degradation [130]. The peptides or hydrolysates not utilised by bacteria can promote various bioactivities.

Process parameters such as enzyme/substrate ratio, composition of medium, heat treatment, temperature, $\mathrm{pH}$ and carbon/nitrogen ratio influence the release of hydrolysates from milk proteins.

Functionality of bioactive milk protein hydrolysates

As already seen, the hydrolysis process allows breaking down milk proteins to 
shorter peptide sequences that happens naturally in the gastrointestinal tract and can be simulated in the laboratory or on an industrial scale. During the normal transit through the gastrointestinal tract, milk proteins are exposed to proteinases such as pepsin, trypsin and chymotrypsin which break them down into smaller peptides. These peptides are further digested by brush border of the intestinal membrane peptidases present at the surface of intestinal epithelial cells where they produce amino acids; however, some oligopeptides still remain intact. In laboratory or at an industrial scale, milk hydrolysates are released either by treatment of milk proteins with food grade enzymes or through fermentation with bacteria. Those shorter peptide sequences often possess bioactive properties beyond their nutritional contribution along with neutralizing any protein-specific allergenicity.

Once the hydrolysates are released, they can potentially have bioactive properties which can exert their effects in receptive cells, including those present in the gastrointestinal tract [131]. The bioactivities of the resulting hydrolysates are variable depending on a range of factors, including the enzyme used, the processing conditions and the final size of the peptide sequence following hydrolysis [124]. The degree of hydrolysis (DH) is defined as the percentage of cleaved peptide bonds, i.e. the number of hydrolysed bonds per total number of peptide bonds in the protein [132]. This affects the size and amino acid composition of the peptides, which subsequently determines the biological activity of the peptide. Hence, DH is an important consideration from the perspective of functional food research [133].

The potential health benefits of milk hydrolysates are a subject of growing commercial interest from a health-promoting functional-food perspective. In this sense, a number of milk-derived bioactives have been characterised with a variety of health benefits in the gastrointestinal tract. These biological activities include 1) supporting the establishment of a healthy commensal microbiome (essential for metastatic melanoma patients), 2) suppressing the colonization of pathogenic bacteria and 3) supporting barrier function. Hydrolysates of casein and whey also impart anti-inflammatory and immunomodulatory activity.

Much of the work to date has been focused on milk, cheese and other dairy products as sources of bioactive proteins and peptides, still, interest in other sources of food-derived bioactive peptides is growing. Some of these sources are fish species such as sardines, tuna, bonito and salmon, as well as other animal products such as blood, eggs and gelatin. Plants are also potential sources, for instance: wheat, rice, soya, pumpkin and mushrooms. A Quantitative structure-activity relationship (QSAR)-based in-silico method was proposed for the prediction of food protein sources that can yield bioactive peptides [134]. To achieve that goal, details of the structure-function properties of active sequences should be known.

\subsubsection{Cross-Linking}

A promising and rather straightforward approach to develop low $\mathrm{pH}$ milk pro- 
teins gels with tailored properties has been conducted using enzymatic modification. Milk proteins gelation is of considerable interest because it can provide new food products with unique functional performance, favorable texture, as well as flavor enhancement properties [135] [136].

Whey protein (WP) gels are most commonly produced using heat treatment [137] [138] [139] [140] [141]. However, gelation of WP can be produced with or without heating through salt addition [142], $\mathrm{pH}$ adjustment [143] [144] and enzyme treatment [145]-[150].

WP gels in acidic conditions $(\mathrm{pH}<4.6)$ remain largely unutilized because of their weak and brittle nature in contrast to the favorable elastic gels produced at neutral or basic conditions. This is mainly due to the absence of the strong covalent chemical disulphide bonds under these acidic conditions and $\mathrm{pH}$-associated effects on the denaturation and aggregation reactions [151]. The creation of chemical crosslinks in acidic whey protein gels could improve their brittle and weak nature.

Cross-linking of food proteins can be catalyzed by enzymes such as peroxidase, tyrosinase, transglutaminase, and laccase [152]. The susceptibility of a protein to cross-linking depends on its macromolecular structure. Individually, both the caseins and whey proteins are good substrates; however in a hybrid solution, caseins seem more susceptible to cross-linking than native whey proteins [153].

Transglutaminase (TG) is one of the most widely used enzyme for cross-linking of milk proteins. TG catalyses the formation of an isopeptide bond between a free amine group (e.g., a protein- or peptide-bound lysine) and the acyl group at the end of the side chain of protein- or peptide-bound glutamine. The reaction also produces a molecule of ammonia. Such an enzyme is classified as EC 2.3.2.13. Bonds formed by transglutaminase exhibit high resistance to proteolysis.

Enzymatic cross-linking of individual milk proteins and other proteins with TG has revealed an increase heat stability, a higher resistance to proteolysis with a considerable effect on their emulsifying properties[154] [155].

Regarding applications, cross-linking may be used for stabilizing products such as yogurt, whipping cream, fresh cheese and novel milk products. Yoghurt from lactoperoxidase-, laccase- glucose oxidase- or transglutaminase-treated milk was characterized by a minor acidity and whey drainage as well as by a more soft, homogeneous and creamy consistency showing better sensory characteristics than yoghurt from untreated milk [156] [157], indicating that cross-linking may be a very useful tool for low-fat fermented products. Improved gel strength and increased viscosity as a result of improved water-holding properties have also been reported [158].

\subsection{Use of Whey Proteins to Obtain Bioemulsifiers}

Most of the commercially available emulsifiers are chemical emulsifiers, mainly petroleum-derived. However, rapid advances in biotechnology and increased environmental awareness among consumers, with expected new legislation has 
provided further impetus for "serious" consideration of biological emulsifiers as credible alternatives to existing products. The bread industry seems to move along in specific countries [159].

Bioemulsifiers are amphiphilic compounds synthesized by microorganisms: bacteria, fungi, and yeast. Interest in those substances has been steadily increasing in recent years due to their low toxicity, biodegradable nature, diversity. environmentally friendly nature and the possibility of their production through fermentation. Their range of potential applications includes enhanced oil recovery, crude oil drilling, lubricants, surfactant-aided bioremediation of water-insoluble pollutants, health care and food processing [160] [161]. Other developing areas for biosurfactants are in cosmetic and soap formulations, foods and both dermal and transdermal drug delivery systems.

They have advantages over their chemical counterparts in biodegradability and effectiveness at extreme temperature or $\mathrm{pH}$ and in having lower toxicity. However, it is necessary to consider that the potential pathogenic nature of many microorganisms to produce bioemulsifiers can restrict their range of uses, especially in the food industry. So, to make bioemulsifiers economically competitive with synthetic emulsifiers much work has to be carried out in various aspects of bioemulsifier production. They must compete with synthetic emulsifiers in at least three respects: cost, functionality and efficiency (implicitly durability and sourcing consistency) so that bioemulsifiers can meet the need of the intended diverse applications.

Whey milk and cheese whey have been reported as potential substrates in the production of bioemulsifiers using by diverse emulsifier-producing microorganisms [162] [163] [164]. Cheese whey as a waste product from cheese production is generally known for being a pollution problem in the dairy industry, so its valorization through the production of bioemulsifiers represents both a solution for the environmental problem and an economic incentive.

An increasing number of patents claiming their use as additives for food, cosmetics and pharmaceutical products demonstrates the global interest in their exploitation [165]. Various strategic intends are noticeable, which are ten years later still confirming rather opportunistic approaches, largely pending on discovery surges and regulation advances necessity.

\subsection{Alternative Non-Food Applications of Milk Proteins}

Although this part of the review has been focused on the uses of milk components in the food industry, it is worth taking into consideration other milk non-food applications.

The following present section will specifically concern the non-food uses of milk proteins, i.e. casein and whey protein, in relation to their structural and functional properties.

Separation and extraction techniques play an important role in the valorisation process of individual proteins.

Casein, the major protein in cow's milk, has a long history of use in the 
non-food area. This gaussian coil protein has been used since the beginning of the nineteenth century in the manufacture of a wide range of products including glues [166], rigid plastics [167] [168], packaging films and biomaterials [169] [170] [171] and additives in paints [172], concrete, cement, asphalt and bitumen [173] [174] [175], cosmetics [176] [177], and rubber [178].

Whey proteins have found less numerous non-food applications. A few examples concern the cosmetic and pharmacological industries [179] [180] and the manufacture of protective films or coatings [181] [182].

In the current green framework, the most important aspect of non-food applications is the valorization of dairy co-products, hence reducing waste streams to compliance with safety and environmental regulations.

Cheese whey, by-product of cheese production, is rich in whey proteins and lactose and some of its value-added applications are: manufacture of fermented products such as biogas, ethanol, butanol, organic acid, polysaccharides, biopolymers, antibiotics, enzymes and yeast biomass [183].

Additionally, it can be used as a source of lactose which is a raw material for diverse lactose derivatives in pharmaceutical and cosmetic formulations (drug carriers, coating agents, lactulose, lactitol, lactobionic acid, adhesives, foams, etc) and also as a substrate for fermentation.

\subsection{Concluding Comments}

The technological and research advances, associated with some environmental, food security and "bio" interests, in the milk industry make it possible to study the biological and nutritional properties of milk ingredients and transfer them to a range of food and non-food applications.

Milk proteins are the most maximized components, resulting in numerous formulations and caseins, with different compositions and applications in a variety of food and pharmaceutical industries. Additionally, the properties of these products are enhanced by their enzymatic modification, (hydrolysis and cross-linking) increasing their functionality and applications. Moreover they can yield bioactive peptides, a field with almost unlimited research potential.

Alternative applications of milk proteins in the non-food area are also essential from the green perspective.

\section{Biomonomers and Corresponding Biopolymers and Polymer-Based Materials}

This section presents an overview of biosourced chemicals and materials, mainly biomonomers and biopolymers, which are produced today allowing to reduce the fossil resources depletion and dependency, and to obtain environmentally-friendlier goods in a leaner energy consuming society.

Natural resources offer a wide range of resources including renewable biomass, which is largely produced with agriculture, silviculture and microbial systems: base ingredients being present in trees, plants, grasses, vegetables, algae, food wastes, animal manures and other organic wastes. 
This renewable resource is composed of several products, among which natural polymers which, according to the hetero-atom of the main chain, are generally classified as 1) carbon-oxygen-containing polymers such as sugar polymers (e.g., cellulose, hemicelluloses, starch, chitin, chitosan and pullulan), phenolics such as lignins, humus, polyesters such as shellac, and lipids, 2) hydrocarbon polymers (e.g., natural rubber), 3) carbon-oxygen-nitrogen/sulphur-containing polymers (e.g., proteins) and 4) carbon-oxygen-nitrogen-phosphorus-containing polymers (e.g., nucleic acids).

The diversity and abundance of these products constitute a very big wealth and potential for 1) the replacement of materials actually stemming from fossil resources, 2) the development of new materials which cannot be easily produced via the classical chemical methods, and new processes involving, for example, new generation of living and biochemical entities systems (enzymes or microorganisms) able to manage their chemical functionalities more efficiently, at lower temperatures and generating fewer emissions than conventional chemical processes.

Nevertheless, even if industrial production is still marginal, a strong research interest in converting underutilized biological materials into useful products constitutes a significant innovation momentum. So, numerous bio-based products, classified as 1) commodity chemicals, 2) specialty chemicals and 3) specialty biochemicals have been produced from renewable biomass and used for power, heat, fuel, biogas, and production of biomaterials [72] [184] [185]. In this context, microorganisms have been employed for the production of various chemicals and materials, but their efficiencies are rather low when they are isolated from nature. During the past few decades successful examples that have overcome this obstacle have combined traditionally employed methods of random mutation and selection with metabolic engineering to produce high-value chemicals in good yield [186] [187].

Recently, metabolic engineering has been systematically and globally upgraded to the systems level (thus systems metabolic engineering) by the integrated use of 1) global technologies of systems biology, 2) adapted design of synthetic biology and 3) rational-random mutagenesis through evolutionary engineering [188] [189] [190].

These three emerging fields can be briefly summarized as follows:

Systems biology aims at unraveling the underlying principles of biological systems through profiling the whole cellular characteristics using high-throughput technologies together with computational methods.

Synthetic biology aims at creating novel biologically functional parts, modules and systems by employing various molecular biology and synthetic DNA tools together with mathematical methodologies, and has been successfully applied in various metabolic engineering experiments. Several synthetic functions and modules have been developed to redirect metabolic pathways to produce novel metabolites. Boolean operations according to input signals, regulate metabolic fluxes in response to environmental changes, perform a specific biologi- 
cal behavior such as on/off switch and oscillation, and allow communication among cells. Synthetic biology has greatly contributed to metabolic engineering by expanding the capacity of the production host, and thereby producing various chemicals and materials that are heterologous to the original host strain.

Evolutionary engineering, in which the expression levels of multiple genes are tuned and adapted simultaneously and autonomously by following the rules of natural selection for the desired cellular properties, can be used as a complementary technique in metabolic engineering [191].

By applying those metabolic engineering tools and strategies to engineer synthetic enzyme pathways, the number and diversity of commodity and specialty chemicals that can be derived directly from renewable feedstocks is rapidly and continually expanding. Moreover, they can be better optimized in a multiplexed way on a genome scale with reduced time and effort.

This of course includes a number of monomer building-block chemicals that can be used to produce replacements to many conventional plastic materials.

This aims to highlight recent and important advancements in the microbial production of the so-called "biomonomers." Relative to naturally-occurring renewable bioplastics, biomonomers offer several important advantages, including improved control over the final polymer structure and purity, the ability to synthesize non-natural copolymers, and allowing products to be extracted from cells which ultimately streamlines downstream recovery and purification.

To highlight these features, a handful of biomonomers have been selected as illustrative examples of recent works, including lactic acid, succinic acid, hydroxyacids, diols and polyamide and styrenic vinyls monomers.

These monomers are used to manufacture important biosourced advanced polymers (e.g. linear and aromatic polyesters, polyamides and styrenic vinyls polymers) which are now able to replace totally or partially polymers currently originating from fossil resources.

Where appropriate, examples of their industrial penetration to date and end-product uses are also highlighted. Novel biomonomers such as these are ultimately paving the way toward new classes of renewable bioplastics that possess a broader diversity of properties than ever before possible.

\subsection{Naturally-Occuring Biomonomers and Biopolymers}

The following section is mainly oriented towards metabolic and pathway engineering that has been studied for the development of novel biocatalysts able to help shape the future of the biopolymers industry.

There are three principal ways to obtain bio-sourced polymers using renewable resources [192]:

- Extraction, purification and eventually partial modification of natural polymers produced by plants (e.g., cellulose, starch, chitin and chitosan, pullulan, lignin...);

- Direct production of bio-sourced polymers by microorganisms (e.g., polyand oligo-saccharides, polyhydroxyalkanoates); 
- Prodution of bio-sourced monomers (e.g., sugars) by fermentation followed by further modification and polymerization.

\subsubsection{Natural Polymers Produced by Plants}

Cellulose [193] [194], starch [195] [196], chitin and chitosan [197], proteins (soya protein, gelatin, casein, whey proteins) etc. [198] [199] [200] and their derivatives are natural polymers which offer a wide range of properties and applications which were summarized in a previous paper [184].

\subsubsection{Biosourced Polymers Produced by Microorganisms \\ Polysaccharides}

Microorganisms (mainly bacteria) can produce natural polymers from sugars. For example, acetobacter xylinum, Rhizobium and sarcinaare are able to produce pure cellulose (i.e. without lignin and hemicelluloses). This bacterial cellulose is characterized by a high mechanical strength and can be used to produce articles with relatively high strength, wound care healing system (XCell.) [201], acoustic diaphragms, paints, oil gas recovery, adhesives, medical films (Biofill., Bioprocess, and Gengiflex) [202].

Other polysaccharides are also produced [203], involving:

- Bacteria (e.g., dextrans and derivatives, hyaluronan and hyaluronic acid by streptococcus, glycogen by E. Coli, Clostridia, Bacillus, and Streptomyces, alginate by Pseudomonas and Azotobacter, glucuronan by Rhizobium and Pseudomonas),

- Fungi (e.g., pullulan by Aureobasidium, Pullularia and Dematium, Chitin and chitosan by Basidomycetes, Ascomycetes...),

- Alga (e.g., alginate by Phaeophyceae and carragenan by Rhodophyceae).

\section{Polyhydroxyalkanoates}

A number of natural biosourced polymers produced by microorganisms are useful as bioplastics.

The most notable are polyhydroxyalkanoates, (PHAs), which are a family of biodegradable linear polyesters composed primarily of monomer subunits of $(R)$-3-hydroxybutyrate $(3 \mathrm{HB})$ and are produced as carbon and energy storage molecules by numerous different microbes from both simple and complex biomass feedstocks. Well-known bacterial PHA producers include species of Ralstonia [204], Bacillus subtilis [205] and Pseudomonas [206], as well as phototrophic cyanobacteria [207].

Although PHAs are efficiently produced by microbes via naturally evolved biosynthesis routes, expressing the requisite pathway enzymes from various natural producers has also enabled their production at high levels in recombinant Escherichia coli, a more tractable host platform [208]. Bacteria have been engineered to achieve PHA biosynthesis at up to $80 \%$ of cell dry weight and at productivities as high as $4 \mathrm{~g} / \mathrm{L}-\mathrm{h}$ from substrates such as glucose [209].

More than 150 PHA monomers have been identified as the constituents of PHAs [210]. Such diversity allows the production of bio-based polymers with a wide range of properties, tailored for specific applications. 
Poly-3-hydroxybutyrate was the first bacterial PHA identified. It has received the greatest attention in terms of pathway characterization and industrial-scale production. Commercial interest in PHAs has been growing, with Metabolix (Cambridge, MA), for example, pursuing their large scale development through their Mirel ${ }^{\mathrm{TM}}$ and Mvera ${ }^{\mathrm{TM}}$ brands, which collectively are expected to have applications in the production of fibers, films, and coatings, as well as for molded and extruded products.

Several companies such as ICI (UK), Chemie Linz (Austria), BASF (Germany), Biomers (Germany), Zhejiang Tian An, (China), Tianjin Green Bioscience (+DSM), have developed PHA copolymers with typically $80 \%$ to $95 \%$ (R)-3-hydroxybutyric acid monomer and $5 \%$ to $20 \%$ of a second monomer in order to improve the properties of PHAs.

\subsubsection{Naturally-Occurring Biomonomers}

Limitations associated with naturally-occurring bioplastics have motivated a recent shift in focus to the alternative production of "biomonomers." Biomonomers are small molecules that can undergo ex situ chemocatalytic polymerization to produce plastics. This strategy offers several distinct advantages.

First, since most biomonomers are often naturally excreted from microorganisms, the need for cell collection and lysis is eliminated, greatly reducing operating expenditures and facilitating downstream product recovery. Polymerization of biomonomers in highly controlled chemocatalytic environments leads to bioplastics with finely tuned and predictable properties and at high purities to satisfy quality control specifications.

Lastly, the ability to copolymerize biomonomers with other desired monomers (biologically or otherwise derived) increases the diversity of plastics that can be produced from renewable resources, widening the range of achievable chemistries and material properties.

As for many specialty chemicals, one can distinguish two classes of biosourced monomers of industrial interest.

The first class can be produced from natural compounds with the aid of catalytic further processing steps. For example, the natural fermentation of sugars yields ethanol which can undergo dehydration to ethylene over a solid acid catalyst [211] [212], before later being polymerized to poly(ethylene) or its copolymers.

The second class concerns those compounds that themselves are directly suitable for polymerization into bioplastics. The list of monomers that can be obtained from biomass is vast and has been recently reviewed [213] [214] [215]. Historically, the main studied monomers were bi-functional molecules.

The most prominent example of a naturally-occurring biomonomer is L(+)-lactic acid, whose polymerization leads to the polyester poly(lactic acid) (PLA). $\mathrm{L}(+)$-lactic acid is a natural fermentation product of numerous microbes, of which well known examples include lactic acid bacteria (including numerous Lactobacilli sp.) and filamentous fungi [216] [217]. 
Moreover, E. coli has been engineered to over-produce both L(+)- [217] and $\mathrm{D}(-)-[218]$ [219] stereroisomers of lactic acid as optically pure products. This is important because lactic acid stereochemistry greatly controls relevant physical properties of PLA such as crystallinity and in turn melting point [220] [221].

A second naturally-occurring biomonomer that has been extensively investigated to date is succinic acid.

which represents a potential bio-based building block able to be transformed into several commodity chemicals (THF, hydroxysuccinimide etc.) or specialty chemicals (organic acids such as fumaric, itaconic etc. and further developed in next paragraph, to produce polymers (polyamides, polyesters and poly(ester amide)s). This 4-carbon diacid is a natural fermentation product of numerous bacteria, including Actinobacillus succinogenes, Anaerobiospirillum succiniciproducens, and Mannheimia succiniciproducens. Moreover, E coli's metabolism has again also been extensively engineered to over-produce this minor fermentation product to near theoretical yields).

Despite the potential advantages of using biomonomers to produce renewable plastics, a limited pool of useful naturally-occurring metabolites ultimately constricts the diversity of bioplastics that can be produced by this approach.

However, by applying metabolic engineering tools and strategies, de novo metabolic pathway engineering provides the potential to produce non-natural biomonomers, and novel bioplastics, that were never before possible. As illustrated by several examples in Table 4, these strategies now offer an important potential to enhance the production of novel biomonomers and, consequently the corresponding biopolymers.

\section{Biopolymers}

This section will highlight the most popular biopolymers resulting from those biomonomers i.e., polyamides, polyesters and styrenic vinyl polymers.

\section{Polyamides}

Polyamides (Pas, also known as nylons) are a class of plastics that balance mechanical strength and durability with chemical resistance, and which find extensive use as textiles and mechanical parts. PAs are formed either as homopolymers of amino acids or as copolymers via condensation of diamines with diacids.

As carbon chain length between amide bonds (typically 2 - 12) strongly influences material properties, a large diversity of PAs can be generated from a limited monomer pool by a combinatorial approach. Table 5 is specifically focused on examples of polyamides produced from combinations of 4- through 6-carbon linear diamines, amino acids, and diacids.

\section{Polyesters}

Aliphatic and aromatic polyesters have a high market share and found an important place in biosourced polymers.

\section{Aliphatic polyesters \\ Poly(lactic) (PLA).}


Table 4. Examples of biomonomers produced using metabolic and pathway engineering.

\begin{tabular}{ccc}
\hline Polyamide building-blocks & Polyester building-blocks & Polyvinyl building-blocks \\
\hline$\underline{\text { Succinic acid }}$ & $\underline{\text { Lactic acid }}$ & $\underline{\text { Styrene }}$ \\
Glutaric acid & $\frac{\text { 3-hydroxybutyric acid }}{\text { p-hydroxystyrene }}$ \\
Adipic acid & $\underline{3 \text {-hyroxyvaleric acid }}$ & Ethylene \\
5-aminovaleric acid & $\underline{\text { 3-hydroxypropionic acid }}$ & Propene \\
Aminocaproic acid & $\underline{\text { 4-hydroxybutyric acid }}$ & 1,4 -butadiene \\
$\underline{\text { Putresceine }}$ & $\underline{1,3 \text {-propanediol }}$ & Isoprene \\
Cadaverine & $\underline{1,4 \text {-butanediol }}$ & - \\
1-6-hexanediamine & $\underline{2,3 \text {-butanediol }}$ & -
\end{tabular}

Monomers with names underlined correspond to monomers produced directly from renewable resources, whereas others were produced via hybrid, biocatalytic-chemocatalytic processes.

Table 5. Examples of polyamides (PAs) produced from combinations of C4-C6 diamines, diacids, and amino acids.

\begin{tabular}{ccc}
\hline \multicolumn{2}{c}{ Homopolyamides } \\
\hline \multicolumn{1}{c}{ Amino Acids } & Polymer \\
4-Aminobutyric Acid & PA-4 \\
5-Aminovaleric Acid & PA-5 \\
6-Aminohexanoic Acid & PA-6 \\
\hline & Copolyamides & Polymer \\
\hline Diamines & Diacids & PA-4,4 \\
\hline Putrescine & Succinic Acid & PA-4,6 \\
Cadaverine & Adipic Acid & PA-5,4 \\
1,6-Hexanediamine & Succinic Acid & PA-5,5 \\
\hline
\end{tabular}

Monomers with names underlined have been produced microbially from renewable resources with the aid of metabolic engineering.

Until now PLA was produced in a complex and expensive two-step fermentation and chemical process of polymerization. However, through the use of a metabolically engineered strain of $E$. coli, a one-stage process was developed which produced polylactic acid and its copolymers through direct fermentation. For this purpose, E. coli was engineered by modifying the substrate specificity of PHA synthase of a Pseudomonas sp. and promoting the production of lactyl-CoA, the monomer precursor, by introducing an evolved propionate CoA-transferase from Clostridium propionicum [222] [223]. This makes the renewable production of PLA and lactate-containing copolymers cheaper and 
more commercially viable.

Polyhydroxyalkanoates ( $P H A$ s),

As mentioned in paragraph 4.1.2, PHAs are produced by microbes via naturally evolved biosynthesis routes. They are a family of biodegradable linear homo- and co-polyesters which are widely used as biomedical implant materials, in drug delivery due to their biocompatibility and controlled degradability.

Succinic acid based polyesters, such as poly(butylene-co-succinate) (PBS).

PBS can be synthesized by direct esterification of succinic acid with 1,4-butanediol through a two steps process. First, an excess of the diol is esterified with the diacid to form PBS oligomers with elimination of water. Then, these oligomers are trans-esterified under vacuum to form a high molar mass polymer whose properties are comparable to those of polypropylene.

Other aliphatic homo- and copolyesters are also manufactured by polycondensation of dicarboxylic esters or dicarboxylic acids with diols [224]-[233].

Poly(ester amide)s, exhibiting high performance and processing ease, are manufactured from $\varepsilon$-caprolactam, adipic acid and 1,4-butanediol. Novel biodegradable biocopolymers, with a periodic sequence structure of ester and amide units, were obtained from succinic acid, dialkyl ester, 1,4-butanediol, and 1,4-butanediamine [234].

\section{Aromatic polyesters}

Poly(ethylene terephtalate) (PET) and poly(butylene terephthalate) (PBT) are commercially important examples. Likewise, DuPont ${ }^{\mathrm{TM}}$ made available partially renewable terephthalate-based polyesters, namely Sorona ${ }^{\circledR}$ poly(trimethylene terephtalate) and Hytrel ${ }^{\circledR}$ : (Poly (butylene terephtalate-b-poly (tetramethylene glycol) which contain 1,3-PDO derived from corn sugar and polyether glycols made from non-food biomass, respectively, [235].

Furan compounds (e.g., 2,5-furandicarboxylic acid (FDCA) and derivatives) and lignin-based compounds such as vanillic, caffeic and ferulic acids are the major sources of aromatic biomonomers [236] [237].

FDCA can be transformed into 2,5-furandicarboxylicdichloride, bis (hydroxyethyl)-2,5-furandicarboxylate, and bis(hydroxypropyl)-2,5-furandicarboxylate which polymerisation has generated a wide diversity of high performance thermoplastic biopolyesters which have been covered in several reviews [238]-[248].

\section{Lignin-based polyesters}

The main monomer precursors used for the synthesis of aromatic polyesters are vanillic, caffeic and ferulic acids [249]-[254].

\section{Styrenic vinyls polymers}

Engineering of novel enzymatic routes are currently applied to obtain both p-hydroxystyrene (pHS) and styrene from glucose. Indeed, Pseudomonas putida S12 was successfully used to overproduce pHS.

More recently, a novel pathway was engineered to enable $E$. coli to produce styrene directly from glucose [255]. The biomonomers are now considered for producing of styrenic vinyl biopolymers. 


\subsection{Biosourced Polymer Blends and Composites}

Biopolymers production capacity is important, but compared to commodity polymers derived from petroleum their properties are often inferior. Blending and incorporation of fillers and reinforcements, have been developed to improve those properties.

The number of papers on the production of biopolymer blends and composites, including incorporation of fillers and reinforcements is vast.

PLA and starch are the most often studied materials. The most representative starch based polymer blends were obtained with PLA [256]-[261]. And PCL [262]-[267]. Some other blends were also elaborated with various biosourced polymers [268]-[285].

Nanocomposites based on biodegradable polymers as matrix (mainly starch and PLA) and various fillers or reinforcements (nanoclay, kaolinite, cellulose nanowhiskers, ultra-fine layered titanate and carbon nanotubes) are now successfully produced [286]-[302].

\subsection{Concluding Comments}

An increasing number of biomonomer building blocks such as lactic acid, succinic acid, hydroxyacids, diols and polyamide and styrenic vinyls monomers are now available and can be used to manufacture important biosourced advanced polymers (e.g., polyamides, linear and aromatic polyesters, and styrenic vinyls polymers) which are now able to replace significant amount of the polymers currently originating from fossil resources. From some of those biopolymers, biomaterials of high interest are also produced.

As generally admitted the properties of most natural occurring biopolymers (e.g., starch, poly(lactic acid) (PHA)) are often inferior to those of the polymers derived from petroleum; blends and composites, exhibiting improved properties, are now successfully produced.

\section{Conclusions and Future Prospects}

The trilogy approach of this review comprising more than 250 references and patents, and about the same number of useful derived literature was to underline that green and bio approaches rely heavily on this selected trilogy, i.e.:

1) recognizing, understanding, translating, adapting, engineering and mastering the mechanism of degradation that renders the bio feedstocks/intermediates and final end-use ingredients vulnerable and non-reliably-durable sources, is the very first step. Therefore oxidation, antioxidations aspects of lipids are the first illustrative chapter of that trilogy.

2) recognizing, understanding, translating, adapting, engineering and mastering the real value, such as nutritional and functional, of massive sources of food, such as milk and the untapped potential of by-products such as whey, moreover sometime causing environmental concerns, is the essential second step. Milk and whey are multifunctionally facetted, which, can make them even better suited 
food ingredient, with added functional-nutrition value, and/or make them materials of choice to engineer biopolymers and other industrial derivatives. Examples are illustrating this second step.

3) recognizing, understanding, translating, adapting, engineering and mastering the novel genomic sequencing tools and engineering biology therewith, yields to demonstrate feasibility, models, new metabolism and also to promote the adoptions of ingredients, monomers, biopolymers and bio-intermediates; which, may be further bioengineered into hybrids entity securing an even more promising future to the green and bio approaches. This is the third step of that trilogy. Practical examples are provided and been implemented already in industrial applications.

All the above being considered one cannot ignore that Bigger Data and Artificial Intelligence have a role to play to further help the scientists to reach so far unreachable qualitative-mass-information, with new augmented intelligent industrial realism as well as societal pragmatisms. Biomimetic and reverse engineering thereof are comforting a natural stand.

The three examples presented in this article clearly illustrate the high potential of nature (plants, animals, microbes) to make possible the manufacture of innovative high value-added products with physical, chemical and biological properties leading to novel applications, particularly in the important domains of both foods and biomaterials.

It is clear that other examples can also illustrate this high potential of bioingredients. They could especially concern developments on:

- marine bioingredients for food and nutraceutical applications,

- multifunctional bakery bioingredients and nutritional supplements for industrial food biopreservation applications and for production of functional and nutritional metabolites,

- novel smart biomaterials based on polysaccharides and derivatives.

Products related to the food industries are lipid antioxidants and milk proteins, while those related to bioplastic materials are biomonomers and corresponding biopolymers.

Antioxidants are able to reduce or inhibit the oxidation of lipids. To this end, synthetic antioxidants have been first used in spite of the health risks related to consumption of some of them. Nowadays, many natural antioxidants, with a positive impact on the safety and acceptability of the food system, have been developed and used. Today, a tremendous variety of substances that can be extracted from plants, or by valorization of by-products, constitutes a substantial source of natural antioxidants with still an underexploited potential.

It must be noted that antioxidants' activity depends significantly not only on their structural characteristics, but also on the properties of the substrate being oxidized and the experimental conditions applied. Structural characteristics of the complex system: oxidizing substrate-antioxidant must be considered. On the basis of this analysis and owing to adapted experimental designs, processes 
modelling and optimisations of the most effective individual antioxidants and binary mixtures could be proposed for highest and optimal lipid stability.

Milk proteins and their derivatives are of great interest, mainly in food and pharmaceutical industries. Milk proteins may be hydrolyzed by enzymatic means or microbial fermentation. The potential health benefits of protein hydrolysates are a subject of growing commercial interest from a health-promoting functional-food perspective. Several commercial products are currently available in the market, and this trend is likely to continue. There are three major areas where developments can be made are:

- the generation of novel hydrolysates which should be carefully designed to yield hydrolysates with diverse bioactivities,

- novel technologies focussing 1) on the process of enrichment of the hydrolysates with active peptides from milk proteins, 2) the investigation of biochemical properties using newly developed modern analytical technologies to understand the cross reactivity between the hydrolysates and the carrier food matrix.

- robust platforms which should allow studying the molecular mechanisms by which the bioactives exert their activities. This area is the most challenging research area as the outcome from these studies forms the basis of tailored dietary formulations.

Nevertheless, some final considerations regarding the use of concentrated or modified milk ingredients in the food industry should be mentioned. Even though milk is a safe product, processing or concentration of its components to obtain the desired beneficial properties, might eventually cause some adverse health effects. It is clear that a deeper understanding of the functional and nutritional properties of these ingredients will be essential to meet consumer expectations and avoid subsequent problems. As specific regulations for these new ingredients are insufficient, the development of standard and regulated in vitro and in vivo procedures to assess their functional and nutritional claims, purity, applications, intolerance, and allergenicity, would be essential for the establishment of those regulations.

Biomonomers and biopolymers, are successfully produced from renewable feedstocks using metabolic engineering tools and strategies that have been systematically and globally upgraded to the systems level by the integrated use of 1) global technologies of systems biology, 2) adapted design of synthetic biology and 3) rational-random mutagenesis through evolutionary engineering. Applying these tools, a great number and diversity of commodity and specialty chemicals, and biomonomers have been obtained and are rapidly and continually expanding. Moreover, they can be better optimized in a multiplexed way on a genome scale with reduced time and effort.

Several biomonomers building blocks are now available and can be used to manufacture biosourced advanced polymers (e.g., polyamides, linear and aromatic polyesters, and styrenic vinyls polymers) together with polymer-based 
materials (blends and composites).

\section{Acknowledgements}

The authors thank:

- Benoit Steffenino: for part of the illustrations and the artistic codesign with authors.

- Antoine Piccirilli: Oleo World Expert, for multiple discussions of high relevance in the lipid domains.

- Miroslawa Lapray: for her exceptional ability to consolidate massive complex matters and make them accessible to most.

- Michael E. Lyons: for his ability to make electrochemistry an art and a science pertinent to industrial mindsets and innovation thereafter; "Paving the Way to the Integration of Smart Nanostructures I and II" [303] [304] generated with S. Rebouillat significant open and innovative exchanges.

\section{Disclaimer}

This article is primarily for educational purposes. Selected cases are strictly illustrative. Neither the author nor the illustrator assumes any liability for any errors or oversights, for how this article or its contents are utilized or interpreted or for any consequences resulting directly or indirectly from the usage of it.

This information is for general knowledge. For critical applications, requirements should be checked with the suppliers. For additional guidance, legal or any other, seek advice from the appropriate qualified professionals; this study can by no means substitute for legal, technical and managerial expert advice.

The opinions expressed by the writers in this article do not necessarily represent the viewpoints of the company one of the authors is employed by.

\section{References}

[1] Rebouillat, S. (2016) Aramids: "Disruptive", Open and Continuous Innovation. In: Chen, X., Ed., Advanced Fibrous Composite Materials for Ballistic Protection, Woodhead Publishing limited, Sawston, 11. https://doi.org/10.1016/B978-1-78242-461-1.00002-9

[2] Rebouillat, S. (1998) Carbon Fiber Applications in Carbon Fibers. 3rd Edition, Edited, Revised and Expanded by Donnet, J.-B., Wang, T.K., Rebouillat, S. and Peng, J.C.M., CRC Press, Marcel Dekker, New-York, 573.

[3] Lapray, M. and Rebouillat, S. (2016) A Science \& Business Equation for "Bio-Inspired" Innovation. The 3rd International Conference on Bioinspired and Biobased Chemistry \& Materials, Nice, 16-19 October 2016.

[4] Rebouillat, S. (2013) A Science and Business Equation for Collaborative Corporate Innovation. Business Strategy, IP Strategy, R \& D Strategy: An All-in-One Business Model. A Review with a Bio-Technology and Green Chemistry Focus. International Journal of Innovation and Applied Studies, 4, 1-19.

[5] Rebouillat, S. and Lapray, D. (2014) A Review Assessing the "Used in the Art" Intellectual Property Search Methods and the Innovation Impact Therewith. International Journal of Innovation and Applied Studies, 5, 160-191. 
[6] Rebouillat, S. and Lapray, M. (2014) Bio-Inspired and Bio-Inspiration: A Disruptive Innovation Opportunity or a Matter of "Semantic"? A Review of a "Stronger than Logic" Creative Path Based on Curiosity and Confidence (4C22C). International Journal of Innovation and Applied Studies, 6, 299-325.

[7] Lapray, D. and Rebouillat, S. (2014) "Bigger Data" Visualization to Visual Analytics: A Path to Innovation. "Happening, Definitely! Misleading, Possibly?" A Review of Some Examples Applicable to IP Discovery. International Journal of Innovation and Applied Studies, 7, 1251-1273.

[8] Lapray, M. and Rebouillat, S. (2014) Innovation Review: Closed, Open, Collaborative, Disruptive, Inclusive, Nested... and Soon Reverse. How about the Metrics: Dream and Reality. International Journal of Innovation and Applied Studies, 9 , $1-28$.

[9] Rebouillat, S. and Ortega-Requena, S. (2015) Potential Applications of Milk Fractions and Valorization of Dairy By-Products: A Review of the State-of-the-Art Available Data, Outlining the Innovation Potential from a Bigger Data Standpoint, Journal of Biomaterials and Nanobiotechnology, 6, 176-203. https://doi.org/10.4236/jbnb.2015.63018

[10] McNaught, A.D. and Wilkinson, A. (Eds.) (1997) Lipids. 2nd Edition, Compendium of Chemical Terminology (the "Gold Book"), Blackwell Scientific Publications, Oxford.

[11] Fahy, E., Subramaniam, S., Murphy, R.C., Nishijima, M., Raetz, C.R., Shimizu, T., Spener, F., van Meer, G., Wakelam, M.J. and Dennis, E.A. (2009) Update of the LIPID MAPS Comprehensive Classification System for Lipids. Journal of Lipid Research, 50, 9-14. https://doi.org/10.1194/jlr.R800095-JLR200

[12] Subramaniam, S., Fahy, E., Gupta, S., Sud, M., Byrnes, R.W., Cotter, D., Dinasarapu, A.R. and Maurya, M.R. (2011) Bioinformatics and Systems Biology of the Lipidome. Chemical Reviews, 111, 6452-6490. https://doi.org/10.1021/cr200295k

[13] Mashaghi, S., Jadidi, T., Koenderink, G. and Mashaghi, A. (2013) Lipid nanotechnology. International Journal of Molecular Sciences, 14, 4242-4282. https://doi.org/10.3390/ijms14024242

[14] Frankel, E.N. (2012) Chapter 1 - Free Radical Oxidation. In: Frankel, E.N., Ed., Woodhead Publishing in Lipid Oxidation, Sawston, 5-24.

[15] Falowo, A.B., Fayemi, P.O. and Muchenje, V. (2014) Natural Antioxidants against Lipid-Protein Oxidative Deterioration in Meat and Meat Products: A Review. Food Research International, 64, 171-181. https://doi.org/10.1016/j.foodres.2014.06.022

[16] Gomez-Estaca, J., Lopez-de-Dicastillo, C., Hernandez-Munoz P., Catala, R. and Gavara, R. (2014) Advances in Antioxidant Active Food Packaging. Trends in Food Science \& Technology, 35, 42-51. https://doi.org/10.1016/j.tifs.2013.10.008

[17] Praticò, D. (2002) Lipid Peroxidation and the Aging Process. Science of Aging knowledge Environment, 2002, re5. https://doi.org/10.1126/sageke.2002.50.re5

[18] Navarro, A., Gomez, C., Sanchez-Pino, M.J., Gonzalez, H., Bandez, M.J., Boveris, A.D. and Boveris, A. (2005) Vitamin E at High Doses Improves Survival, Neurological Performance, and Brain Mitochondrial Function in Aging Male Mice. American Journal of Physiology. Regulatory, Integrative and Comparative Physiology, 289, 1392-1399. https://doi.org/10.1152/ajpregu.00834.2004

[19] Navarro, A. and Boveris, A. (2007) The Mitochondrial Energy Transduction System and the Aging Process. American Journal of Physiology. Regulatory, Integrative and Comparative Physiology, 292, 670-686. https://doi.org/10.1152/ajpcell.00213.2006 
[20] Navarro, A., Lopez-Cepero, J.M.. Bandez, M.J., Sanchez-Pino, M.J., Gomez, C., Cadenas, E. and Boveris, A. (2008) Hippocampal Mitochondrial Dysfunction in Rat Aging. American Journal of Physiology. Regulatory, Integrative and Comparative Physiology, 294, 501-509. https://doi.org/10.1152/ajpregu.00492.2007

[21] Coupland, J.N. and Mc Clements, D.J. (1996) Droplet Composition Affects the Rate of Oxidation of Emulsified Ethyl Linoleate-Supporting Evidence. Journal of the American Oil Chemists Society, 73, 1207-1207. https://doi.org/10.1007/BF02523387

[22] Coupland, J.N., and Mc Clements, D.J. (1996) Lipid Oxidation in Food Emulsions. Trends in Food Science \& Technology, 7, 83-91. https://doi.org/10.1016/0924-2244(96)81302-1

[23] Frankel, E.N., Huang, S.W., Kanner, J. and German J.B. (1994) Interfacial Phenomena in the Evaluation of Antioxidants-Bulk Oils vs Emulsions. Journal of Agricultural and Food Chemistry, 42, 1054-1059. https://doi.org/10.1021/jf00041a001

[24] McClements, D.J., and Decker E.A. (2000) Lipid Oxidation in Oil-in-Water Emulsions: Impact of Molecular Environment on Chemical Reactions in Heterogeneous Food Systems. Journal of Food Science, 65, 1270-1282.

https://doi.org/10.1111/j.1365-2621.2000.tb10596.x

[25] Mei, L.Y., Decker, E.A. and McClements, D.J. (1998) Evidence of Iron Association with Emulsion Droplets and Its Impact on Lipid Oxidation. Journal of Agricultural and Food Chemistry, 46, 5072-5077. https://doi.org/10.1021/jf9806661

[26] Eboh, A.S. (2014) Biochemistry of Free Radicals and Antioxidants. Scholars Academic Journal of Biosciences, 2, 110-118.

[27] Uluata, S., McClements, D.J. and. Decker, E.A. (2015) How the Multiple Antioxidant Properties of Ascorbic Acid Affect Lipid Oxidation in Oil-in-Water Emulsions. Journal of Agricultural and Food Chemistry, 63, 1819-1824. https://doi.org/10.1021/jf5053942

[28] Chaiyasit, W., Elias, R.J., McClements, D.J. and Decker, E.A. (2007) Role of Physical Structures in Bulk Oils on Lipid Oxidation. Critical Reviews in Food Science and Nutrition, 47, 299-317. https://doi.org/10.1080/10408390600754248

[29] Kulas, E. and Ackman, R.G. (2001) Protection of Alpha-Tocopherol in Nonpurified and Purified Fish Oil. Journal of the American Oil Chemists Society, 78, 197-203. [29] Kulas, E. and Ackman, R.G. (2001) Protection of Alpha-Tocopherol in Nonpurified and Purified Fish Oil. Journal of the American Oil Chemists Society, 78, 197-203. https://doi.org/10.1007/s11746-001-0269-0

[30] Evans, J.C., Kodali, D.R. and Addis, P.B. (2002) Optimal Tocopherol Concentrations to Inhibit Soybean Oil Oxidation. Journal of the American Oil Chemists Society, 79, 47-51. https://doi.org/10.1007/s11746-002-0433-6

[31] Let, M.B., Jacobsen, C. and Meyer, A.S. (2007) Ascorbyl Palmitate, Gamma-Tocopherol, and EDTA Affect Lipid Oxidation in Fish Oil Enriched Salad Dressing Differently. Journal of Agricultural and Food Chemistry, 55, 2369-2375. https://doi.org/10.1021/jf062675c

[32] Pourmorad, F., Hosseinimehr, S.J. and Shahabimajd, N. (2006) Antioxidant Activity, Phenol and Flavonoid Contents of Some Selected Iranian Medicinal Plants. African Journal of Biotechnology, 5, 1142-1145. http://www.academicjournals.org/AJB

[33] Sahreen, S., Khan, M.R. and Khan, R.A. (2011) Phenolic Compounds and Antioxidant Activities of Rumex hastatus D. Don. Leaves. Journal of Medicinal Plants Research, 5, 2755-2765. http://www.academicjournals.org/JMPR 
[34] Enko, J. and Gliszczyńska-Świgło, A. (2015) Influence of the Interactions between tea (Camellia sinensis) Extracts and Ascorbic Acid on Their Antioxidant Activity: Analysis with Interaction Indexes and Isobolograms. Food Additives \& Contaminants. Part A, 32, 1234-1242.

[35] Ranjbar Nedamani, E., Sadeghi Mahoonak, A., Ghorbani, M. and Kashaninejad, M. (2014) Evaluation of Antioxidant Interactions in Combined Extracts of Green Tea (Camellia sinensis), Rosemary (Rosmarinus officinalis) and Oak Fruit (Quercus branti). Journal of Food Science and Technology, 52, 4565-4571. https://doi.org/10.1007/s13197-014-1497-1

[36] Reische, D.W., Lillard, D.A. and Eitenmiller, R.R. (2002) Antioxidants. In: Akoh, C.C. and Min, D.B., Ed., Food Lipids-Chemistry, Nutrition, and Biotechnology, Marcel Dekker, New York. https://doi.org/10.1201/9780203908815.ch15

[37] Yi, O.S., Han, D. and Shin, H.K. (1991) Synergistic Antioxidative Effects of Tocopherol and Ascorbic Acid in Fish Oil/Lecithin/Water System. Journal of the American Oil Chemists Society, 68, 881-883. https://doi.org/10.1007/BF02660606

[38] Turan, S., Karabulut, I. and Vural, H. (2007) Influence of sn-1,3-lipase-catalysed Interesterification on the Oxidative Stability of Soybean Oil-Based Structured Lipids. Journal of the Science of Food and Agriculture, 87, 90-97. https://doi.org/10.1002/jsfa.2679

[39] Hamilton, R.J., Kalu, C., McNeill, G.P., Padley, F.B. and Pierce, J.H. (1998) Effects of Tocopherols, Ascorbyl Palmitate, and Lecithin on Autoxidation of Fish Oil. Journal of the American Oil Chemists Society, 75, 813-822. https://doi.org/10.1007/s11746-998-0231-4

[40] Vicetti, R., Ishitani, T., Salas, A. and Ayala, M. (2005) Use of Alpha-Tocopherol Combined with Synergists and Compared to Other Antioxidants on the Oxidative Stability of Sardine Skin Lipids. Journal of Food Composition and Analysis, 18, 131-137. https://doi.org/10.1016/j.jfca.2003.12.010

[41] Romano, C.S., Abadi, K., Repetto, V., Vojnov, A.A. and Moreno, S. (2009) Synergistic Antioxidant and Antibacterial Activity of Rosemary plus Butylated Derivatives. Food Chemistry, 115, 456-461. https://doi.org/10.1016/j.foodchem.2008.12.029

[42] Panya, A., Kittipongpittaya, K., Laguerre, M., Bayrasy, C., Lecomte, J., Villeneuve, P., McClements, D.J. and Decker, E.A. (2012) Interactions between Alpha-Tocopherol and Rosmarinic Acid and Its Alkyl Esters in Emulsions: Synergistic, Additive, or Antagonistic Effect? Journal of Agriculture and Food Chemistry, 60, 10320-10330. https://doi.org/10.1021/jf302673j

[43] Budilarto, E.S., and Kamal-Eldin, A. (2015) The Supramolecular Chemistry of Lipid Oxidation and Antioxidation in Bulk Oils. European Journal of Lipid Science and Technology, 117, 1095-1137. https://doi.org/10.1002/ejlt.201400200

[44] Khan, M.A. and Shahidi, F. (2000) Tocopherols and Phospholipids Enhance the Oxidative Stability of Borage and Evening Primrose Triacylglycerols. Journal of Food Lipids, 7, 143-150. https://doi.org/10.1111/j.1745-4522.2000.tb00167.x

[45] Koga, T. and Terao, J. (1995) Phospholipids Increase Radical-Scavenging Activity of Vitamin E in a Bulk Oil Model System. Journal of Agricultural and Food Chemistry, 43, 1450-1454. https://doi.org/10.1021/jf00054a007

[46] Jacobsen, C., Let, M.B., Nielsen, N.S. and Meyer, A.S. (2008) Antioxidant Strategies for Preventing Oxidative Flavour Deterioration of Foods Enriched with n-3 Polyunsaturated Lipids: A Comparative Evaluation. Trends in Food Science \& Technology, 19, 76-93. https://doi.org/10.1016/j.tifs.2007.08.001

[47] Frankel, E.N., Huang, S.W., Prior E. and Aeschbach, R. (1996) Evaluation of Anti- 
oxidant Activity of Rosemary Extracts, Carnosol and Carnosic Acid in Bulk Vegetable Oils and Fish Oil and Their Emulsions. Journal of the Science of Food and Agriculture, 72, 201-208.

https://doi.org/10.1002/(SICI)1097-0010(199610)72:2<201::AID-JSFA632>3.0.CO;2 $-\mathrm{Q}$

[48] Laguerre, M., Bayrasy, C., Panya, A., Weiss, J., McClements, D.J., Lecomte, J., Decker, E.A. and Villeneuve, P. (2014) What Makes Good Antioxidants in Lipid-Based Systems? The Next Theories beyond the Polar Paradox. Critical Reviews in Food Science and Nutrition, 55, 183-201.

https://doi.org/10.1080/10408398.2011.650335

[49] Laguerre, M., Lopez Giraldo, L.J., Lecomte, J., Figueroa-Espinoza, M.-C., Barea, B., Weiss, J., Decker E.A. and Villeneuve. P. (2010) Relationship between Hydrophobicity and Antioxidant Ability of "Phenolipids" in Emulsion: A Parabolic Effect of the Chain Length of Rosmarinate Esters. Journal of Agricultural and Food Chemistry, 58, 2869-2876. https://doi.org/10.1021/jf904119v

[50] Laguerre, M., Lopez Giraldo, L.J., Lecomte, J., Figueroa-Espinoza, M.-C., Barea, B., Weiss, J., Decker E.A. and Villeneuve. P. (2009) Chain Length Affects Antioxidant Properties of Chlorogenate Esters in Emulsion: The Cutoff Theory Behind the Polar Paradox. Journal of Agricultural and Food Chemistry, 57, 11335-11342. https://doi.org/10.1021/jf9026266

[51] Medina, I., Lois, S., Alcantara, D., Lucas, R. and Morales, J.C. (2009) Effect of Lipophilization of Hydroxytyrosol on Its Antioxidant Activity in Fish Oils and Fish Oil-in-Water Emulsions. Journal of Agricultural and Food Chemistry, 57, 9773-9779. https://doi.org/10.1021/jf9023867

[52] Sørensen, A.-D.M., Nielsen, N.S., Yang, Z., Xu, X. and Jacobsen, C. (2012) Lipophilization of Dihydrocaffeic Acid Affects Its Antioxidative Properties in Fish-Oil-Enriched Emulsions. European Journal of Lipid Science and Technology, 114, 134-145. https://doi.org/10.1002/ejlt.201100002

[53] Hu, M., McClements, D.J. and Decker, E.A. (2003) Impact of Whey Protein Emulsifiers on the Oxidative Stability of Salmon Oil-in-Water Emulsions. Journal of Agricultural and Food Chemistry, 51, 1435-1439. https://doi.org/10.1021/jf0203794

[54] Donnelly, J.L., Decker, E.A. and McClements, D.J. (1998) Iron-Catalyzed Oxidation of Menhaden Oil as Affected by Emulsifiers. Journal of Food Science, 63, 997-1000. https://doi.org/10.1111/j.1365-2621.1998.tb15841.x

[55] Klinkesorn, U.T., Sophanodora, P., Chinachoti, P., McClements, D.J. and Decker, E. A. (2005) Increasing the Oxidative Stability of Liquid and Dried Tuna Oil-in-Water Emulsions with Electrostatic Layer-by-Layer Deposition Technology. Journal of Agricultural and Food Chemistry, 53, 4561-4566. https://doi.org/10.1021/jf0479158

[56] Mei, L., McClements, D.J. and Decker, E.A. (1999) Lipid Oxidation in Emulsions as Affected by Charge Status of Antioxidants and Emulsion Droplets. Journal of Agricultural and Food Chemistry, 47, 2267-2273. https://doi.org/10.1021/jf980955p

[57] Sørensen, A.D., Baron, C.P., Let, M.B., Bruggemann, D.A., Pedersen, L.R. and Jacobsen, C. (2007) Homogenization Conditions Affect the Oxidative Stability of Fish Oil Enriched Milk Emulsions: Oxidation Linked to Changes in Protein Composition at the Oil-Water Interface. Journal of Agricultural and Food Chemistry, 55, 1781-1789. https://doi.org/10.1021/jf0623900

[58] McClements, D.J. (2005) Food Emulsions: Principles, Practice, and Techniques. CRC Press Inc., Boca Raton.

[59] Kumar, Y., Yadav, D.N., Ahmad, T. and Narsaiah, K. (2015) Recent Trends in the 
Use of Natural Antioxidants for Meat and Meat Products. Comprehensive Reviews in Food Science and Food Safety, 14, 796-812. https://doi.org/10.1111/1541-4337.12156

[60] Yang, C.S., Chung, J.Y., Yang, G.Y., Chhabra, S.K. and Lee, M.J. (2000) Tea and Tea Polyphenols in Cancer Prevention. Journal of Nutrition, 130, 472S-478S. https://doi.org/10.1093/jn/130.2.472S

[61] Leanderson, P., Faresjo, A.O. and Tagesson, C. (1997) Green Tea Polyphenols Inhibit Oxidant-Induced DNA Strand Breakage in Cultured Lung Cells. Free Radical Biology and Medicine, 23, 235-242. https://doi.org/10.1016/S0891-5849(96)00590-4

[62] Lotito, S.B., and Fraga, C.G. (1998) (+)-catechin Prevents Human Plasma Oxidation. Free Radical Biology and Medicine, 24, 435-441. https://doi.org/10.1016/S0891-5849(97)00276-1

[63] Wang, Z.Y., Huang, M.T., Lou, Y.R., Xie, J.G., Reuhl, K.R., Newmark, H.L., Ho, C.T., Yang, C.S. and Conney, A.H. (1994) Inhibitory Effects of Black Tea, Green Tea, Decaffeinated Black Tea, and Decaffeinated Green Tea on Ultraviolet-B light-Induced Skin Carcinogenesis in 7,12-dimethylbenz[a]anthracene-initiated SKH-1 Mice. Cancer Research, 54, 3428-3435.

[64] Albertos, I., Jaime, I., Diez, A.M., Gonzalez-Arnaiz, L. and Rico, D. (2015) Carob Seed Peel as Natural Antioxidant in Minced and Refrigerated $\left(4{ }^{\circ} \mathrm{C}\right)$ Atlantic Horse Mackerel (Trachurus trachurus). Lwt-Food Science and Technology, 64, 650-656. https://doi.org/10.1016/j.lwt.2015.06.037

[65] Anal, A.K., Jaisanti, S. and Noomhorm, A. (2014) Enhanced Yield of Phenolic Extracts from Banana Peels (Musa acuminata Colla AAA) and Cinnamon Barks (Cinnamomum varum) and Their Antioxidative Potentials in Fish Oil. Journal of Food Science and Technology, 51, 2632-2639. https://doi.org/10.1007/s13197-012-0793-x

[66] Ling, S.S.C., S.K., Chang, Sia, W.C.M. and Yim, H.S. (2015) Antioxidant Efficacy of Unripe Banana (Musa acuminata Colla) Peel Extracts in Sunflower Oil during Accelerated Storage. Acta Scientiarum Polonorum-Technologia Alimentaria, 14, 343-356. https://doi.org/10.17306/J.AFS.2015.4.34

[67] Cagdas, E. and Kumcuoglu, S. (2015) Effect of Grape Seed Powder on Oxidative Stability of Precooked Chicken Nuggets during Frozen Storage. Journal of Food Science and Technology, 52, 2918-2925. https://doi.org/10.1007/s13197-014-1333-7

[68] Figueroa-Espinoza, Cruz, M., Zafimahova, A., Maldonado Alvarado, P.G., Dubreucq, E. and Poncet-Legrand, C. (2015) Grape Seed and Apple Tannins: Emulsifying and Antioxidant Properties. Food Chemistry, 178, 38-44. https://doi.org/10.1016/j.foodchem.2015.01.056

[69] Ozvural, E.B. and Vural, H. (2014) Which Is the Best Grape Seed Additive for Frankfurters: Extract, Oil or Flour? Journal of the Science of Food and Agriculture, 94, No. 4. https://doi.org/10.1002/jsfa.6442

[70] Bhaskar Reddy, G.V., Sen, A.R., Nair, P.N., Sudhakar Reddy, K., Kondal Reddy, K. and Kondaiah, N. (2013) Effects of Grape Seed Extract on the Oxidative and Microbial Stability of Restructured Mutton Slices. Meat Science, 95, 288-294. https://doi.org/10.1016/j.meatsci.2013.04.016

[71] Shi, C., Cui, J., Yin, X., Luo, Y. and Zhou, Z. (2014) Grape Seed and Clove Bud Extracts as Natural Antioxidants in Silver Carp (Hypophthalmichthys molitrix) Fillets during Chilled Storage: Effect on Lipid and Protein Oxidation. Food Control, 40, 134-139. https://doi.org/10.1016/j.foodcont.2013.12.001

[72] Rebouillat, S. and Ortega-Requena, S. (2015) Potential Applications of Milk Frac- 
tions and Valorization of Dairy By-Products: A Review of the State-of-the-Art Available Data, Outlining the Innovation Potential from a Bigger Data Standpoint. Journal of Biomaterials and Nanobiotechnology, 6, 176-203. https://doi.org/10.4236/jbnb.2015.63018

[73] Ramana, K.V., Srivastava, S. and Singhal, S.S. (2013) Lipid Peroxidation Products in Human Health and Disease. Oxidative Medicine and Cellular Longevity, 2013, 3. https://doi.org/10.1155/2013/583438

[74] Cai, Y., Luob, Q., Sunc, M. and Corkea, H. (2004) Antioxidant Activity and Phenolic Compounds of 112 Traditional Chinese Medicinal Plants Associated with Anticancer. Life Sciences, 74, 2157-2184. https://doi.org/10.1016/j.lfs.2003.09.047

[75] Mates, J.M., Perez-Gomez, C. and De Castro, I.N. (1999) Antioxidant Enzymes and Human Diseases. Clinical Biochemistry, 32, 595-603.

https://doi.org/10.1016/S0009-9120(99)00075-2

[76] Frankel, E.N. (1980) Lipid Oxidation. Progress in Lipid Research, 19, 1-22. https://doi.org/10.1016/0163-7827(80)90006-5

[77] Hudson. B.J.F. and Karis, I.G.J. (1976) Stability of Lipids and Proteins in Leaf Protein Concentrates Journal of the Science Food and Agriculture, 27, 443-448.

[78] Hudson, B.J.F. and Warwick, M.J. (1977) Lipids Stabilisation in Leaf Protein Concentrate from Ryegrass. Journal of the Science Food and Agriculture, 28, 259-264. https://doi.org/10.1002/jsfa.2740280307

[79] Wijesinha-Bettoni, R. and Burlingame, B. (2014) Milk and Dairy Composition. In: Muehlhoff, E., Bennett, A., McMahon, D. and Goff, D., Eds., Introduction to Dairy Science and Technology: Milk History, Consumption, Production, and Composition; World-Wide Milk Consumption and Production, Dairy Science and Technology, University of Guelph, Guelph, 41-102.

[80] McGregor, R.A. and Poppitt, S.D. (2013) Milk Protein for Improved Metabolic Health: A Review of the Evidence. Nutrition and Metabolism, 10, 46-58. https://doi.org/10.1186/1743-7075-10-46

[81] Fox, P.F. (2001), Milk Proteins as Food Ingredients. International Journal of Dairy Technology, 54, 41-55. https://doi.org/10.1046/j.1471-0307.2001.00014.x

[82] Fox, P.F., Uniacke-Lowe, T., McSweeney, P.L.H. and O’Mahony, J.A. (2015) Dairy Chemistry and Biochemistry. Springer International Publishing, Cham, Heidelberg, New York, Dordrecht, London. https://doi.org/10.1007/978-3-319-14892-2

[83] Haug, A., Høstmark, A.T. and Harstad, O.M. (2007) Bovine Milk in Human Nutrition-A Review. Lipids in Health and Disease, 6, 25-40. https://doi.org/10.1186/1476-511X-6-25

[84] Ebringer, L., Ferencík, M. and Krajcovic, J. (2008) Beneficial Health Effects of Milk and Fermented Dairy Products-A Review. Folia Microbiological (Praha), 53, 378-394. https://doi.org/10.1007/s12223-008-0059-1

[85] Park, Y.W., Juàrez, M., Ramos, M. and Haenlein, G.F.W. (2007) Physico-Chemical Characteristics of Goat and Sheep Milk. Small Ruminant Research, 68, 88-113. https://doi.org/10.1016/j.smallrumres.2006.09.013

[86] Donovan, S.M. (2006) Role of Human Milk Components in Gastrointestinal Development: Current Knowledge and Future Needs. Journal of Pediatrics, 149, S49-S61. https://doi.org/10.1016/j.jpeds.2006.06.052

[87] Pouliot, Y. and Gauthier, S.F. (2006) Milk Growth Factors as Health Products: Some Technological Aspects. International Dairy Journal, 16, 1415-1420. https://doi.org/10.1016/j.idairyj.2006.06.006 
[88] Clare, D.A. and Swaisgood, H.E. (2000) Bioactive Milk Peptides: A Prospectus. Journal of Dairy Science, 83, 1187-1195. https://doi.org/10.3168/jds.S0022-0302(00)74983-6

[89] Sabahelkhier, M.K., Faten, M.M. and Omer, F.I. (2012) Comparative Determination of Biochemical Constituents between Animals (Goat, Sheep, Cow and Camel) Milk with Human Milk. Short Communication Research Journal of Recent Sciences, 1, 69-71. www.isca.in

[90] Laben, R.C. (1963) Factors Responsible for Variation in Milk Composition. Journal of Dairy Science, 46, 1293-1301. https://doi.org/10.3168/jds.S0022-0302(63)89264-4

[91] Walker, G.P., Dunshea, F.R. and Doyle, P.T. (2004) Effects of Nutrition and Management on the Production and Composition of Milk Fat and Protein. A Review. Australian Journal of Agricultural Research, 55, 1009-1028.

https://doi.org/10.1071/AR03173

[92] Jenkins, T.C. and McGuire, M.A. (2006) Major Advances in Nutrition: Impact on Milk Composition. Journal of Dairy Science, 89, 1302-1310. https://doi.org/10.3168/jds.S0022-0302(06)72198-1

[93] Pouliot, Y. (2008) Membrane Processes in Dairy Technology-From a Simple Idea to Worldwide Panacea. International Dairy Journal, 18, 735-740. https://doi.org/10.1016/j.idairyj.2008.03.005

[94] Saboya, L.V. and Maubois, J.L (2000) Current Developments of Microfiltration Technology in the Dairy Industry. INRA Edition, Lait, 80, 541-553. https://doi.org/10.1051/lait:2000144

[95] Lawrence, N.D., Kentish, S.E., O'Connor, A J., Barber, A.R. and Stevens, G.W. (2008) Microfiltration of Skim Milk Using Polymeric Membranes for Casein Concentrate Manufacture Separation and Purification Technology, 60, 237-244.

[96] Hurt, E., Zulewska, J., Newbold, M. and Barbano, D.M. (2010) Micellar Casein Concentrate Production with a 3X, 3-Stage, Uniform Transmembrane Pressure Ceramic Membrane Process at $50^{\circ} \mathrm{C}$. Journal of Dairy Science, 93, 5588-5600. https://doi.org/10.3168/jds.2010-3169

[97] Hurt, E. and Barbano, D.M. (2010) Processing Factors that Influence Casein and Serum Protein Separation by Microfiltration. Journal of Dairy Science, 93, 4928-4941. https://doi.org/10.3168/jds.2010-3121

[98] Karasu, K., Glennon, N., Lawrence, N.D., Stevens G.W., O’Connor, A.J., Barber, A.R., Yoshikawa, S. and Kentish, S.E. (2010) A Comparison between Ceramic and Polymeric Membrane Systems for Casein Concentrate Manufacture. International Journal of Dairy Technology, 63, 284-289. https://doi.org/10.1111/j.1471-0307.2010.00582.x

[99] Brans, G., Schroën, C.G.P.H., van der Sman, R.G.M. and Boom, R.M. (2004) Membrane Fractionation of Milk: State of the Art and Challenges. Journal of Membrane Science, 243, 263-272. https://doi.org/10.1016/j.memsci.2004.06.029

[100] Skrzypek, M. and Burger, M. (2010) Isoflux', Ceramic Membranes-Practical Experiences in Dairy Industry. Desalination, 250, 1095-1100. https://doi.org/10.1016/j.desal.2009.09.116

[101] Bendixen, N., Hansen, S. and Lindau, J. (2008) Method in the Protein Fractionation of Skim Milk by Means of Microfiltration. Tetra Laval Holdings \& Finance SA, US Patent No. 20080171119.

[102] O'Mahony, J.A., Smith, K.E. and Lucey, J.A. (2007) Purification of Beta-Casein from Milk. Wisconsin Alumni Research Foundation, WO/2007/055932. 
[103] Yan, L., Xiaohui, L., Fangxu, W. and Liebing, Z. (2010) Method for Separating Alpha S-Casein. China Agricultural University, CN Patent No. 101824085.

[104] Etzel, M.R., Arunkumar, A. and Agarwal, S. (2014) Methods and Compositions for Protein Concentration. Wisconsin Alumni Research Foundation, WO/2014/127339.

[105] Yver, A.L., Bonnaillie, L.M., Yee, W., McAloon, A. and Tomasula, P.M. (2012) Fractionation of Whey Protein Isolate with Supercritical Carbon Dioxide-Process Modeling and Cost Estimation. International Journal of Molecular Sciences, 13, 240-259. https://doi.org/10.3390/ijms13010240

[106] Bonnaillie, L., Qi, P., Wickham, E. and Tomasula, P. (2014) Enrichment and Purification of Casein Glycomacropeptide from Whey Protein Isolate Using Supercritical Carbon Dioxide Processing and Membrane Ultrafiltration. Foods, 3, 94-109. https://doi.org/10.3390/foods3010094

[107] Smith, K.E. (2001) Background on Milk Protein Products. Wisconsin Center for Dairy Research, Madison, WI.

[108] Rebouillat, S. (2011) The Deformation of Saturated Soft Porous Materials: 1-Addressing the Determination of the Activation Energy for a Global Effective Transfer of Fluid through the Contact Zones during Multimode Shear/Compression Chemical Engineering Science, 66, 5891-5898. https://doi.org/10.1016/j.ces.2011.08.008

[109] Ortega Requena, S. (2012) Biocatalytic Synthesis of Polyglycerol Polyricinoleate. $\mathrm{PhD}$ Dissertation, Department of Chemical Engineering, University of Murcia, Murcia.

[110] Dickinson, E. (1997) Properties of Emulsions Stabilized with Milk Proteins: Overview of Some Recent Developments. Journal of Dairy Science, 80, 2607-2619. https://doi.org/10.3168/jds.S0022-0302(97)76218-0

[111] Food and Agriculture Organization/World Health Organization (1990) Protein Quality Evaluation; Report of the Joint FAO/WHO Expert Consultation. FAO Food and Nutrition Paper 52, Rome.

[112] United States Dairy Export Council (1999) Reference Manual for U.S. Whey Products 2nd Edition, United States Dairy Export Council, Baltimore, MD.

[113] Sarwar, G. (1997) The Protein Digestibility-Corrected Amino Acid Score Method Overestimates Quality of Proteins Containing Antinutritional Factors and of Poorly Digestible Proteins Supplemented with Limiting Amino Acids in Rats. Journal of Nutrition, 127, 758-764. https://doi.org/10.1093/jn/127.5.758

[114] Hoffman, J.R. and Falvo, M.J. (2004) Protein-Which Is Best? Journal of Sports Science and Medicine, 3, 118-130. http://www.jssm.org

[115] Walstra, P. (1999) Casein Sub-Micelles: Do They Exist? International Dairy Journal, 9, 189-192. https://doi.org/10.1016/S0958-6946(99)00059-X

[116] Roman, J.A. and Sgarbieri, V. C. (2006) The Hydrophilic, Foaming and Emulsifying Properties of Casein Concentrates Produced by Various Methods. International Journal of Food Science and Technology, 41, 609-617. https://doi.org/10.1111/j.1365-2621.2005.01090.x

[117] Geiser, M. (2003) The Wonders of Whey Protein. NSCA's Performance Training Journal, 2, 13-15.

[118] Jovanović, S., Barać, M. and Maćej, O. (2005) Whey Proteins-Properties and Possibility of Application. Mljekarstvo, 55, 215-233. http://hrcak.srce.hr/1483

[119] Hartmann, R. and Meisel, H. (2007) Food-Derived Peptides with Biological Activity: From Research to Food Applications. Current Opinion in Biotechnology, 18, 
163-169. https://doi.org/10.1016/j.copbio.2007.01.013

[120] Kitts, D. and Weiler, K. (2003) Bioactive Proteins and Peptides from Food Sources. Applications of Bioprocesses Used in Isolation and Recovery. Current Pharmaceutical Design, 9, 1309-1323. https://doi.org/10.2174/1381612033454883

[121] Banach, J.C., Lin, Z. and Lamsal, B.P. (2013) Enzymatic Modification of Milk Protein Concentrate and Characterization of Resulting Functional Properties. Lwt-Food Science and Technology, 54, 397-403. https://doi.org/10.1016/j.lwt.2013.06.023

[122] Gaonkar, G., Koka, R., Chen, K. and Campbell, B. (2010) Emulsifying Functionality of Enzyme-Modified Milk Proteins in O/W and Mayonnaise-Like Emulsions. African Journal of Food Science, 4, 16-25.

[123] Panyam, D. and Kilara, A. (1996) Enhancing the Functionality of Food Proteins by Enzymatic Modification. Trends in Food Science and Technology, 7, 120-125. https://doi.org/10.1016/0924-2244(96)10012-1

[124] Clemente, A. (2000) Enzymatic Protein Hydrolysates in Human Nutrition. Trends in Food Science and Technology, 11, 254-262.

https://doi.org/10.1016/S0924-2244(01)00007-3

[125] Yamamoto, N., Akino, A. and Takano, T. (1994) Antihypertensive Effect of the Peptides Derived from Casein by an Extracellular Proteinase from Lactobacillus helveticus CP790. Journal of Dairy Science, 77, 917-922.

https://doi.org/10.3168/jds.S0022-0302(94)77026-0

[126] Korhonen, H. (2009) Milk-Derived Bioactive Peptides: From Science to Applications. Journal of Functional Foods, 1, 177-187.

https://doi.org/10.1016/j.jff.2009.01.007

[127] Choi, J., Sabikhi, L., Hassan, A. and Anand, S. (2012) Bioactive Peptides in Dairy Products. International Journal of Dairy Technology, 65, 1-12. https://doi.org/10.1111/j.1471-0307.2011.00725.x

[128] Fitzgerald, R.J. and Murray, B.A., (2006) Bioactive Peptides and Lactic Fermentations. International Journal of Dairy Technology, 59, 118-125. https://doi.org/10.1111/j.1471-0307.2006.00250.x

[129] Agyei, D. and Danquah, M.K. (2012) Rethinking Food-Derived Bioactive Peptides for Antimicrobial and Immunomodulatory Activities. Trends in Food Science and Technology, 23, 62-69. https://doi.org/10.1016/j.tifs.2011.08.010

[130] Hafeez, Z., Cakir-Kiefer, C., Roux, E., Perrin, C., Miclo, L. and Dary-Mourot, A. (2014) Strategies of Producing Bioactive Peptides from Milk Proteins to Functionalize Fermented Milk Products. Food Research International, 63, 71-80. https://doi.org/10.1016/j.foodres.2014.06.002

[131] Ricci-Cabello, I., Herrera, M.O. and Artacho, R. (2012) Possible Role of Milk-Derived Bioactive Peptides in the Treatment and Prevention of Metabolic Syndrome. Nutrition Reviews, 70, 241-255. https://doi.org/10.1111/j.1753-4887.2011.00448.x

[132] Nielsen, P., Petersen, D. and Dambmann, C. (2001) Improved Method for Determining Food Protein Degree of Hydrolysis. Journal of Food Science, 66, 642-646. https://doi.org/10.1111/j.1365-2621.2001.tb04614.x

[133] Jamdar, S.N., Rajalakshmi, V., Pednekar, M.D., Juan, F., Yardi, V. and Sharma, A. (2010) Influence of Degree of Hydrolysis on Functional Properties, Antioxidant Activity and ACE Inhibitory Activity of Peanut Protein Hydrolysate. Food Chemistry, 121, 178-184. https://doi.org/10.1016/j.foodchem.2009.12.027 
[134] Udenigwe, C.C. and Aluko, R.E. (2012) Food Protein-Derived Bioactive Peptides: Production, Processing, and Potential Health Benefits. Journal of Food Science, 77, R11-R24. https://doi.org/10.1111/j.1750-3841.2011.02455.x

[135] Gezimati, J., Singh, H. and Creamer, L. K. (1996) Aggregation and Gelation of Bovine -Lactoglobulin, $\square$-Lactalbumin, and Serum Albumin. ACS Symposium Series, 650, 113-123.

[136] Mleko, S. (1997) Rheological Properties of Milk and Whey Protein Desserts. Milchwissenschaft, 52, 262-266.

[137] Kavanagh, G.M., Clark, A.H. and Ross-Murphy, S.B. (2002) Heat-Induced Gelation of Globular Proteins. Part 5. Creep Behavior of $\square$-Lactoglobulin Gels. Rheologica Acta, 41, 276-284. https://doi.org/10.1007/s00397-001-0220-0

[138] Kavanagh, G.M., Clark, A.H. and Ross-Murphy, S.B. (2000) Heat-Induced Gelation of Globular Proteins: Part 3. Molecular Studies on Low pH-Lactoglobulin Gels. International Journal of Biological Macromolecules, 28, 41-50. https://doi.org/10.1016/S0141-8130(00)00144-6

[139] Kavanagh, G.M., Clark, A.H. and Ross-Murphy, S.B. (2000) Heat-Induced Gelation of Globular Proteins: 4. Gelation Kinetics of Low pH-Lactoglobulin Gels. Langmuir, 16, 9584-9594. https://doi.org/10.1021/la0004698

[140] Tobitani, A. and Ross-Murphy, S.B. (1997) Heat-Induced Gelation of Globular Proteins. 2. Effect of Environmental Factors on Singlecomponent and Mixed-Protein Gels. Macromolecules, 30, 4855-4862. https://doi.org/10.1021/ma970113b

[141] Tobitani, A. and Ross-Murphy, S.B. (1997) Heat-Induced Gelation of Globular Proteins. 1. Model for the Effects of Time and Temperature on the Gelation Time of Bsa Gels. Macromolecules, 30, 4845-4854. https://doi.org/10.1021/ma970112j

[142] Barbut, S. and Foegeding, E.A. (1993) Calcium-Induced Gelation of Preheated Whey Protein Isolate. Journal of Food Science, 58, 867-871. https://doi.org/10.1111/j.1365-2621.1993.tb09379.x

[143] Mleko, S. and Foegeding, E.A. (2000) pH Induced Aggregation and Weak Gel Formation of Whey Protein Polymers Journal of Food Science, 65, 139-143.

[144] Britten, M. and Giroux, H.J. (2001) Acid-Induced Gelation of Whey Protein Polymers: Effects of $\mathrm{pH}$ Andcalcium Concentration during Polymerization. Food $\mathrm{Hy}$ drocolloids, 15, 609-617. https://doi.org/10.1016/S0268-005X(01)00049-2

[145] Dickinson, E. (1997) Enzymic Crosslinking as a Tool for Food Colloid Rheology Control and Interfacial Stabilization. Trends in Food Science and Technology, 8, 334-339. https://doi.org/10.1016/S0924-2244(97)01067-4

[146] Faergemand, M., Otte, J. and Qvist, K.B. (1997) Enzymic Crosslinking of Whey Proteins by a $\mathrm{Ca}^{2+}$-Independent Microbial Transglutaminase from Streptomyces Lydicus. Food Hydrocolloids, 11, 19-25. https://doi.org/10.1016/S0268-005X(97)80006-9

[147] Faergemand, M. and Qvist, K.B. (1997) Transglutaminase: Effect on Rheological Properties, Microstructure and Permeability of Set Style Acid Skim Milk Gel. Food Hydrocolloids, 11, 287-292. https://doi.org/10.1016/S0268-005X(97)80058-6

[148] Faergemand, M., Murray, B.S. and Dickinson, E. (1997) Crosslinking of Milk Proteins with Transglutaminase at the Oil-Water Interface. Journal of Agricultural and Food Chemistry, 45, 2514-2519. https://doi.org/10.1021/jf9609789

[149] Wilcox, C.P. and Swaisgood, H.E. (2002) Modification of the Rheological Properties of Whey Protein Isolate through the Use of an Immobilized Microbial Transglutaminase. Journal of Agricultural and Food Chemistry, 50, 5546-5551. 
https://doi.org/10.1021/jf0117154

[150] Wilcox, C.P., Clare, D.A., Valentine, V.W. and Swaisgood, H.E. (2002) Immobilization and Utilization of the Recombinant Fusion Proteins Trypsin-Streptavidin and Streptavidin-Transglutaminase for Modification of Whey Protein Isolate Functionality. Journal of Agricultural and Food Chemistry, 50, 3723-3730. https://doi.org/10.1021/jf011603c

[151] Errington, A.D. and Foegeding, E.A. (1998) Factors Determining Fracture Stress and Strain of Fine-Stranded Whey Protein Gels. Journal of Agricultural and Food Chemistry, 46, 2963-2967. https://doi.org/10.1021/jf980112y

[152] Motoki, M. and Seguro, K. (1998) Transglutaminase and Its Use for Food Processing. Trends in Food Science \& Technology, 9, 204-210. https://doi.org/10.1016/S0924-2244(98)00038-7

[153] Han, X.-Q. and Damodaran, S. (1996) Thermodynamic Compatibility of Substrate Proteins Affects Their Cross-Linking by Transglutaminase. Journal of Agricultural and Food Chemistry, 44, 1211-1217. https://doi.org/10.1021/jf950569x

[154] Hinz, K., Huppertz, T., Kulozik, U. and Kelly, A.L. (2007) Influence of Enzymatic Cross-Linking on Milk Fat Globules and Emulsifying Properties of Milk Proteins. International Dairy Journal, 17, 289-293.

https://doi.org/10.1016/j.idairyj.2006.05.001

[155] O’Sullivan, M.M., Kelly, A.L. and Fox, P.F. (2002) Influence of Transglutaminase Treatment on Some Physico-Chemical Properties of Milk. The Journal of Dairy Research, 69, 433-442. https://doi.org/10.1017/S0022029902005617

[156] Lorenzen, P.C., Mautner, A. and Schlimme, E. (1999) Effect of Enzymatic Cross-Linking of Milk Proteins on the Resulting Properties of Yoghurt Products. Kieler Milchwirtschaftliche Forschungsberichte, 51, 89-97.

[157] Lorenzen, P.C., Neve, H., Mautner, A. and Schlimme, E. (2002) Effect of Enzymatic Cross-Linking of Milk Proteins on Functional Properties of Set-Style Yoghurt. International Journal of Dairy Technology, 55, 152-157. https://doi.org/10.1046/j.1471-0307.2002.00065.x

[158] Kuraishi, C., Yamazaki, K. and Susa, Y. (2001) Transglutaminase: Its Utilization in the Food Industry. Food Reviews International, 17, 221-246. https://doi.org/10.1081/FRI-100001258

[159] Nitschke, M. and Silva, S.S. (2017) Recent Food Applications of Microbial Surfactants. Critical Reviews in Food Science and Nutrition, 58, 631-638. https://doi.org/10.1080/10408398.2016.1208635

[160] Banat, I.M., Makkar, R.S., and Cameotra, S.S. (2000) Potential Commercial Applications of Microbial Surfactants. Applied Microbiology and Biotechnology, 53, 495-508. https://doi.org/10.1007/s002530051648

[161] Nitschke, M. and Costa, S.G.V.A.O. (2007) Biosurfactants in Food Industry. Trends in Food Science \& Technology, 18, 252-259. https://doi.org/10.1016/j.tifs.2007.01.002

[162] Nitschke, M., Ferraz, C. and Pastore, G.M. (2004) Selection of Microorganisms for Biosurfactant Production Using Agroindustrial Wastes. Brazilian Journal of Microbiology, 35, 81-85. https://doi.org/10.1590/S1517-83822004000100013

[163] Rodrigues, L., Moldes, A., Teixeira, J. and Oliveira, R. (2006) Kinetic Study of Fermentative Biosurfactant Production by Lactobacillus Strains. Biochemical Engineering Journal, 28, 109-116. https://doi.org/10.1016/j.bej.2005.06.001

[164] Dubey, K. and Juwarkar, A. (2001) Distillery and Curd Whey Wastes as Viable Al- 
ternative Sources for Biosurfactant Production. World Journal of Microbiology and Biotechnology, 17, 61-69. https://doi.org/10.1023/A:1016606509385

[165] Shete, A.M., Wadhawa, G., Banat, I.M. and Chopade, B.A. (2006) Mapping of Patents on Bioemulsifier and Biosurfactant: A Review. Journal of Scientific \& Industrial Research, 65, 91-115.

[166] Tague, E.L. (1926) Casein. Its Preparation, Chemistry and Technical Utilizations, Van Nostrand Company, New York.

[167] Collins, J.H. (1952) Casein Plastics and Allied Materials. The Plastic Institute, London.

[168] Munro P.A., Southward C.R. and Elston, P.D. (1980) The Effect of Casein Manufacturing Variables on the Properties of Rennet Casein Plastics. New Zealand Journal of Dairy Science and Technolology, 15, 177-190.

[169] Kinsella, J.E. (1984) Milk Proteins: Physicochemical and Functional Properties. CRC Critical Reviews in Food Science and Nutrition, 21, 197-261. https://doi.org/10.1080/10408398409527401

[170] Kinsella, J.E., Whitehead, D.M., Brady, J. and Bringe N.A. (1989) Milk Proteins: Possible Relationships of Structure and Function. In: Fox P.F., Ed., Developments in Dairy Chemistry. 4-Functional Milk Proteins, Elsevier Applied Science Publishers, London, 55-95.

[171] Krochta, J.M., Pavlath, A.E. and Goodman, N. (1990) Edible Films from Casein-Lipid Emulsions for Lightly-Processed Fruits and Vegetables. In: Spiess W.E.L. and Schubert, H., Eds., Engineering and Food, 2, Preservation Processed Fruits and Vegetables, Elsevier Applied Science Publishers, New York, 329-340.

[172] Warth, A.H. and Browne, F.L. (1939) Casein Paints. In: Sutermeister, E. and Browne, F.L., Eds., Casein and Its Industrial Applications, 2nd Edition, Reinhold Publishing Corporation, New York, 315-353.

[173] Parker, J. (1930) Manufacture of Bituminous Emulsions. GB Patent No. 333303.

[174] Pilz, E. and Regenhardt, O. (1967) Method for Representing Real D Sharp Azo-Dyes for Pressure and Dyeing. German Democratic Republic, Patent Application 62133.

[175] Southward, C.R. and Walker, N.J. (1980) The Manufacture and Industrial Use of Casein. New Zealand Journal of Dairy Science and Technolology, 15, 201-217.

[176] Salzberg, H.K. (1967) Processed Milk Casein for Hair and Skin Cosmetics. American Perfurmer Cosmetics, 82, 41-50.

[177] Cotte, J. (1991) The Milk, a Material of Future for the Cosmetic. Lait, 71, 213-224. https://doi.org/10.1051/lait:1991216

[178] Dunlop Rubber Company Ltd. (1964) Textile Fibers Coated with an Adhesive Composition, Usable in Particular for the Rubber Strengthening, and Their Preparation. FR Patent 1371652.

[179] Grollier, J.F. and L'OREAL, S.A. (1981) Treatment Process of Hair to Improve Their Aspect by Means of a Composition Containing a Hydrolysate of Lactalbumine. FR Patent 2471 778, 1981.

[180] Hidalgo, J., Jost R. and Société des Produits Nestlé, S.A. (1980) Cosmetic or Therapeutic Compositions for Topical Use. DE Patent 3001300 A1.

[181] Coupland, J.N., Shaw, N.B., Monahan, F.J., O’Riordan, E.D. and O'Sullivan, M. (2000) Modeling the Effect of Glycerol on the Moisture Sorption Behavior of Whey Protein Edible Films. Journal of Food Engineering A, 43, 25-30. https://doi.org/10.1016/S0260-8774(99)00129-6 
[182] McHugh, T.H. and Krochta, J.M. (1994) Sorbitol- vs. Glycerol-Plasticized Whey Protein Edible Films: Integrated Oxygen Permeability and Tensile Property Evaluation. Journal of Agricultural and Food Chemistry, 42, 841-845. https://doi.org/10.1021/jf00040a001

[183] Audic, J.L., Chaufer, B. and Daufin, G. (2003) Non-Food Applications of Milk Components and Dairy Co-Products: A Review. Le Lait, 83, 417-438. https://doi.org/10.1051/lait:2003027

[184] Rebouillat, S. and Pla, F. (2016) Recent Strategies for the Development of Biosourced-Monomers, Oligomers and Polymer-Based Materials: A Review with an Innovation and a Bigger Data Focus. Journal of Biomaterials and Nanobiotechnology, 7,167-213. https://doi.org/10.4236/jbnb.2016.74017

[185] Rebouillat, S. and Pla, F. (2013) State of the Art Manufacturing and Engineering of Nanocellulose: A Review of Available Data and Industrial Applications. Journal of Biomaterials and Nanobiotechnology, 4, 165-188. https://doi.org/10.4236/jbnb.2013.42022

[186] Jarboe, L.R., Zhang, X., Wang, X., Moore, J.C., Shanmugam, K.T. and Ingram, L.O. (2010) Metabolic Engineering for Production of Biorenewable Fuels and Chemicals: Contributions of Synthetic Biology. Journal of Biomedicine and Biotechnology, 2010, 1-18. https://doi.org/10.1155/2010/761042

[187] Mainguet, S.E. and Liao, J.C. (2010) Bioengineering of Microorganisms for C3 to C5 Alcohols Production. Biotechnology Journal, 5, 1297-1308. https://doi.org/10.1002/biot.201000276

[188] Wang, X., Dalkik, E., WU, M. and Chan, C. (2008) Gene Module Level Analysis: Identification to Networks and Dynamics. Current Opinion in Biotechnology, 19, 482-491. https://doi.org/10.1016/j.copbio.2008.07.011

[189] Quek, L.E., Wittmann, C., Nielsen, L.K. and Krömer, J.O. (2009) OpenFLUX: Efficient Modelling Software for 13C-Based Metabolic Flux Analysis. Microbial Cell Factories, 8, 1-15. https://doi.org/10.1186/1475-2859-8-25

[190] Picataggio, S. (2009) Potential Impact of Synthetic Biology on the Development of Microbial Systems for the Production of Renewable Fuels and Chemicals. Current Opinion in Biotechnology, 20, 325-329. https://doi.org/10.1016/j.copbio.2009.04.003

[191] Heinemann, M. and Panke, S. (2006) Synthetic Biology-Putting Engineering into Biology. Bioinformatics, 22, 2790-2799. https://doi.org/10.1093/bioinformatics/btl469

[192] Babu, R.P., O’Connor, K. and Seeram, R. (2013) Current Progress on Bio-Based Polymers and Their Future Trends. Progress in Biomaterials, 2, 1-16. https://doi.org/10.1186/2194-0517-2-8

[193] Klemm, D., Heublein, B., Fink, H.P. and Bohn, A. (2005) Cellulose: Fascinating Biopolymer and Sustainable Raw Material. Angewandte Chemie International Edition, 44, 3358-3393. https://doi.org/10.1002/anie.200460587

[194] Simon, J., Muiller, H.P., Koch, R. and Muiller, V. (1998) Thermoplastic and Biodegradable Polymers of Cellulose. Polymer Degradation and Stability, 59, 107-115. https://doi.org/10.1016/S0141-3910(97)00151-1

[195] Wang, Z.-F., Fang, L., Zhang, K.-X. and Fu, X. (2008) Application and Research Progress of Starch in Polymer Materials. Journal for Clinical Rehabilitation Tissue Engineering Research, 19, 3789-3792.

[196] Kalambur, S. and Rizvi, S.S.H. (2006) An Overview of Starch Based Plastic Blends 
From Reactive Extrusion. Journal of Plastic Film \& Sheeting, 22, 39-58. https://doi.org/10.1177/8756087906062729

[197] Pillai, C.K.S., Willi, P. and Sharma, C.P. (2009) Chitin and Chitosan Polymers: Chemistry, Solubility and Fiber Formation. Progress in Polymer Science, 34, 641-678. https://doi.org/10.1016/j.progpolymsci.2009.04.001

[198] Hearle, J.W.S. (2007) Protein Fibers: Structural Mechanics and Future Opportunities. Journal of Materials Science, 42, 8010-8019. https://doi.org/10.1007/s10853-006-1280-4

[199] Poole, A.J., Church, J.S. and Huson, M.G. (2008) Environmentally Sustainable Fibers from Regenerated Protein. Biomacromolecules, 10, 1-8. https://doi.org/10.1021/bm8010648

[200] Heino, J., Huhtala, M., Käpylä, J. and Johnson, M.S. (2009) Evolution of Collagen-Based Adhesion Systems. International Journal of Biochemistry \& Cell Biology, 41, 341-348. https://doi.org/10.1016/j.biocel.2008.08.021

[201] Czaja, W., Krystynowicz, A., Bielecki, S. and Brown, R.M. (2006) Microbial Cellulose-The Natural Power to Heal Wounds. Biomaterials, 27, 145-151. https://doi.org/10.1016/j.biomaterials.2005.07.035

[202] Hoenich, N. (2006) Cellulose for Medical Applications: Past, Present, and Future. Bioresources, 1, 270-280. http://ncsu.edu/bioresources

[203] Berezina, N. and Martelli, S.M. (2014) Chapter 1: Bio-Based Polymers and Materials. In: Lin, C. and Luque, R., Eds., Renewable Resources for Biorefineries, Royal Society of Chemistry, Series: Green Chemistry, London, 1-28.

https://doi.org/10.1039/9781782620181-00001

[204] Reinecke, F. and Steinbuchel, A. (2009) Ralstonia Eutropha Strain H16 as Model Organism for PHA Metabolism and for Biotechnological Production of Technically Interesting Biopolymers. Journal of Molecular Microbiology and Biotechnology, 16, 91-108. https://doi.org/10.1159/000142897

[205] Singh, M., Patel, S.K.S. and Kalia, V.C. (2009) Bacillus subtilis as Potential Producer for Polyhydroxyalkanoates. Microbial Cell Factories, 8, 38-48. https://doi.org/10.1186/1475-2859-8-38

[206] Rojas-Rosas, O., Villafana-Rojas, J., Lopez-Dellamary, F.A., Nungaray-Arellano, J. and Gonzalez-Reynoso, O. (2007) Production and Characterization of Polyhydroxyalkanoates in Pseudomonas aeruginosa ATCC (9027) from Glucose, an Unrelated Carbon Source. Canadian Journal of Microbiology, 53, 840-851. https://doi.org/10.1139/W07-023

[207] Asada, Y., Miyake, M., Miyake, J., Kurane, R. and Tokiwa, Y. (1999) Photosynthetic Accumulation of Poly-(Hydroxybutyrate) by Cyanobacteria-The Metabolism and Potential for CO2 Recycling. International Journal of Biological Macromolecules, 25, 37-42. https://doi.org/10.1016/S0141-8130(99)00013-6

[208] Schubert, P., Steinbuchel, A. and Schlegel, H.G. (1988) Cloning of the Alcaligenes eutrophus Genes for Synthesis of Poly-Beta-Hydroxybutyric Acid (PHB) and Synthesis of PHB in Escherichia coli. Journal of Bacteriology, 170, 5837-5847. https://doi.org/10.1128/jb.170.12.5837-5847.1988

[209] Lee, S.Y., Choi, J.I. and Wong, H.H. (1999) Recent Advances in Polyhydroxyalkanoate Production by Bacterial Fermentation: Mini-Review. International Journal of Biological Macromolecules, 25, 31-36. https://doi.org/10.1016/S0141-8130(99)00012-4

[210] Steinbüchel, A. and Valentin, H.E. (1995) Diversity of Bacterial Polyhydroxyalka- 
noic Acids. FEMS Microbiology Letters, 128, 219-228.

https://doi.org/10.1016/0378-1097(95)00125-O

[211] Takahara, I., Saito, M., Inaba, M. and Murata, K. (2005) Dehydration of Ethanol into Ethylene over Solid Acid Catalysts. Catalysis Letters, 105, 249-252.

https://doi.org/10.1007/s10562-005-8698-1

[212] Hu, Y.C., Zhan, N.N., Dou, C., Huang, H., Han, Y.W., Yu, D.H. and Hu, Y. (2010) Selective Dehydration of Bio-Ethanol to Ethylene Catalyzed by Lanthanum-Phosphorous-Modified Hzsm-5, Influence of the Fusel. Biotechnology Journal, 5, 1186-1191. https://doi.org/10.1002/biot.201000139

[213] Mathers, R.T. (2012) How Well Can Renewable Resources Mimic Commodity Monomers and Polymers? Journal of Polymer Science Part A: Polymer Chemistry, 50, 1-15. https://doi.org/10.1002/pola.24939

[214] Yao, K. and Tang, C. (2013) Controlled Polymerization of Next-Generation Renewable Monomers and Beyond. Macromolecules, 46, 1689-1712. https://doi.org/10.1021/ma3019574

[215] Kobayashi, H. and Fukuoka, A. (2013) Synthesis and Utilisation of Sugar Compounds Derived from Lignocellulosic Biomass. Green Chemistry, 15, 1740-1763. https://doi.org/10.1039/c3gc00060e

[216] Kosakai, Y., Soo Park, Y., and Okabe, M. (1997). Enhancement of L(+)-Lactic Acid Production Using Mycelial Flocs of Rhizopus oryzae. Biotechnology and Bioengineering, 55, 461-470. https://doi.org/10.1002/(SICI)1097-0290(19970805)55:3<461::AID-BIT1>3.0.CO;2$\underline{\mathrm{A}}$

[217] Zhou, Y., Dominguez, J.M., Cao, N., Du, J. and Tsao, G.T. (1999) Optimization of L-Lactic Acid Production from Glucose by Rhizopus oryzae ATCC 52311. Applied Biochemistry and Biotechnology, 78, 401-407. https://doi.org/10.1385/ABAB:78:1-3:401

[218] Zhou, S., Causey, T.B., Hasona, A., Shanmugam, K.T. and Ingram, L.O. (2003) Production of Optically Pure D-Lactic Acid in Mineral Salts Medium by Metabolically Engineered Escherichia coli W3110. Applied and Environmental Microbiology, 69, 399-407. https://doi.org/10.1128/AEM.69.1.399-407.2003

[219] Mazumdar, S., Clomburg, J.M. and Gonzalez, R. (2010) Escherichia coli Strains Engineered for Homofermentative Production of D-Lactic Acid from Glycerol. Applied and Environmental Microbiology, 76, 4327-4336.

https://doi.org/10.1128/AEM.00664-10

[220] Lunt, J. (1998) Large-Scale Production, Properties and Commercial Applications of Polylactic Acid Polymers. Polymer Degradation and Stability, 59, 145-152. https://doi.org/10.1016/S0141-3910(97)00148-1

[221] Sodergard, A. and Stolt, M. (2002). Properties of Lactic Acid Based Polymers and Their Correlation with Composition. Progress in Polymer Science, 27, 1123-1163. https://doi.org/10.1016/S0079-6700(02)00012-6

[222] Jung, Y.K., Kim, T.Y., Park, S.J. and Lee, S.Y. (2010) Metabolic Engineering of Escherichia Coli for the Production of Polylactic Acid and Its Copolymers. Biotechnology and Bioengineering, 105, 161-171. https://doi.org/10.1002/bit.22548

[223] Yang, T.H., Kim, T.W., Kang, H.O., Lee, S.H., Lee, E.J., Lim, S.C., Oh, S.O., Song, A.J., Park, S.J. and Lee, S.Y. (2010) Biosynthesis of Polylactic Acid and Its Copolymers Using Evolved Propionate CoA Transferase and PHA Synthase. Biotechnology and Bioengineering, 105,150-160. https://doi.org/10.1002/bit.22547 
[224] Wang, X., Zou, J. and Li, L. (2007) Multiple Melting Behavior of Poly(Butylene Succinate). European Polymer Journal, 43, 3161-3170. https://doi.org/10.1016/j.eurpolymj.2007.05.013

[225] Xu, Y., Xu, J., Gou, B. and Xie, X. (2007) Crystallization Kinetics and Morphology of Biodegradable Poly(Butylene Succinate-Co-Propylene Succinate)s. Journal of Polymer Science Part B : Polymer Physics, 45, 420-428. https://doi.org/10.1002/polb.20877

[226] Jovanovic, D., Nikolic, M.S. and Djonlagic, J. (2004) Synthesis and Characterisation of Biodegradable Aliphatic Copolyesters with Hydrophilic Soft Segments. Journal of the Serbian Chemical Society, 69, 1013-1028. https://doi.org/10.2298/JSC0412013J

[227] Pepic, D., Zagar, E., Zigon, M., Krzan, A., Kunaver, M. and Djonlagic, J. (2008) Synthesis and Characterization of Biodegradable Aliphatic Copolyesters with Poly(Ethylene Oxide) Soft Segments. European Polymer Journal, 44, 904-917. https://doi.org/10.1016/j.eurpolymj.2007.11.035

[228] Ahn, B.D., Kim, S.H., Kim, Y.H. and Yang, J.S. (2001) Synthesis and Characterization of the Biodegradable Copolymers from Succinic Acid and Adipic Acid with 1,4-Butanediol. Journal of Applied Polymer Science, 82, 2808-2826. https://doi.org/10.1002/app.2135

[229] Velmathi, S., Nagahata, R., Sujiyama, J. and Takeuchi, K. (2005) A Rapid Eco-Friendly Synthesis of Poly(Butylene Succinate) by a Direct Polyesterification under Microwave Irradiation. Macromolecular Rapid Communications, 26, 1163-1167. https://doi.org/10.1002/marc.200500176

[230] Zhu, C.Y., Zhang, Z.G., Liu, Q.P., Wang, Z.P. and Jin, J. (2003) Synthesis and Biodegradation of Aliphatic Polyesters from Dicarboxylic Acids and Diols. Journal of Applied Polymer Science, 90, 982-990. https://doi.org/10.1002/app.12722

[231] Bikiaris, D.N., Papageorgiou, G.Z. and Achilias, D.S. (2006) Synthesis and Comparative Biodegradability Studies of Three Poly(Alkylene Succinates). Polymer Degradation and Stability, 91, 31-43.

https://doi.org/10.1016/j.polymdegradstab.2005.04.030

[232] Kim, M.N., Kim, K.H., Jin, H.J., Park, J.K. and Yoon, J.S. (2001) Biodegradability of Ethyl and N-Octyl Branched Poly(Ethylene Adipate) and Poly(Butylene Succinate). European Polymer Journal, 37, 1843-1847. https://doi.org/10.1016/S0014-3057(01)00003-9

[233] Jin, H.J., Lee, B.Y., Kim, M.N. and Yoon, J.S. (2000) Thermal and Mechanical Properties of Mandelic Acid-Copolymerized Poly(Butylene Succinate) and Poly(Ethylene Adipate). Journal of Polymer Science Part B: Polymer Physics, 38, 1504-1511.

https://doi.org/10.1002/(SICI)1099-0488(20000601)38:11<1504::AID-POLB100>3.0. $\mathrm{CO} ; 2-4$

[234] Abe, H. and Dui, Y. (2004) Novel Biodegradable Copolymers with a Periodic Sequence Structure Derived from Succinate Butane-1,4-Diol, and Butane-1,4-Diamine. Macromolar Rapid Communications, 25, 1303-1308. https://doi.org/10.1002/marc.200400154

[235] DuPont Performance Polymers (2013). http://www2.dupont.com/Plastics/en_US/assets/downloads/news/PP-EU-2013-09_ The_Science_Behind_ENGLISH.pdf

[236] Bozell, J.J. and Petersen, G.R. (2010) Technology Development for the Production of Biobased Products from Biorefinery Carbohydrates-The US Department of Energy's “Top 10" Revisited. Green Chemistry, 12, 539-554. 
https://doi.org/10.1039/b922014c

[237] Marshall, A.L. and Alaimo, P.J. (2010) Useful Products from Complex Starting Materials: Common Chemicals from Biomass Feedstocks. Chemistry-A. European Journal, 16, 4970-4980. https://doi.org/10.1002/chem.200903028

[238] Belgacem, M.N. and Gandini, A. (2008) Monomers, Polymers and Composites from Renewable Resources. Elsevier, Amsterdam, 560.

[239] Gandini, A. (2011) The Irruption of Polymers from Renewable Resources on the Scene of Macromolecular Science and Technology. Green Chemistry, 13, 1061-1083. https://doi.org/10.1039/c0gc00789g

[240] Gandini, A. (2010) Furans as Offspring of Sugars and Polysaccharides and Progenitors of a Family of Remarkable Polymers: A Review of Recent Progress. Polymer Chemistry, 1, 245-251. https://doi.org/10.1039/B9PY00233B

[241] Gandini, A., Silvestre, A.J.D., Neto, C.P. and Sousa, A.F. (2009) The Furan Counterpart of Poly(Ethylene Terephthalate): An Alternative Material Based on Renewable Resources. Journal of Polymer Science Part A: Polymer Chemistry, 47, 295-298. https://doi.org/10.1002/pola.23130

[242] Gandini, A., Coelho, D., Gomes, M., Reis, B. and Silvestre, A. (2009) Materials from Renewable Resources Based on Furan Monomers and Furan Chemistry: Work in Progress. Journal of Materials Chemistry, 19, 8656-8664. https://doi.org/10.1039/b909377j

[243] Gomes, M., Gandini, A., Silvestre, A.J.D. and Reis, B. (2011) Ring-Opening Synthesis of Polyethylene Furanoate (PEF) as a Renewable Resource-Based Substitute for Polyethylene Terephthalate (PET). Journal of Polymer Science Part A: Polymer Chemistry, 49, 3759-3768. https://doi.org/10.1002/pola.24812

[244] Ma, J., Pang, Y., Wang, M., Xu, J., Ma, H. and Nie, X. (2012) The Copolymerization Reactivity of Diols with 2,5-Furandicarboxylic Acid for Furan-Based Copolyester Materials. Journal of Materials Chemistry, 22, 3457-3461. https://doi.org/10.1039/c2jm15457a

[245] Sousa, A.F., Matos, M., Freire, C.S.R., Silvestre, A.J.D. and Coelho, J.F.J. (2013) New Copolyesters Derived from Terephthalic and 2,5-Furandicarboxylic Acids: A Step forward in the Development of Biobased Polyesters. Polymer, 54, 513-519. https://doi.org/10.1016/j.polymer.2012.11.081

[246] Pan, T., Deng, J., Xu, Q., Zuo, Y., Guo, Q.X. and Fu, Y. (2013) Catalytic Conversion of Furfural into a 2,5-Furandicarboxylic Acid-Based Polyester with Total Carbon Utilization. ChemSusChem, 6, 47-50. https://doi.org/10.1002/cssc.201200652

[247] Papageorgiou, G.Z., Guigo, N., Tsanaktsis, V., Papageorgiou, D.G., Exarhopoulos, S., Sbirrazzuoli, N. and Bikiaris, D.N. (2015) On the Bio-Based Furanic Polyesters: Synthesis and Thermal Behavior Study of Poly(Octylene Furanoate) Using Fast and Temperature Modulated Scanning Calorimetry. European Polymer Journal, 68, 115-127. https://doi.org/10.1016/j.eurpolymj.2015.04.011

[248] Wu, L., Mincheva, R., Xu, Y., Raquez, J.M. and Dubois, P. (2012) High Molecular Weight Poly(Butylene Succinate-Co-Butylenefurandicarboxylate) Copolyesters: From Catalyzed Polycondensation Reaction to Thermomechanical Properties. Biomacromolecules, 13, 2973-2981. https://doi.org/10.1021/bm301044f

[249] Mialon, L., Pemba, A.G. and Miller, S.A. (2010) Biorenewable Polyethylene Terephthalate MimicsDerived from Lignin and Acetic Acid. Green Chemistry, 12, 1704-1706. https://doi.org/10.1039/c0gc00150c

[250] Miller, S.A. and Mialon, L. (2013) Poly(Dihydroferulic Acid) a Biorenewable Po- 
lyethylene Terephthalate Mimic Derived from Lignin and Acetic Acid and Copolymers Thereof. US Patent No. 2013/0137847 A1.

[251] Mialon, L., Vanderhenst, R., Pemba, A.G. and Miller, S.A. (2011) Polyalkylenehydroxybenzoates (PAHBS): Biorenewable Aromatic/Aliphatic Polyesters from Lignin. Macromolecular Rapid Communications, 32, 1386-1392. https://doi.org/10.1002/marc.201100242

[252] Firdaus, M. and Meier, M.A.R. (2013) Renewable Co-Polymers Derived from Vanillin and Fatty Acid Derivatives. European Polymer Journal, 49, 156-166. https://doi.org/10.1016/j.eurpolymj.2012.10.017

[253] Dong, W., Li, H., Chen, M., Ni, Z., Zhao, J., Yang, H. and Gijsman, P. (2011) Biodegradable Bio-Based Polyesters with Controllable Photo-Crosslinkability, Thermal and Hydrolytic Stability. Journal of Polymer Research, 18, 1239-1247. https://doi.org/10.1007/s10965-010-9526-x

[254] Dong, W., Ren, J., Lin, L., Shi, D., Ni, Z. and Chen, M. (2012) Novel Photocrosslinkable and Biodegradable Polyester from Bio-Renewable Resource. Polymer Degradation and Stability, 97, 578-583. https://doi.org/10.1016/j.polymdegradstab.2012.01.008

[255] McKenna, R. and Nielsen, D.R. (2011) Styrene Biosynthesis from Glucose by Engineered E. coli. Metabolic Engineering, 13, 544-554. https://doi.org/10.1016/j.ymben.2011.06.005

[256] Pellegrini, C. and Tomka, I. (1998) Starch Alkanoates as Models for Thermoplastic Polysaccharides. Macromolecular Symposia, 127, 31-35. https://doi.org/10.1002/masy.19981270107

[257] Wang, H., Sun, X.Z. and Seib, P. (2002) Mechanical Properties of Poly(Lactic Acid) and Wheat Starch Blends with Methylenediphenyl Diisocyanate. Journal of Applied Polymer Science, 84, 1257-1262. https://doi.org/10.1002/app.10457

[258] Zhang, J.F. and Sun, X.Z. (2004) Mechanical Properties of Poly(Lactic Acid)/Starch Composites Compatibilized by Maleic Anhydride. Biomacromolecules, 5, 1446-1451. https://doi.org/10.1021/bm0400022

[259] Kim, S.H., Chin, I.J., Yoon, J.S., Kim, S.H. and Jung, J.S. (1998) Mechanical Properties of Biodegradable Blends of Poly(L-Lactic Acid) and Starch. Korea Polymer Journal, 6, 422-427.

[260] Park, J.W., Lee, D.J., Yoo, E., Im, S.S., Kim, S.H. and Kim, Y.H. (1999) Biodegradable Polymer Blends of Poly(Lactic Acid) and Starch. Korea Polymer Journal, 7, 93-101.

[261] Park, J.W. and Im, S.S. (2000) Biodegradable Polymer Blends of Poly(L-Lactic Acid) and Gelatinized Starch. Polymer Engineering Science, 40, 2539-2550. https://doi.org/10.1002/pen.11384

[262] Koenig, M.F. and Huang, S.T. (1995) Biodegradable Blends and Composites of Polycaprolactone and Starch Derivatives. Polymer, 36, 1877-1882. https://doi.org/10.1016/0032-3861(95)90934-T

[263] Averous, L., Moro, L., Dole, P. and Fringant, C. (2000) Properties of Thermoplastic Blends: Starch-Polycaprolactone. Polymer, 41, 4157-4167. https://doi.org/10.1016/S0032-3861(99)00636-9

[264] Mani, R. and Bhattacharya, M. (2001) Properties of Injection Moulded Blends of Starch and Modified Biodegradable Polyesters. European Polymer Journal, 37, 515-526. https://doi.org/10.1016/S0014-3057(00)00155-5

[265] Bastioli, C., Cerutti, A., Guanella, I., Romano, G.C. and Tosin, M. (1995) Physical 
State and Biodegradation Behavior of Starch-Polycaprolactone Systems. Journal of Environmental Polymer Degradation, 3, 81-95. https://doi.org/10.1007/BF02067484

[266] Mani, R., Tang, J. and Bhattacharya, M. (1998) Synthesis and Characterization of Starch-Graft-Polycaprolactone as Compatibilizer for Starch/Polycaprolactone Blends. Macromolecular Rapid Communications, 19, 283-286.

https://doi.org/10.1002/(SICI)1521-3927(19980601)19:6<283::AID-MARC283>3.0. CO;2-C

[267] Choi, E.J., Kim, C.H. and Park, J.K. (1999) Structure-Property Relationship in PCL/Starch Blend Compatibilized with Starch-g-PCL Copolymer. Journal of Polymer Science Part B: Polymer Physics, 37, 2430-2438.

https://doi.org/10.1002/(SICI)1099-0488(19990901)37:17<2430::AID-POLB14>3.0. CO;2-4

[268] Avella, M., Errico, M.E., Rimedio, R. and Sadocco, P. (2001) Preparation of Biodegradable Polyesters/High Amylose Starch Composites by Reactive Blending and Their Characterization. Journal of Applied Polymer Science, 83, 1432-1442. https://doi.org/10.1002/app.2304

[269] Cai, H.Y., Yu, J. and Qiu, Z.B. (2012) Miscibility and Crystallization of Biodegradable Poly(3-Hydroxybutyrate-Co-3-Hydroxyhexanoate)/Poly(Vinyl Phenol) Blends. Polymer Engineering Science, 52, 233-241. https://doi.org/10.1002/pen.22069

[270] Yang, J., Liu, M.K., Zhang, B., Chen, X.C., Fu, R.W. and Zhang, M.Q. (2011) Intrinsic Fluorescence Studies of Compatibility in Thermoplastic Phenol Formaldehyde Resin/Poly(ع-Caprolactone) Blends. Express Polymer Letters, 5, 698-707. https://doi.org/10.3144/expresspolymlett.2011.68

[271] Furukawa, T., Sato, H., Murakami, R., Zhang, J.M., Noda, I., Ochiai, S. and Ozaki, Y. (2007) Comparison of Miscibility and Structure of Poly(3-Hydroxybutyrate-Co-3-Hydroxyhexanoate)/Poly(L-Lactic Acid) Blends with Those of Poly(3hydroxybutyrate)/Poly(L-Lactic Acid) Blends Studied by Wide Angle X-Ray Diffraction, Differential Scanning Calorimetry, and FTIR Microspectroscopy. Polymer, 48, 1749-1755. https://doi.org/10.1016/j.polymer.2007.01.020

[272] Wasantha, L.M., Gunaratne, K. and Shanks, R.A. (2008) Miscibility, Melting, and Crystallization Behavior of Poly(Hydroxybutyrate) and Poly(D,L-Lactic Acid) Blends. Polymer Engineering \& Science, 48, 1683-1692. https://doi.org/10.1002/pen.21051

[273] Park, J.W. and Im, S.S. (2002) Phase Behavior and Morphology in Blends of Poly(L-Lactic Acid) and Poly(Butylene Succinate). Journal of Applied Polymer Science, 86, 647-655. https://doi.org/10.1002/app.10923

[274] Hinuber, C., Hausler, L., Vogel, R., Brunig, H., Heinrich, G. and Werner, C. (2011) Hollow Fibers Made from a Poly(3-Hydroxybutyrate)/Poly- $\varepsilon$-Caprolactone Blend. Express Polymer Letters, 5, 643-652. https://doi.org/10.3144/expresspolymlett.2011.62

[275] Sungsanit, K., Kao, N. and Bhattacharaya, S.N. (2011) Properties of Linear Poly(Lactic Acid)/ Polyethylene Glycol Blends. Polymer Engineering \& Science, 52, 108-116. https://doi.org/10.1002/pen.22052

[276] Lovera, D., Marquez, L., Balsamo, V., Taddei, A., Castelli, C. and Muller, A.J. (2007) Crystallization, Morphology, and Enzymatic Degradation of Polyhydroxybutyrate/Polycaprolactone (PHB/PCL) Blends. Macromolecular Chemistry and Physics, 208, 924-937. https://doi.org/10.1002/macp.200700011

[277] Suttiwijitpukdee, N., Sato, H., Unger, M. and Ozaki, Y. (2012) Effects of Hydrogen 
Bond Intermolecular Interactions on the Crystal Spherulite of Poly(3-Hydroxybutyrate) and Cellulose Acetate Butyrate Blends: Studied by FT-IR and FT-NIR Imaging Spectroscopy. Macromolecules, 45, 2738-2248.

https://doi.org/10.1021/ma201598s

[278] Zhang, K.Y., Ran, X.H., Wang, X.M., Han, C.Y., Han, L.J., Wen, X., Zhuang, Y.G. and Dong, L.S. (2011) Improvement in Toughness and Crystallization of Poly(L-Lactic Acid) by Melt Blending with Poly(Epichlorohydrin-Co-Ethylene Oxide). Polymer Engineering \& Science, 51, 2370-2380.

https://doi.org/10.1002/pen.22009

[279] Jiao, J., Wang, S.J., Xiao, M., Xu, M. and Meng, Y.Z. (2007) Processability, Property, and Morphology of Biodegradable Blends of Poly(Propylene Carbonate) and Poly(Ethylene-Co-Vinyl Alcohol). Polymer Engineering \& Science, 47, 174-180. https://doi.org/10.1002/pen.20694

[280] Cao, Y.X., Du, F.G., Wang, X.L. and Meng, Y.Z. (2006) New Biodegradable Blends from Aliphatic Polycarbonate and Poly(Vinyl Alcohol). Polymers and Polymer Composites, 14, 577-584.

[281] Silva, S.S., Goodfellow, B.J., Benesch, J., Rocha, J., Mano, J.F. and Reis, R.L. (2007) Morphology and Miscibility of Chitosan/Soy Protein Blended Membranes. Carbohydrate Polymers, 70, 25-31. https://doi.org/10.1016/j.carbpol.2007.02.023

[282] Li, L.H., Ding, S. and Zhou, C.R. (2004) Preparation and Degradation of PLA/Chitosan Composite Materials. Journal of Applied Polymer Science, 91, 274-277. https://doi.org/10.1002/app.12954

[283] Coffin, D.R. and Fishman, M.L. (1997) Films fabricated from Mixtures of Pectin and Poly(Vinyl Alcohol). U.S. Patent No. 5,646,206.

[284] Fishman, M.L., Coffin, D.R., Onwulata, C.I. and Willett, J.L. (2006) Two Stage Extrusion of Plasticized Pectin/Poly(Vinyl Alcohol) Blends. Carbohydrate Polymers, 65, 421-429. https://doi.org/10.1016/j.carbpol.2006.01.032

[285] Nishio, Y. and Manley, R.St.J. (1988) Cellulose/Poly(Vinyl Alcohol) Blends Prepared from Solution in N,N-Dimethylacetamide Lithium Chloride. Macromolecules, 21, 1270-1277. https://doi.org/10.1021/ma00183a016

[286] Masson, J.F. and Manley, R.St.J. (1992) Solid-State NMR of Some Cellulose/Synthetic Polymer Blends. Macromolecules, 25, 589-592.

https://doi.org/10.1021/ma00028a016

[287] Park, H., Li, X., Jin, C., Park, C., Cho, W. and Ha, C. (2002) Preparation and Properties of Biodegradable Thermoplastic Starch/Clay Hybrids. Macromolecular Materials and Engineering, 287, 553-558.

https://doi.org/10.1002/1439-2054(20020801)287:8<553::AID-MAME553>3.0.CO;2 $\underline{-3}$

[288] Park, H., W., Lee, C. Park, Cho, W. and Ha, C. (2003) Environmentally Friendly Polymer Hybrids. Part 1 Mechanical, Thermal and Barrier Properties of Thermoplastic Starch/Clay Nanocomposites. Journal of Materials Science, 38, 909-915. https://doi.org/10.1023/A:1022308705231

[289] Wilhelm, H.M., Sierakowski, M.R., Souza, G.P. and Wypych, F. (2003) Starch Films Reinforced with Mineral Clay. Carbohydrate Polymers, 52, 101-110. https://doi.org/10.1016/S0144-8617(02)00239-4

[290] Huang, M., Yu, J. and Ma, X. (2006) High Mechanical Performance MMT-Urea and Formamide-Plasticized Thermoplastic Cornstarch Biodegradable Nanocomposites. Carbohydrate Polymers, 63, 393-399. https://doi.org/10.1016/j.carbpol.2005.09.006 
[291] Pandey, J.K. and Sing, R.P. (2005) Green Nanocomposites from Renewable Resources: Effect of Plasticizer on the Structure and Material Properties of Clay-Filled Starch. Starch, 57, 8-15. https://doi.org/10.1002/star.200400313

[292] Chiou, B.S., Wood, D., Yee, E., Imam, S.H., Glenn, G.M. and Orts, W.J. (2007) Extruded Starch-Nanoclay Nanocomposites: Effects of Glycerol and Nanoclay Concentration. Polymer Engineering Science, 47, 1898-1904. https://doi.org/10.1002/pen.20903

[293] McGlashan, S.A. and Halley, P.J. (2003) Preparation and Characterization of Biodegradable Starch-Based Nanocomposite Materials. Polymer International, 52, 1767-1773. https://doi.org/10.1002/pi.1287

[294] Kalambur, S. and Rizvi, S.S.H. (2005) Biodegradable and Functionally Superior Starch-Polyester Nanocomposites from Reactive Extrusion. Journal of Applied Polymer Science, 96, 1072-1082. https://doi.org/10.1002/app.21504

[295] Park, H., Misra, M., Drzal, L.T. and Mohanty, A.K. (2004) Green Nanocomposites from Cellulose Acetate Bioplastic and Clay: Effect of Eco-Friendly Triethyl Citrate Plasticizer. Biomacromolecules, 5, 2281-2288. https://doi.org/10.1021/bm049690f

[296] Oksman, K., Mathew, A.P., Bondeson, D. and Kvien, I. (2006) Manufacturing Process of Cellulose Whiskers/Polylactic Acid Nanocomposites. Composites Science and Technology, 66, 2776-2784. https://doi.org/10.1016/j.compscitech.2006.03.002

[297] Bondeson, D. and Oksman, K. (2007) Polylactic Acid/Cellulose Whisker Nanocomposites Modified by Polyvinyl Alcohol. Composites. Part A, 38, 2486-2492. https://doi.org/10.1016/j.compositesa.2007.08.001

[298] de Menezes, A.J., Siqueira, G., Curvelo, A.A.S. and Dufresne, A. (2009) Extrusion and Characterization of Functionalized Cellulose Whiskers Reinforced Polyethylene Nanocomposites. Polymer, 50, 4552-4563.

https://doi.org/10.1016/j.polymer.2009.07.038

[299] Mancera Garcia, K.M., Meimaroglou, D., Hoppe, S., Pla, F. and Escobar-Barrios, V.A. (2015) Design and Process Modeling for the Manufacture by Extrusion of Recycled Polyethylene Terephtalate and Low Density Polyethylene Nanocomposites Reinforced with Cellulose Nanocrystals. Proceedings of the 10th European Congress of Chemical Engineering, Nice, 27 September-1 October 2015, 655.

[300] Bandyopadhyay, S., Chen, R. and Giannelis, E.P. (1999) Biodegradable Organic Inorganic Hybrids Based on Poly(L-Lactic Acid). Polymeric Materials. Science and Engineering, 81, 159-160.

[301] Maiti, P., Yamada, K., Okamoto, M., Ueda, K. and Okamoto, K. (2002) New Polylactide/Layered Silicate Nanocomposites Role of Organoclay. Chemistry of Materials, 14, 4654-4661. https://doi.org/10.1021/cm020391b

[302] Cabedo, L., Feijoo, J.L., Villanueva, M.P., Lagaron, J.M. and Gimenez, E. (2006) Optimization of Biodegradable Nanocomposites Based on PLA/PCL Blends for Food Packaging Applications. Macromolecular Symposia, 233, 191-197. https://doi.org/10.1002/masy.200690017

[303] Lyons, M.E.G. and Rebouillat, S. (2009) Paving the Way to the Integration of Smart Nanostructures: Part 1 Paving the Way to the Integration of Smart Nanostructures: Part 1: Nanotethering and Nanowiring via Material Nanoengineering and Electrochemical. International Journal of Electrochemical Science, 4, 481-515.

[304] Rebouillat, S., Lyons, M.E.G., Doyle, B.M.P. and Richard, L. (2011) Paving the Way to the Integration of Smart Nanostructures: Part II: Nanostructured Microdispersed Hydrated Metal Oxides for Electrochemical Energy Conversion and Storage Applications. International Journal of Electrochemical Science, 6, 5830-5917. 


\section{Abbreviation List}

\begin{tabular}{|c|c|}
\hline $\mathrm{AH}$ & Chain-breaking antioxidants \\
\hline BHA & 2- and 3-ter-butyl-4-hydroxyanisole \\
\hline $\mathrm{BHT}$ & 2, 6-di-terbutyl-4-methylphenol \\
\hline $\mathrm{BV}$ & Biological Value \\
\hline CCL & Critical Chain Length \\
\hline $\mathrm{DH}$ & Degree of hydrolysis \\
\hline DNA & Deoxyribonucleic acid \\
\hline EDTA & Ethylenediaminetetraacetic acid \\
\hline FDCA & 2,5-furandicarboxylic acid \\
\hline $3 \mathrm{HB}$ & $(R)$-3-hydroxybutyrate \\
\hline LAB & Lactic acid bacteria \\
\hline MPC & Milk protein concentrate \\
\hline MVA & Mevalonic acid \\
\hline NFDM & Non-Fat Dry Milk \\
\hline $\mathrm{NIH}$ & Not Invented Here \\
\hline Pas & Polyamides \\
\hline PBT & Poly(butylene terephthalate) \\
\hline PBS & Poly(butylene-co-succinate \\
\hline PCL & $\operatorname{Poly}(\varepsilon$ caprolactam $)$ \\
\hline PDCAAS & Protein digestibility corrected amino acid score \\
\hline 3-PDO & 1,3-propanediol \\
\hline PER & Protein Efficiency Ratio \\
\hline PET & Poly(ethylene terephtalate) \\
\hline PG & Propyl gallate \\
\hline $\operatorname{PHA}(s)$ & Polyhydroxyalkanoate(s) \\
\hline pHS & p-hydroxystyrene \\
\hline $\mathrm{pI}$ & Isoelectric point \\
\hline PLA & Poly(lactic acid), \\
\hline PLs & Phospholipids \\
\hline PUFA & Polyunsaturated fatty acids \\
\hline QSAR & Quantitative structure-activity relationship \\
\hline $\mathrm{R}$ & Carbon-centred radical \\
\hline $\mathrm{RH}$ & Activated methylene \\
\hline RNS & Reactive Nitrogen Species \\
\hline ROO & Peroxyl radical \\
\hline $\mathrm{ROOH}$ & Hydroperoxide \\
\hline ROS & Reactive Oxygen Species \\
\hline RS & Thiyl radicals \\
\hline TBHQ & Tert-butylhydroquinone \\
\hline THF & Tetrahydrofurane \\
\hline TG & Transglutaminase \\
\hline UF & Ultrafiltration \\
\hline
\end{tabular}


UTP

UV

WPC
Uniform trans-membrane pressure Ultra Violet

Whey protein concentrate 